\title{
Effects of color and animation on visual short -term memory in computer-environment learning tasks
}

Marc Debiase

West Virginia University

Follow this and additional works at: https://researchrepository.wvu.edu/etd

\section{Recommended Citation}

Debiase, Marc, "Effects of color and animation on visual short -term memory in computer-environment learning tasks" (2009). Graduate Theses, Dissertations, and Problem Reports. 2895.

https://researchrepository.wvu.edu/etd/2895

This Dissertation is protected by copyright and/or related rights. It has been brought to you by the The Research Repository @ WVU with permission from the rights-holder(s). You are free to use this Dissertation in any way that is permitted by the copyright and related rights legislation that applies to your use. For other uses you must obtain permission from the rights-holder(s) directly, unless additional rights are indicated by a Creative Commons license in the record and/ or on the work itself. This Dissertation has been accepted for inclusion in WVU Graduate Theses, Dissertations, and Problem Reports collection by an authorized administrator of The Research Repository @ WVU.

For more information, please contact researchrepository@mail.wvu.edu. 
Effects of Color and Animation on Visual Short-Term Memory in Computer-Environment Learning Tasks

Marc Debiase

Dissertation submitted to the College of Human Resources and Education

at West Virginia University

in partial fulfillment of the requirements

for the degree of

Doctor of Education

in

Instructional Design and Technology

Terence C. Ahern, Ph.D. Chair

Daniel Hursh, Ph.D. Chair

Richard T. Walls, Ph.D.

R. Neal Shambaugh, Ph.D.

Sebastian R. Diaz, Ph.D., J.D.

Department of Technology, Learning and Culture

Morgantown, West Virginia

2009

Copyright 2009 - Marc Debiase 


\author{
ABSTRACT \\ Effects of Color and Animation on Visual Short-Term Memory in \\ Computer-Environment Learning Tasks
}

Marc Debiase

The goals of this research study were to gain a better understanding of the effects of color and animation on visual short-term memory (STM) in computer-environment learning tasks. The research methodology was based on an investigative design that attempted to address weaknesses of previous visual STM research (Klauer \& Zhao, 2004) to provide information readily applicable to instructional design and technology. A 3 × 2 × 3 totally-within participants, repeated-measures Factorial Analysis of Variance (ANOVA) design was utilized to investigate limitations on visual short-term memory learning processes in computer-learning environments. Participant scores for accuracy of visual learning tasks and participant latency in responses to visual learning tasks were measured. Findings suggest achromatic color information interferes with visual STM learning tasks in specific contexts. Findings also suggest that the use of animations in visual STM learning tasks may interfere with complex visual STM learning. Numerous questions are raised for further research utilizing experimental designs that focus on visual STM learning tasks in contrast to designs that focus solely on identifying visual STM parameters.

Keywords: Computer aided instruction; Computer based instruction; Double dissociations; Dual coding; Multimedia learning theory; Information processing, Instructional design, Phonological loop, Short-term memory, Visual and spatial short-term memory, Visual stimuli, Visuospatial sketch pad, Working memory 


\section{ACKNOWLEDGEMENTS}

In recognition of my family and friends: Having completed the requirements for the degree of Doctor of Education in Instructional Design and Technology I would like to take a moment to reflect on the people who have impressed me, guided me, and made this accomplishment possible.

First, I would like to mention the profound impression Dr Patricia Rice had on me as a freshman in the Sociology \& Anthropology program at West Virginia University beginning in 1986. Dr Rice encouraged me to look deeply at humanity from a perspective of prehistory up through modern times. At this time I really began to look at myself in context of a world that existed far beyond the universe as I had known it.

Dr Ronald Althouse provided me guidance in pursuing the study of Sociology. Dr Althouse put Marx, Spencer, Durkheim, Weber, Mead and many others in my constant thoughts. Understanding of the differing perceptions of society between east and west became a passion. And, it was Dr Althouse who encouraged me to pursue Technology Education, many years before I actually found myself doing just that.

Dr Edward Caldwell provided me an unyielding interest in Psychology. Dr Caldwell encouraged me to instruct, and gave me an opportunity to tutor when I was a freshman. This was the beginning.

Dr David McCrory provided me Technology Education during the golden age of his career. His guidance provided me the courage to write and produce a technology documentary entitled Morgantown \& American: Transportation Yesterday, Today, and Tomorrow.

Dr Neal Shambaugh played a very encouraging role in the pursuit of my education. Dr Shambaugh taught me Instructional Design. During this time, what it meant to become an instrument of education was realized.

Dr Richard T. Walls provide me unyielding encouragement also. He encouraged me to pursue my interests in Psychology and research. I respected his knowledge and benefited greatly from his wisdom, guidance, and advice.

Dr Terence Ahern provided me with an understanding of instructional systems. This way of perceiving the complexities of education provided me the knowledge to make new connections with the elements of the universe, peoples, societies, organizations, and more. And, it provided me the insight to clearly provide context to those I teach.

Lastly, I would like to reflect on the effort of Dr Daniel Hursh. Quite honestly Dr Hursh's unyielding presence, understanding, academic guidance, and respect of my accomplishments as a scholar provided the anchor that the culmination of my education required. And, he provided me the opportunity to finally, after many years of pursuit, teach. 


\section{TABLE OF CONTENTS}

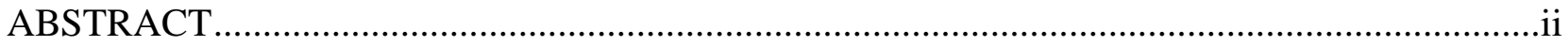

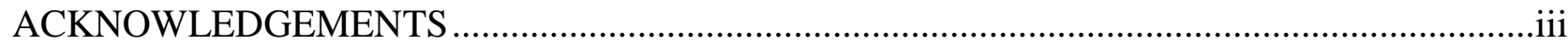

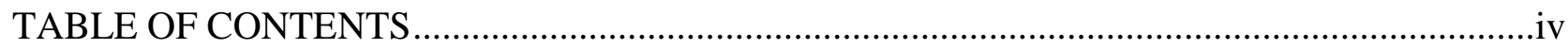

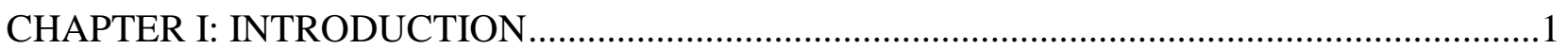

Emerging technology in education ...................................................................

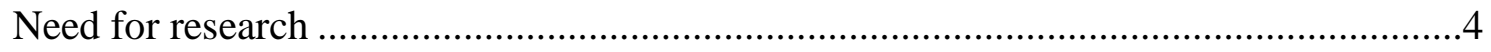

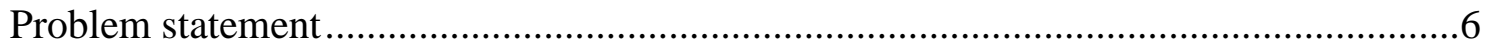

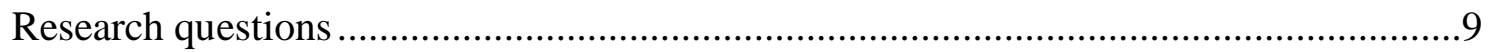

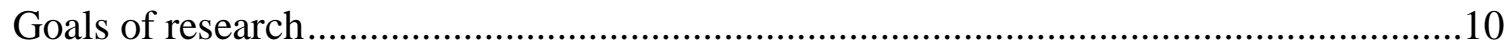

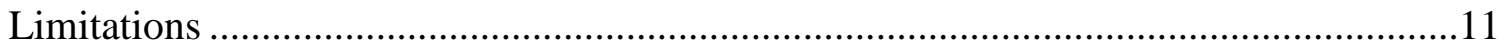

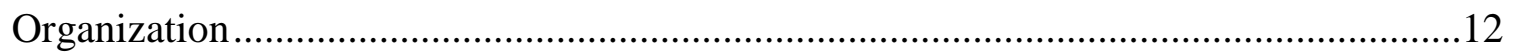

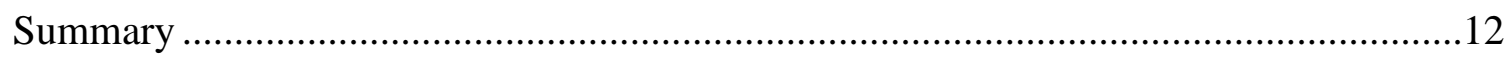

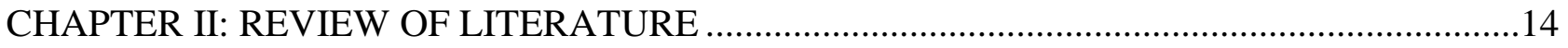

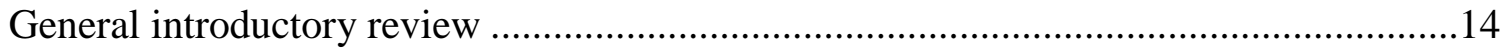

Computer based instructional development ..........................................................16

Role of instructional design and technology .........................................................19

Approaches to research and development of computer-learning environments ..............23

Traditional instruction verse computer instruction comparative models ........27

Usability evaluations - Task oriented studies ............................................29

Psychometric approaches to research and development ..............................32

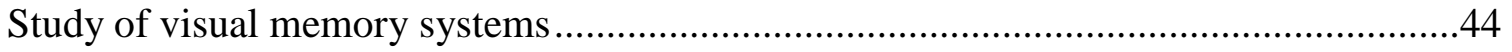

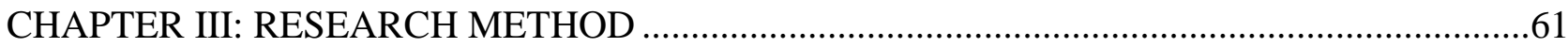

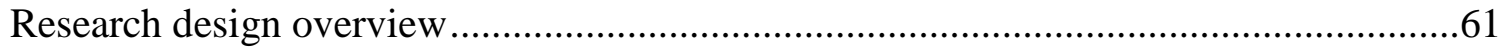

Hypotheses ...................................................................................61 
Independent variables.....................................................................62

Dependant variables ..........................................................................63

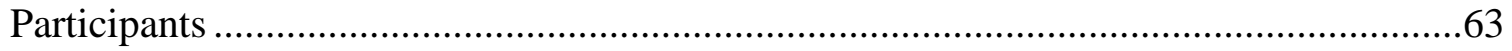

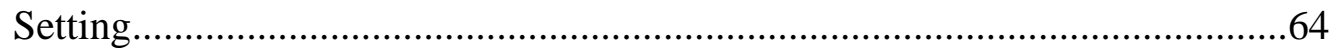

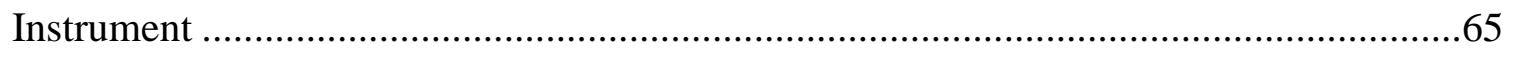

Stimuli ............................................................................................65

Stimulus conditions .......................................................................... 71

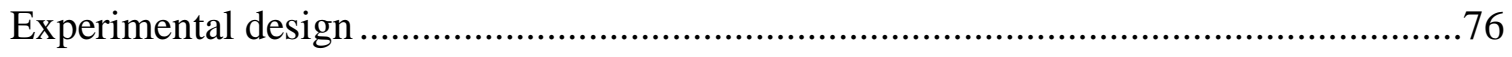

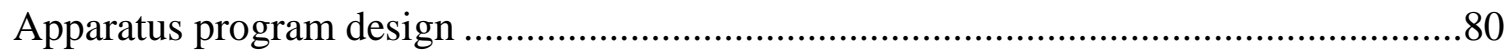

Limitations of experimental design and apparatus ..................................83

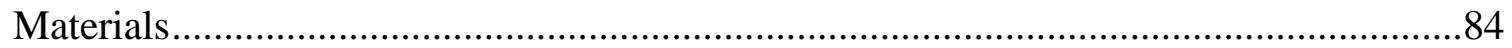

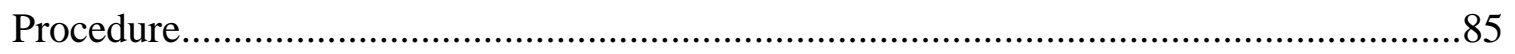

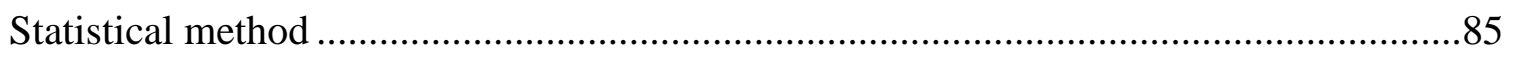

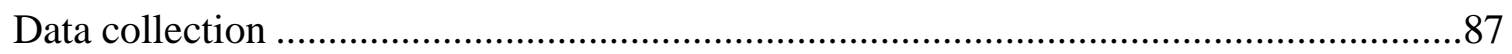

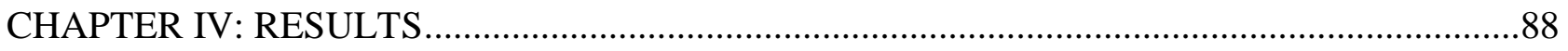

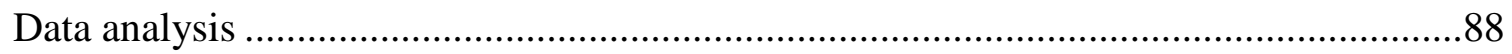

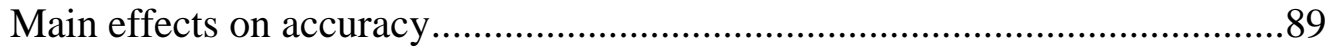

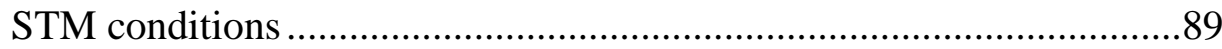

Color conditions ......................................................................90

Animation conditions ....................................................................90

Interaction effects on accuracy........................................................91

STM conditions* color conditions ................................................91

STM conditions*animation conditions ...........................................91

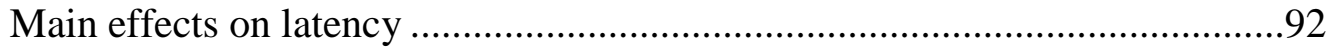

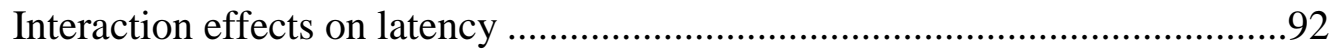




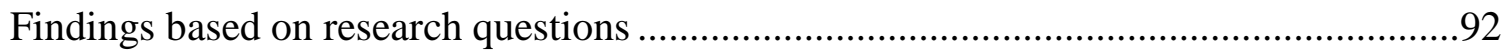

Research question 1: Analysis and findings.............................................99

Research question 2: Analysis and findings..............................................92

Research question 3: Analysis and findings..............................................93

Research question 4: Analysis and findings............................................93

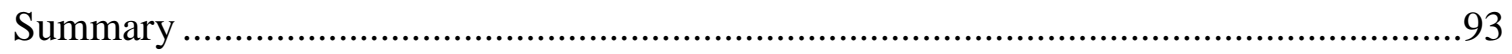

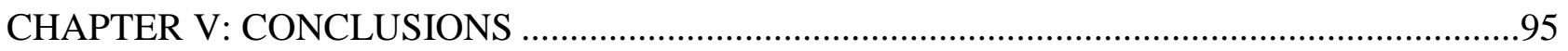

Conclusions Based on Research Conditions ..........................................................95

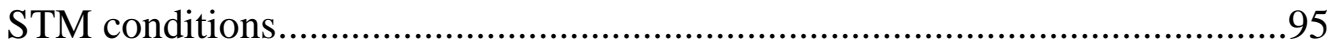

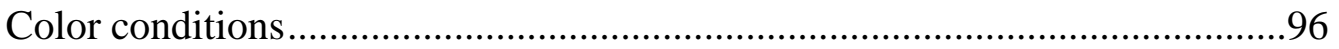

STM conditions*Animation conditions .....................................................99

Significance of Findings Considerations .............................................................100

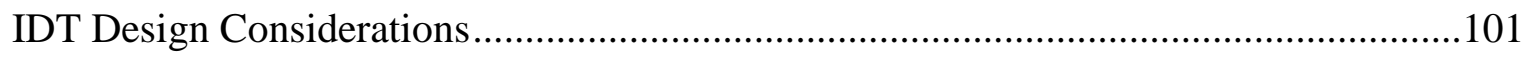

The achromatic visual information effect ...............................................101

Chromatic visual information .............................................................102

Target visual information conflicts ........................................................102

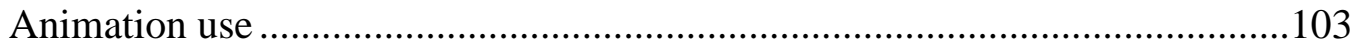

Suggestions for Further Research ..................................................................103

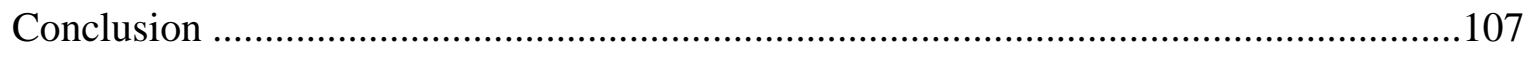

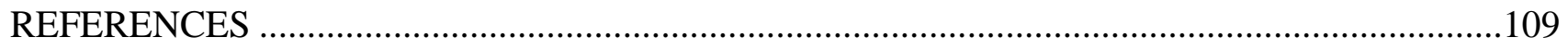

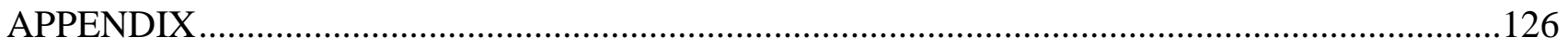

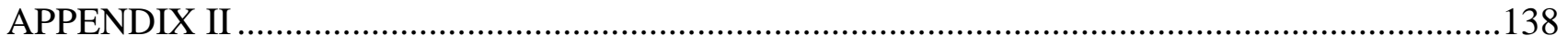




\section{CHAPTER I:}

\section{INTRODUCTION}

\section{Emerging Technology in Education}

As of fall 2007, more than 3.9 million higher education students—more than 20\%—were taking fully online courses in the United States (Allen \& Seaman, 2008); and, the evidence of online-course enrollments continues to increase at rates that exceed the total higher education population. Allen and Seaman (2008) report the 2007 annual higher education total student population growth rate of $1.2 \%$ was dwarfed by the $12 \%$ growth rate of online-course enrollments. While the online course enrollment trend has seen some fluctuation, the growth rate continues. For example, even though the fall 2007 growth rate of online-course enrollments was down $24.5 \%$ from rates reported fall 2005, online-course enrollment as a percent of total higher education enrollment continued to steadily increase to 21.9\%, up 2.7\% from 2005.

These statistics suggest, in addition to new students entering higher education as online learners, more and more students who have taken courses in traditional settings are now also enrolling in online courses. There is a huge trend toward online higher education. And, the trend is going to continue. Allen and Seaman (2008) report there is widespread agreement increases in fuel prices will impact the online course enrollment-trend momentum even more. And, the current state of the economy has prompted those who were previously career-sound to rethink higher education opportunities.

But, the trend among higher education student enrollment is just part of the increasing rates for online education. In k-12 settings in the United States in 2007-2008 the number of students engaged in online courses exceeded one million, representing a $47 \%$ increase since 
2005-2006 (Picciano \& Seaman, 2009). And, Bersin \& Associates (2009) report e-learning in corporate training programs is exploding. Organizations are integrating training programs throughout, restructuring, and creating new organizational roles that reflect new emerging corporate training ideologies. In 2006 training budgets increased by 7\%, the largest increase since 2001 (Bersin \& Associates, 2009). And they are continuing to rise dramatically.

The modes of online course delivery, the technologies utilized, and formats of content vary greatly among institutions, organizations, training programs, and individual developers. Much of the diverse variability emerging in computer training environments may be amplified by the use of Learner Management Systems (LMS) and Learning Content Managing Systems (LCMS) such as WebCT. These technologies are proliferating online academic education. In private industry also, Bersin \& Associates (2009) report in excess of 40\% of large organizations and $70 \%$ of large enterprises were utilizing LMS in their training programs in 2006. These numbers too are increasing.

Both LMS and LCMS are characterized by a variety of course developer tools enabling course developers to create, import, store, assemble, and design content for instructional course delivery. Course developers are also capable of designing a wide variety of course delivery systems within the contexts of the LMS/LCMS including navigation structures, graphic design elements, and color schemes.

At the root of computer mediated learning is digital course content. These systems are becoming ever more user friendly and sophisticated in terms of online course content management. Ultimately digital course content is created and imported into the LMS/LCMS by human beings where it is then designed into instruction. Much of the typical digital course 
content includes images, audio, video, texts, interactive games, animations, simulations, and streaming multimedia.

A broader view of defining the scope of digital course content also includes the contexts of the course delivery systems within the computer-environments. They involve a variety of colorful frameworks and graphic user interfaces that the learner engages and utilizes to access instructional content. Each online learning experience typically requires learners to first gain knowledge of the computer-environment as a course delivery system, including the design of the information delivery navigation system and the digital content contexts (e.g., frameworks, graphics, color schemes/codes, etc.). They are typically characterized by a variety of hyperlinked-hypermedia infrastructures and navigation systems with a purpose of aiding the learners in locating the target instructional content. In light of the great variability of digital content in the computer-learning environment, the quality of e-learning and effectiveness of elearning outcomes raise significant questions (Bersin \& Associates, 2009; Picciano, 2002).

There are numerous approaches to accounting for the quality of e-learning and the effectiveness of e-learning outcomes. Early research compared groups of students who engaged online or computer mediated courses with students who engaged a traditional course of instruction. Test scores of students and quality survey reports were typically sources of data (Olsen \& Di Fazio, 1983; Saettler, 2000). However, this approach leaves much to be answered in terms of instructional design (ID) principles derived of learning theory (Mayer, 2003). Other approaches described as usability evaluations have studied learner behavior as a means to understanding efficient human-computer interfacing attributes, and also as a window to the cognitive state of learners as the computer-learning environment is engaged. Usability evaluations are case study research and development experiments that seek to target and 
eliminate problems with the design of course delivery systems and digital content through attaining real-time feedback from users (Snyder, 2003). Data is analyzed to correct system and content problems. This research also leaves much to be answered in terms of ID principles derived of learning theory (Mayer, 2003). More sophisticated approaches to understanding the effectiveness of computer-learning environments has explored information processing theory, specifically an aspect of information processing theory termed cognitive load theory (CLT) (Kirschner, 2002; Mayer \& Moreno, 2002). These approaches to studying the effectiveness of computer mediated learning environments are very promising. Research models have targeted the sensory register (SR) systems (e.g., auditory systems, visual systems), multiple formats of media stimulus, short-term memory (STM), and long term memory (LTM) retention. Much has been learned through these research approaches and they have informed the instructional design and technology (IDT) field immensely (Mayer \& Moreno, 2002). Still much remains unanswered.

\section{Need for Research}

From the early days of information processing theory, defining the psychological constructs of human learning has been the primary focus of the research (Atkinson \& Shiffrin, 1968). Researchers have sought to define the psychological parameters and processes of human learning through a multitude of research designs. These studies have contributed immensely to how the process of teaching and learning of information in academic environments are perceived today. They have contributed to how instruction is designed and implemented. Contemporarily, information processing theory, CLT, working memory (WM) theory, and dual coding theory (DCT) all contribute to designing effective computer-learning environments (Atkinson \& Shiffrin; 1968; Sweller, 1988; Baddeley \& Hitch, 1974; Paivio, 1971; 1986). Modern 
psychometric research designs targeting computer-learning environments focus on understanding the mental processes e-learners experience during computer-environment learning tasks (Mayer \& Moreno, 2002). Findings inform the development of computer-learning environments that best facilitate learning experiences (Morrison, Ross \& Kemp, 2004). These are basic principles of the psychometric approach to research and development of computer-learning environments and perhaps the most advantageous from the perspectives of IDT in terms of learning theory.

In light of the great variability potential for the development of digital content delivery system interfaces and digital multimedia instructional content today, little research focuses on defining how visual information impacts human information processing in computerenvironment learning tasks. Considering the types of previous research conducted, exploring visual information in modern computer-learning environments is needed. Research that informs IDT in terms of developing computer-environments that best facilitate learning based on visual information studies will greatly improve what is currently known in this area (Mayer, 2003).

Early research during the mid-twentieth century began to define many of the properties of visual information, specifically color and shapes, in television monitors during information searching and grouping tasks (Barker \& Krebs, 1977). While findings of this research have supported design of visual information in modern computer environments (Galotti, 2004) it is very limited and leaves much to be explored (Mayer, 2003).

Other approaches are limited as well. The vast majority of usability testing has been task specific and focuses on the effectiveness of human interactions with user interfaces. Human information processing based on learning theory is not the focus of usability testing. Interface usability studies have typically provided visual information findings through case-study research 
experiments that inform design of satisfactory user experiences and task flow efficiency (Snyder, 2003). Although interface design information gathered from case studies by experts may be viewed as informative to designing principles suggested for ID in general (Kim \& Yoon, 2005), generalizing case-study findings is not recommended (Richey \& Klein, 2007). Researchers also contend, findings derived of usability evaluations are user-interface task-specific and provide little information on the underlying human learning processes (Mehlenbacher, et al., 2005).

Psychometric studies have been promising, but also leave much to be explored. Psychometric-studies of computer-learning environments have placed much focus on the impact of target instructional-multimedia-content upon information processes during learning tasks. Measuring the impact of non-target-information during learning tasks in computer environments has not been a primary focus of previous psychometric investigation (cf. Mayer \& Moreno, 2002; Mayer, 2003). Considering previous psychometric research exploring learning in computer environments, more research is needed to better understand how multiple varieties of visual information in computer-learning environments impacts the learning processes. Research efforts that focus on how visual information is perceived in computer-learning environments will further inform development of visual instructional content for computer based learning. Additionally, research efforts may also inform development of computer-environment-specific IDT models derived of learning theory.

\section{Problem Statement}

The rapid increase in e-learning as an emerging primary source of higher education experiences, k-12 education, and corporate training programs, coupled with globalizing academic and corporate communities, requires an exploration of e-learners' experiences and 
learning efficiency (Allen \& Seaman, 2008; Bersin \& Associates, 2009; Derry, 2007; Fritz, 2006; Edmondson, 2007; Picciano, 2002; Reimann, 2003). Schnotza and Loweb, (2003) argue a number of misconceptions about multimedia content designed for learning have emerged among educators. Not for lack of understanding of information technology, but rather for lack of expertise in cognitive science, psychology, and educational science in the use of multimedia content for e-learning instruction.

Modern e-learning courseware development software requires developers possess many competencies in order to produce effective e-learning environments. Developers who now have a wide variety of publishing tools capable of producing a wide variety of digital content do not always appropriately consider the implications of content development for e-learners in terms of effective learning content and learning outcomes (Frommann \& Phan Tan, 2005).

Schnotza and Loweb, (2003) contend, multiple modalities of multimedia content are not always beneficial for learning. Understanding the affect multimedia content has on learning requires understanding the semiotic and sensory aspects of multimedia content through focusing research on student learning. The authors report, “...complex interactions take place between the external representations provided by increasingly sophisticated educational technologies and the internal (mental) representations constructed by learners...The potential effectiveness of educational multimedia materials is therefore likely to be influenced by the extent to which their design takes these complex interactions into account” (Schnotza \& Loweb, 2003, p. 118).

At the root of much research addressing learner mental representations of content and learning outcomes in e-learning environments is CLT (Mayer, 2001; Niegemann, 2001, as cited in Brünken, Plass, \& Leutner, 2003). CLT specifically explores excessive cognitive-load derived 
of instructional materials in general. Kirschner (2002) describes CLT as a theory that can inform ID of educational materials that optimize intellectual performances during learning tasks. Identifying instructional materials that compromise STM processes and the instructional strategies to alleviate cognitive-load have been the focus of this line of research (Brünken, Plass, \& Leutner, 2003; Kirschner, 2002).

Limitations on memory processes began to proliferate within the study of learning psychology and education in the mid- $20^{\text {th }}$ century through research by scientists such as Miller (1956) and Atkinson and Shiffrin (1968). Scientists such as these provided much of the foundations of contemporary CLT research. The classic research elaborated the psychological constructs of memory components and processes from the exterior stimuli through the organism's senses (i.e., sensory registers) to memory storage. Contemporary information processing research has expanded this focus to include approaches of CLT and WM limitations (Kirschner, 2002; Mayer, 2003; Reimann, 2003; Schnotza \& Loweb, 2003).

Much current research focuses on multimedia learning content and implications on WM capacity within a CLT framework (Mayer \& Moreno, 1998; Moreno, 2006). However, little is known about how non-target-learning content in computer-environments, described here as 'laden digital information,' impacts visual STM learning. Laden digital information in computer-learning environments is characterized by any visual information such as colors or graphics, environmental aesthetics, animations used for advertisements, or any other non-targetlearning visual content.

In light of the growing complexity of e-learning content management systems and the variety of digital content perceived within computer-learning environments, an exploration that 
addresses the effectiveness of e-learning in terms of accounting for visual learning tasks is warranted. Addressing visual learning in computer-learning environments from a visual STM framework is proposed.

\section{Research Questions}

This research study proposes to explore the effects of color and animation on visual STM in computer-environment learning tasks. Exploring visual STM in experimental environments will provide insight into how a variety of digital visual information environments have an effect on human learning processes.

This research proposal addresses color and animated objects in computer environments as non-target visual information that may potentially impact the visual STM learning processes during learning tasks. Visual learning tasks in black and white environments (i.e., achromatic) in contrast to visual learning tasks in digital-color-laden environments (i.e., chromatic) with and without animations are of interest. Gaining an understanding of how achromatic interference, chromatic interference, and animation interference impact visual STM in terms of image recognition (i.e., visual image STM) and image location recognition (i.e., visual spatial/movement STM) is explored. The research findings will inform multiple parameters of visual perception of digital information in computer-learning environments in terms of optimization of visual STM learning. Both accuracy of visual STM information retention and latency response time will be explored.

The research questions under investigation are as follows:

RQ1: Is there a significant difference in visual STM learning-task response-accuracy between black and white digital learning environments and digital learning environments laden with 
colors? As previously mentioned, laden digital information in computer-learning environments is characterized by any visual information such as colors or graphics, environmental aesthetics, animations used for advertisements, or any other non-target-learning visual content.

RQ2: Is there a significant difference in visual STM learning-task response-latency between black and white digital learning environments and digital learning environments laden with colors? It is questioned whether digital learning environments laden with colors require more time for participants to respond in contrast to black and white digital learning environments, whether accurately or inaccurately.

RQ3: Is there a significant difference in visual STM learning-task response-accuracy between black and white digital learning environments with animation and digital learning environments laden with colors and animation?

RQ4: Is there a significant difference in visual STM learning-task response-latency between black and white digital learning environments with animation and digital learning environments laden with colors and animation?

\section{Goals of Research}

The goals of this research study are to gain a better understanding of the effects of color and animation on visual STM in computer-environment learning tasks. In line with Moreno and Mayer (nd.) and Mayer and Moreno (2002), a goal of this research is to provide information for the research and development of computer-learning-environment-specific ID models stemming from the psychological processes of learning. Ally (2004) also contends computer-learning environments must be designed based on effective learning theory. In line with Ally (2004), providing the development community with furthering information to aid in this exploration is 
also supported by the goals of this research. The findings of this research may provide for informing specific psychometric parameters of effective visual instructional content in computerlearning environments. Therefore, aide in developing models of ID specific to computerlearning environments that consider a theoretical model based on learning theory.

\section{Limitations}

While much may be gained through scientific exploration in terms of further defining the parameters of visual STM in computer-environment learning tasks, these parameters, no matter how well defined and described through scientific explorations are only a small fraction of the scope of human information processing model components. Visual STM is just a small part of the entire human learning mechanism, alongside auditory STM and the components of all other SR information processing models. Further, STM information processing in general is only a fraction of the entire human learning, memory storage/retrieval mechanism.

What can be gained through this research study is a better understanding of how visual information impacts visual STM in learning tasks in computer environments. Findings from research such as this may aid immensely to the development of design principles of effective visual information for instructional purposes in computer environments. Additionally, findings from research such as this may aid in developing sound learning theory for computer environments derived of visual information processing.

Although the limitations of the research are confined to the implications of the findings in terms of visual STM parameters and their application to ID modeling and learning theory, it is safe to say results of this research will generalize to the sample population. Given a substantial participation group and a sound research design, the nature of psychometric-studies often 
elucidates a typology of the general human capacity and psychological conditions. However, because children and elderly adults do not fall within the sample of participants, these two groups are eliminated from general application of findings.

\section{Organization}

The study consists of five chapters. Chapter one provides an overview of emerging technology in education and a need for research as a response. The problem statement of the research derived of emergent technology in education if followed by the research questions. Goals of the research are discussed as well as research limitations. Chapter two provides an overview of the computer's role in education as well as the role of instructional design and technology. Research approaches to development of computer aided instruction are discussed including comparative models, usability models, and psychometric models. Chapter three provides the research methodology including the research design, hypothesis, research questions, participant information, research setting, stimuli, stimuli conditions, experimental design, statistical method, variables, apparatus, limitations, materials, procedure, and data collection. Chapter four provides findings of the research study, and chapter five discusses the implications of findings, considerations of applications to instructional design, and future experimentation.

\section{Summary}

Recent reports indicate e-learning in academic and corporate enterprise is steadily on the rise (Allen \& Seaman, 2008; Bersin \& Associates, 2009; Picciano \& Seaman, 2009). Supporting the proliferation of e-learning and computer-environment learning development are new development tools that provide developers a vast variety of digital media options. Researchers 
question the quality and effectiveness of e-learning environments as a result of the development opportunity for great diversity in digital content (Picciano, 2002; Bersin \& Associates, 2009).

A variety of approaches have sought to account for the quality and effectiveness of computer-environment learning including the study of test scores, quality surveys, user interface research and design, and psychometric-studies (Mayer \& Moreno, 2002; Richey \& Klein, 2007). While much of this research informs ID of computer-learning environments, only psychometric research explores learner information processing as the foundation of learning theory for ID devoted to computer-learning environments. Limitations of psychometric research to date leave much to be answered in terms of the impacts of visual information on learning in computer environments.

Addressing visual learning in e-learning environments from a memory capacity framework that targets visual STM, target-learning content, and laden digital information (i.e., non-learning-target content) is proposed. This research proposal addresses color and animated objects as non-target visual information that may potentially impact the visual STM learning processes of target information during visual learning tasks in computer environments. Research efforts that better define how visual information is perceived in computer-learning environments will further inform development of content for computer based instruction (CBI) and development of computer-environment-specific ID models derived of learning theory. 


\section{CHAPTER II:}

\section{REVIEW OF LITERATURE}

\section{General Introductory Review}

E-learning is becoming ever more expansive (Allen \& Seaman, 2008), and development of computer-learning environments and digital instructional materials is taking on many new and dynamic features (Horton, 2000). The opportunities to integrate digital multimedia into hypermedia-environments are escalating with every new emerging technology requiring new approaches to ID and technology education (Maughan, 2001; Van Dusen, 2000). Soon, mobile technologies will also be better able to integrate and deliver dynamic instructional content to mobile learners. Gaming development for e-learning is also exploring ID and technology education. As an example, New York University has recently established the NYU Game Center, a center devoted to research and design of digital games (The Wired Campus, 2008).

Computer-learning environments provide much beyond the scope of traditional textbooks, chalkboards, and lecturing. The modern contexts of information delivery are impacting learning in many ways that are yet to be accounted for (Tomei, 2002). Multimedia production for many years had primarily been an entertainment industry activity, and its use was limited in academic settings. Digital technologies and the modern communications explosion are rapidly changing all that. And with it, emergent in the modern contexts of digital educational environments is a real need to define digital content that facilitates targeted learning and efficient learning through ID (Dabbage \& Bannan-Ritland, 2005; Mayer, 2003).

Instructional content has a long and rich history. Reiser \& Gagné (1983) have defined instructional media as any physical means through which instruction is presented to learners. By 
this definition, textbooks, chalkboards, computers, images, films, multimedia, etc. are all considered instructional media. Visual instructional media such as photographs, magic lantern slide shows, and educational films began to be produced and published for educational purposes in the early twentieth-century with publications such as Visual Education by the Keystone View Company in 1908 (Reiser and Dempsey, 2002). Curricular material needs for teachers also began to surface about the same time with publications such as Visual Instruction in the Public Schools authored by Anna Dorris in 1928 (Van Dusen, 2000). Reiser and Dempsey (2002) also report, audio and visual content were used quite extensively through the 1950's in the United States. And, the development of the television and its proliferation during this time brought with it instructional television as another form of instructional media.

Computer technology was also developed for instructional purposes and was termed computer aided instruction (CAI) in the 1950's (Reiser \& Dempsey, 2002). Computer technology did not begin to take notice and proliferate until the 1980's though with the development of the microcomputer (Saettler, 2000). By 1983 40\% of elementary schools and $75 \%$ of secondary schools in the United States were using computers for instructional purposes (Center for Social Organization and Schools, 1983, as reported in Reiser \& Dempsey, 2002).

Typically computers were first used for their computational power in mathematics and statistics courses (Saettler, 2000). Computers resided in classroom laboratories where students accessed them to perform computational tasks. Computers were also typically used as quick evaluation stations for many fields of study. Students gathered personal evaluation results via computer and test card technology in an innovative self paced instructional methodology termed Personalized System of Instruction (PSI) (Caldwell et al., 1978; Caldwell, 1985). With the emergence of local computer networks, computers as communication machines were recognized 
as having potential for broader education, but it was a very expensive consideration (Harasim, Hiltz, Teles, \& Turoff, 2001). With the Internet the communicative power of the computer was realized in a more affordable infrastructural system and computer mediated instruction (CMI) began to rapidly become part of education on many new dynamic levels (Minoli, 1996).

The computational power and communicative power of computers were both harnessed within new educational contexts (Saettler, 2000). The utility of computers in education recently has become very broad scope in use. Facilitating modern computer-learning environments are new and advancing computer technologies, especially applications technologies such as LMS/LCMS (e.g., WebCT, Blackboard, and Angel). Other new and rapidly advancing technologies are multimedia production software applications such as Adobe Labs® Master Collection $($ (2009). New and advanced software applications are becoming easier for developers to adopt and use. With advancing technology in educational settings bringing with it great variability of digital content in the computer-learning environment, the quality of elearning and effectiveness of e-learning raise questions (Bersin \& Associates, 2009; Mayer, 2003; Picciano, 2002; Van Dusen, 2000).

\section{Computer Based Instructional Development}

With millions of higher education students enrolling in online courses (Allen \& Seaman, 2008), more than a million k-12 students utilizing computer based courses (Picciano \& Seaman, 2009), and corporate organizations in the United States expanding training programs at substantial rates (Bersin \& Associates, 2009) there are a number of computer based methods of instruction being utilized. For the most part these methods are characterized as supplemental instruction, hybrid instruction, and full course instruction in both asynchronous and synchronous 
delivery modes. Facilitating the methods of CBI are many new emerging technologies with purposes of developing and managing digital learning content.

The utility of LMS/LCMS courseware applications and digital media content development software has provided developers an opportunity to create computer-learning environments and digital learning content with a wide variety of characteristics and features. Characteristics and features include a wide variety of course delivery systems within the contexts of the LMS/LCMS. They also include variable navigation structures, variable graphic design elements, and variable color schemes.

Barron \& Liskawa (2001, as reported in Dabbagh \& Bannan-Ritland, 2005) describe LMS/LCMS as have the following capabilities:

- Asynchronous communication

- Synchronous communication

- Online testing

- Home pages (for students and instructors)

- Security password features

- Course design and management

- Student management

- Student and site tracking

While there are several variations of this list of LMS/LCMS features in the literature (Center for Curriculum Transfer and Technology, 2000; Shelton \& Saltsman, 2005) descriptions include 'developer content-creation and delivery tools' and 'student learning tools' as pedagogical features of an LMS/LCMS. Dabbagh and Bannan-Ritland (2005) describe 'content- 
creation and delivery tools' as tools that a developer can use to create documents native to the LMS/LCMS or tools that enable upload of a variety of digital documents to the LMS/LCMS system as course content. Learning tools are described by Dabbagh and Bannan-Ritland (2005) as tools that enable the learner to manipulate course content in a meaningful way and engage in learning activities.

Dabbagh and Bannan-Ritland (2005) comment that pedagogical issues in course development are truly ID issues. This brings to bear on the effectiveness of LMS/LCMS 'developer tools' and 'learner tools’ as pedagogical tools, as they are dependent upon the effectiveness of the ID. The effectiveness of the ID rests at the foundations of all the tools within the LMS/LCMS computer-learning environment, whether developer tools or learner tools. It is the ID that guides development of the course content; structures, steps, and sequences course content; creates the entire content computer-environment navigation system; and enables the appropriate engagement of learner tools in context.

Effective e-learning courseware development requires developers possess many competencies, including knowledge and practice of ID methods that ensure effective pedagogical use of the LMS/LCMS tools. The wide variety of publishing tools characterized by LMS/LCMS are capable of producing a wide variety of digital content and engagement activities that may not consider the implications of pedagogy in terms of effective learning content and learning outcomes otherwise (Frommann \& Phan Tan, 2005). Wilson (2004) contends the computerlearning environments must be thoroughly planned, integrating sound pedagogical practice. This includes design of content and the navigation structures of the content. 
ID is a critical concern that rests at the foundations of sound development of computerlearning environments. There is a great need for further development of ID methods specific to computer-learning environments, and there is a great need for developers to implement what is known about effective ID specific to computer-learning environments (Lynch \& Horton, 2008; Mayer, 2003; Roblyer, 2004). The need to learn about ID methods and implement ID practices based on methods specific to computer-learning environments is a concept that is shared among technology educationalists. Clark and Lyons (1999) note each technological revolution brings with it new instructional modes that are unique and require new approaches to understanding and implementing them effectively.

\section{Role of Instructional Design and Technology}

Instructional design has been historically influenced by theories of learning and instruction. New approaches to ID amidst emerging educational technologies are maintaining this tradition. IDT is an expanded field derived of ID that has become the new systemic approach to research and development of computer-learning environments (Reiser \& Dempsey, 2002). And, like ID, IDT is greatly influenced by theories of learning and instruction (Dabbagh \& Bannan-Ritland, 2005; Reiser \& Dempsey, 2002). New IDT approaches to researching and developing CAI/CMI are targeting psychometric constructs (Mayer, 2003). The efforts of these approaches are being applied to developing more effective computer-learning environments and digital instructional content based on learning theory (Mayer, 2003; Reiser \& Dempsey, 2002).

In a broad sense ID, the foundations of IDT, is a systematic practice described by Reiser and Dempsey (2002) as follows:

- Instructional design is learner-centered 
- Instructional design is goal-oriented

- Instructional design focuses on real-world performance

- Instructional design focuses on outcomes that can be measured in a reliable and valid way

- Instructional design is empirical

- Instructional design is a team effort

ID is also characterized by a modular-systems approach to resolving instructional problems (Morrison, Ross \& Kemp, 2004; Reiser \& Dempsey, 2002). Models facilitate the dynamics of the entire instructional environment. Although models vary (cf. Dick \& Carey model; ADDIE model; Kemp model in Morrison, Ross \& Kemp, 2004; Reiser \& Dempsey, 2002) few emphasize the development of instructional materials as a specific modular component of the ID system (cf. Fig. 1).

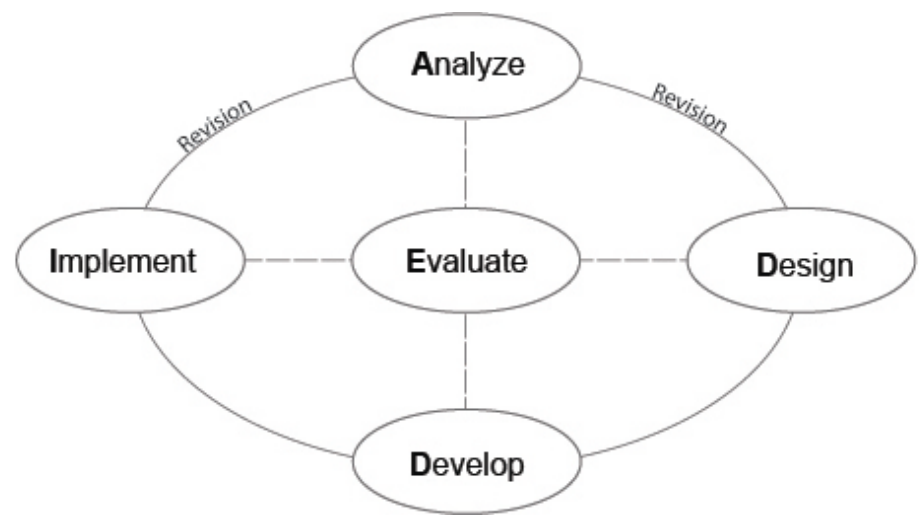

Fig. 1: Core elements of instructional design as described by Reiser \& Dempsey (2002).

Although instructional materials in the design process are assumed to fit within the contexts of the ID models as aspects of dynamic component relationships, only models such as the Kemp model explicitly provide a ‘development of instruction’ component to the model (cf. Kemp model and Dick \& Carey model in Morrison, Ross \& Kemp, 2004; Reiser \& Dempsey, 
2002). Morrison, Ross \& Kemp (2004) devote a chapter to developing instructional materials, placing emphasis on minimizing cognitive load. This approach is concerned with developing instructional materials that minimize stress on the human-mental-capacities to learn.

Founded in the ideas of researchers such as Markle (1967, as reported in Richey \& Klein, 2007), who called for developing empirically grounded instructional materials to strengthen the knowledge base of the IDT field, the research of Mayer (2003) is an example of the huge trend in modern research and design that places great emphasis on multimedia and digital content in the ID process. Systems of ID today are in need of maintaining focus on the implications of the great variability in content presentations in computer-learning environments (Van Dusen, 2000; Mayer, 2003). There is a growing need for IDT models that reflect this emphasis on instructional materials in CBI.

The roots of ID originally emerged from the development of instructional materials and learner engagement with instructional materials resulting in learning behavior (Dabbagh \& Bannan-Ritland, 2005; Reiser \& Dempsey, 2002). Reiser and Dempsey (2002) report, instructional design in the United States emerged out of research and theory based on instruction, learning, and human behavior via the efforts of experts such as Robert Gagné and Leslie Briggs. Through the 1940's and 1950's psychologists worked on solving instructional problems through newly formed organizations such as the American Institute for Research (Reiser \& Dempsey, 2002). Instructional task analysis methodology, design of instruction, and evaluation procedures during this time were beginning to be viewed as systems of ID (Dick, 1987; Miller, 1953; 1962 as reported in Reiser \& Dempsey, 2002). 
With the 1954 publication of B. F. Skinner's The Science of Learning and the Art of Teaching a revolution in computer mediated education began (Reiser \& Dempsey, 2002). In this publication Skinner detailed specific characteristics of effective instructional materials. The materials were described as being presented in small steps, requiring active bi-directional engagement between the learners and instruction, providing immediate feedback, and enabling self paced advancement learning opportunities (Reiser \& Dempsey, 2002).

Oddly, Skinner's idea of instructional materials was seemingly designed for modern computer-learning environments. In fact Skinner even labeled them 'programmed instructional materials' and described them within the context of mechanical devices of instruction. If we were to compare the programming features of modern computer-learning environments with the characteristics of Skinner's programmed instructional materials via mechanical instruction we would find striking similarities. The ideology of Skinner's empirical approach to instructional materials is very similar to modern approaches that involve gathering data to identify instructional material's weaknesses and strengths, and then redesigning programmed materials based on learning outcomes (cf. Mayer, 2003) (Reiser \& Dempsey, 2002; Skinner, 1954).

A very important aspect of the ID modular-system approach, aside the importance of effective instructional materials, is the concept of learning objectives. Robert Mager popularized the concept of learning objectives when he published the curricular materials entitled Preparing Objectives for Programmed Instruction in 1962 (Reiser \& Dempsey, 2002). The work defined learning objectives in terms of what was to be learned (e.g., desired behavior), the context of learning (e.g., programmed materials), and the criteria of evaluation (e.g., learner feedback). The ideas described in Mager's learning objectives are still, to a degree, fundamental concepts sought in understanding the modern computer-learning environment (cf. Mayer, 2003). 
During the 1970's the value of instructional/learner feedback began to take notice within the emerging popularity of information processing theory (Reiser \& Dempsey, 2002). And this became important for ID and computer science. Information processing theory was similar to behavioral theory in that the environment played an important role to stimulating learning. However, information processing theory accounted for learning as internal processes (Atkinson \& Shiffrin, 1968; Reiser \& Dempsey, 2002). Among instructional designers and models of ID, focus turned to aspects of the ID process that would provide for effective information processing for learning, including appropriate environmental conditions and appropriate materials. The information processing model has evolved in modern applications of research and development of computer-learning environments. Information processing models include the concepts of CLT, WM, and DCT (Baddeley \& Hitch, 1974, Sweller, 1998; Paivio, 1971; 1986). Each of these theories describes construct models of the psychological processes of human learning and seeks to provide modern IDT with information for development of effective computer-learning environments and effective computer-learning instructional materials.

\section{Approaches to Research and Development of Computer-learning Environments}

Research and development of computer based environments are credited with spawning initially out of the research of behavioral scientists such as B. F. Skinner (Reiser \& Dempsey, 2002). Approaches to research and development, then termed developmental research, in general have taken on many forms since those early times (Richey \& Klein, 2007). Research and development of computer-learning environments have reflected the popular movements of research trends over the decades. Following the overt behavioral approach during the 1950's and 1960's scientists began to focus attention on the inner mental processes of human learning (Roblyer, 2004). Prior to formal CAI research, research through the 1950's innovatively sought 
to understand how visual information in television monitors best facilitated behavioral tasking of finding and identifying objects through color coding, and the mental processes involved with these tasks (Barker \& Krebs, 1977; Galotti, 2004). This research had a focus on the human cognitive capacity of learning and reflects the methods of user-interface (UI) research and design today (cf. Galotti, 2004; Snyder, 2003). This early research sought to identify the weaknesses and strengths of visual stimuli (viz., colors and shapes) based on participant feedback during visual tasking such as searching, locating, and identifying objects (Barker \& Krebs, 1977). The findings of this research were adapted to designing UIs such as airplane-control-tower radar system screens among many other applications (Barker \& Krebs, 1977; Galotti, 2004). Since that time, ideas derived of this early research implicating the utility of colors for searching, identifying, and grouping information have been applied to the development of computer based environments (Lauer \& Pentak, 2005; Spool, Scanlon, Schroeder, Snyder, \& DeAngelo, 1999).

Although the behavioral methods of B.F. Skinner are noted as starting an educational revolution in computer-learning environment development (Reiser \& Dempsey, 2002), behavioral research methods did not immediately proliferate computer-learning environment development (Galotti, 2004). During the 1950’s and 1960’s scientists began to view computers as electronic modeling machines that may emulate the information processes of human learning (Roblyer, 2004). With this movement the cognitive-learning-theorists began to focus on information processing as a theory of human learning (Galotti, 2004; Roblyer, 2004; Walls, 1999). At the time computers were just beginning to emerge in educational settings, they were very large, very expensive, and not many researchers had them available for research studies (Saettler, 2000). 
Proliferating in the 1980's, research and development of CAI that considered the effectiveness of learning outcomes and user satisfaction of CAI had been conducted through many designs. Research designs are developed to facilitate the needs and goals of the researchers in efforts to gather specific information (Richey \& Klein, 2007). Generally, understanding more about the effectiveness of CAI in terms of effective learning through any research design requires a definition of 'learning,' an understanding of the 'instructional practices' leading to learning within the CAI environment, and a description of 'learning as a result of CAI.' In this way the effectiveness of learning can be measured as a result of specific instructional practices within the computer-based learning environment.

There are many definitions for learning in the literature. Walls (1999) provides two definitions for learning that are closely related, each reflecting its own theoretical underpinnings. The first is a behavioral definition for learning, which states, "Learning is a change in behavior after experience or practice” (Walls, 1999, p. 6). The second is a process definition for learning, stating, "Learning is a process that is shown by a change in behavior after experience or practice” (Walls, 1999, p. 7). Both of these definitions are acceptable with little difference. Each definition shares a concern with the product of the experience of learning, whether a shaping of behavior or an inner process, to verify learning has occurred through measuring a change in behavior. In short, Walls (2004) describes the concerns of these two definitions as, "Learning is concerned with behavior change after experience or practice and the process of acquiring the information leading to change...[O]thers concerned about learning only have external behavior to gauge the storage of new information by the learner” (Walls, 2004, p. 1-1). This explanation makes clear the need to design research that accounts for behavior change as a 
demonstration or performance of specific attained knowledge, indicating learning has occurred of that knowledge, and to a measured degree.

Considering an understanding of instructional practices, Oosterhof, Conrad \& Ely (2008) provide characteristics of the experience and practice of learning within computer-learning environments, which may be viewed as equivalent to instructional practices. These instructional practices may also aide in providing for understanding more about the process of acquiring information during learning in computer environments. The experience and practice characteristics of learning within the contexts of computer environments are described by Oosterhof, Conrad \& Ely (2008) as:

- learner-content interaction

- learner-instructor interaction

- learner-learner interaction

- learner’s capabilities

- learner's performance

Lastly, an external behavior to gauge the storage of new information by the learner requires accounting for the learner's new found knowledge, as knowledge is the product of learning. A demonstration of performance of knowledge by the learner is a behavior that explicitly indicates learning has occurred, and how much learning has occurred. Demonstrations of knowledge as a performance are often termed learning outcomes (cf. Linn \& Miller, 2005; Oosterhof, Conrad \& Ely, 2008).

By methodology of instruction a learner typically interacts with instructional content, instructor, and other learners to attain experience and practice during the learning process. As a 
result of this learning activity, specific information may be stored into learner memory as new knowledge. Learning outcomes are characterized by typologies of knowledge performances (e.g., information, concepts, rules, or problem solving) quantitatively and qualitatively via means of an evaluation instrument (Oosterhof, Conrad \& Ely, 2008). Results of evaluations may inform researchers of specific learner knowledge performances, instructional content value, and instructor value among other dimensions of the learner, learning environment, and learning process. When CAI environments are researched, questions concerning the effectiveness of the environments as learning environments can be answered within the contexts of a specific research design and its limitations based on evaluating instructional practices and learning outcomes (Oosterhof, Conrad \& Ely, 2008; Richey \& Klein, 2007).

\section{Traditional Instruction Verse Computer Instruction Comparative Models}

The intensity of CAI research in general increased as a result of the introduction of the microcomputer and the post-industrial-revolution high-tech economy that required workers to train and retrain many times during the course of a career (Olsen \& Di Fazio, 1983; Reiser \& Dempsey, 2002). For example, in 1982 training-program research by Digital Equipment Corporation sought to compare contemporary modes of training involving video cassettes and printed materials with innovative CAI coupled with interactive multimedia. The focus of this research was to compare modes of instruction in terms of accounting for learning outcomes (Olsen \& Di Fazio, 1983). This is one of the earliest studies that focused on understanding the effectiveness of CAI through measuring learner performance. The researchers compared learning outcomes of contemporary models of instruction with learning outcomes of newly emerging CAI. 
This comparison model is still quite extensively used in researching the effectiveness of learning environments. Test scores and quality surveys gather performance and attitudinal data from research participants in traditional learning environments and CAI learning environments. Data are then compared to understand more about how CAI compares to traditional modes of instruction on multiple levels. This approach to researching CAI is valuable. Results of evaluations derived of this type of research design model may inform researchers of specific learner knowledge performances, the effectiveness of instructional content, and the effectiveness of the instructor among other dimensions of the learner, learning environment, and learning process. Data comparisons may clearly describe performance differences and quality differences between traditional modes of instruction and CAI providing valuable information on the overall effectiveness of the computer-based learning environment. This research is concerned with evaluating performances of knowledge attained through learning processes within contexts of computer-learning environments. However, this type of research does not focus on underlying constructs of learning theory such as STM as applied to IDT. For this reason this research does not inform researchers, and especially ID technologists, of the relationship between the computer-learning environment and underlying learning processes. Research such as this is often conducted as action research in the development of specific courses of instruction and is generally not performed in efforts to generalize information to IDT (cf. Abutarbush. Et al., 2006; Basile \& D’Aquila, 2002; Herrot, Bishop \& Truby, 2004; Jacoby, Smith \& Albanese, 1984; Mullen \& Love, 1980; Paperny \& Starn, 1989; Predavec, 2001; Sangster, 1992; Steel, Johnson Palensky, Lynch, Lacey \& Duffy, 2002). Although comparative research models may be found to inform IDT, there is a call to focus computer-learning environment research on the underlying 
psychometric processes of human-learning to better understand the mental processes e-learners experience during computer-environment learning tasks (Mayer \& Moreno, 2002).

Usability Evaluations - Task Oriented Studies

Norman (2002) has commented “...not all of the knowledge required for precise behavior has to be in the head. It can be distributed-partly in the head, partly in the world, and partly in the constraints of the world...Much of the information a person needs to do a task can reside in the world...Behavior is determined by combining the information in memory (in the head) with that in the world” (p. 54-55). This sentiment resides at the foundation of human-computer interaction research. A form of human-computer interaction (HCI) research that better describes rich user experiences in computer environments is described as usability evaluation research (Snyder, 2003). This research focuses on the UI as a model for research and development of effective and satisfactory user experiences when engaging computer environments.

Usability evaluation research developed out of human-information processing theory and HCI theory (Card, Moran, \& Newell, 1983; Newell \& Simon, 1972; Simon, 1979, 1981, as reported in Mehlenbacher, et al., 2005). Usability evaluation research is a design and development approach to rapid prototyping of UI (Snyder, 2004), the development of products (e.g., tool research), and processes (e.g., model research) (Richey \& Klein, 2007). Much usability evaluation research has also focused on cognitive walkthroughs, heuristic evaluations, remote usability evaluation methods, and lab-based usability testing (Castillo et al., 1998; Hix \& Hartson, 1993; Nielsen, 1994; Polson et al., 1992 as reported by Howarth, Andre \& Hartson, 2007). 
Researchers have suggested usability evaluation research focus on all aspects of the UI in computer environments to better understand design guidelines that facilitate learning experiences (Galizt, 2007; Nielsen \& Loranger, 2006; Spool, Scanlon, Schroeder \& DeAngelo, 1999; Wilson, 2004). Galitz (2007) suggests a design process model of usability evaluation research that facilitates a focus on all aspects of the computer-learning environment to accomplish these goals. This process model approach includes:

- Engage users in active feedback

- Gain a complete understanding of users and their tasks

- Create the appropriate design

- Perform rapid prototyping and testing

- Modify and iterate the design as much as necessary

Process models of usability evaluation research such as the Galitz (2007) model provide a framework for evaluating user experiences during specific instructional practices in computer environments developed for learning. Much rich data can be gathered about the design of computer-environment instructional practices through a number of effective protocols such as think-aloud activities that enable users to voice their experiences on a wide range of evaluations during engagement with the UI (Snyder, 2003).

Usability evaluations are case study research and development experiments that seek to target and eliminate problems with the design of course delivery systems and digital content through attaining real-time feedback from users (Snyder, 2003). Usability research has proven a successful approach to developing UI products and models that facilitate satisfactory and productive user experiences (Nielsen \& Loranger, 2006). Although UI research is a well defined 
systematic process for developing interfaces in computer-learning environments, products, and models, it meets some difficulty when informing instructional design. The main problem with usability testing as a holistic research approach that facilitates development of IDT models for CAI is accounting for the effectiveness of the learning experience outcomes. While usability research can define a user interface that meets user satisfaction criteria, researches view usability evaluation research as task-oriented-studies toward e-learning-user-interfaces and as having unknown implications for underlying learning theory (Mehlenbacher, et al., 2005). And, although interface design information gathered from case studies by usability experts is generalized to designing principles used by instructional designers (Kim \& Yoon, 2005), it is difficult to generalize from case studies (Richey \& Klein, 2007). At best, findings can be considered only within the contexts of further research and not as generally applicable to development of new environments. Further, while user satisfaction may define the success of usability evaluation research, gaining understanding of the effectiveness of computer-learning environments in terms of learning outcomes requires a multi-methods approach to measurement that accounts for learning.

Richey \& Klein (2007) describe usability testing as potentially a multi-methods approach to research and design. The usability multi-methods approach may derive research criteria from the literature including psychometric studies that have targeted underlying learning theory in their designs. It is important to understand while the scope of usability evaluation studies may include criteria derived of psychological studies describing task specific functionality desirable of a UI, usability evaluation studies do not specifically measure target psychological-learningconstructs such as STM by research design (cf. Catani \& Biers, 1998; George, 2005; Howarth, 
Andre \& Hartson, 2007; Kim \& Yoon, 2005; Mehlenbacher, et al., 2005; Marx, 1994; Säde,

Nieminen \& Riihiaho, 1998; Uceta, Dixon \& Resnick, 1998; Vatrapu \& Pérez-Quinoñes, 2006).

Psychometric Approaches to Research and Development

The discussion on the approaches to research and development of computer-learning environments so far has relied on measuring the effectiveness of CAI in terms of effective learning outcomes in comparative studies, with the additions of user-interface satisfaction and task efficiency during CAI in usability evaluation research. As described previously, comparative studies and usability evaluation research depend upon a working definition of 'learning,' an understanding of the 'instructional practices' leading to learning within the CAI environment, and a description of 'learning as a result of CAI.'

In contrast, psychometric approaches to research and development of computer-learning environments also rely on a working definition of 'learning,' an understanding of the ‘instructional practices’ leading to learning within the CAI environment, and a description of 'learning as a result of CAI.' The psychometric approaches to research and development of CAI also focus on underlying theoretical psychological constructs described as the information processes of learning. Defining the parameters of information processing is a goal of this research. Another goal of this research is to describe and develop learning environments that best facilitate the psychological information processes, providing for effective learning experiences (Mayer, 2003).

The birth of modern scientific research into learning and memory-specifically STM information processing - may be seen as beginning in the mid $19^{\text {th }}$ century with experimentation such as that of Frans C. Donders and Hermann Ebbinghaus (Kantowitz \& Roediger, 1980). The 
branch of psychology called cognitive psychology gave formal rise to information processing theory in the 1950’s and 1960's when cognitive-learning theorists proposed a model that would provide a visual representation of psychological processes that are impossible to observe directly (Roblyer, 2004). Cognitive theories place emphasis on the stimulus environment and on a demonstration of behavior as an indicator that learning has occurred, however cognitive theories view learning as an internal process (Galotti, 2004; Walls, 1999; Worchel \& Shebilske, 1995). This theory dominated cognitive psychology in the 1970's and various models of information processing including computer information processing simulation models emerged. These models continue to be the focus of research today (Galotti, 2004; Reiser \& Rempsey, 2002; Roblyer, 2004).

The goal of information processing theory is to describe how humans learn and remember information (Galotti, 2004; Walls, 1999; Worchel \& Shebilske, 1995). The general model of information processing theory attempts to explain sequences, or stages, of underlying human psychological processes that occur as mental functions. The sequences or stages are described as a simulation of theoretical internal psychological constructs that interact as interconnected components during learning (Walls, 1999; Worchel \& Shebilske, 1995). These underlying psychological processes are preceded by inputs from the outside stimulus environment and then followed by external human behavior (Galotti, 2004; Walls, 1999; Worchel \& Shebilske, 1995). There are three stages of the general model of information processing theory that are described as the Sensory SR, STM, and LTM (Galotti, 2004; Roblyer, 2004; Walls, 1999; Worchel \& Shebilske, 1995) (Fig. 2). 


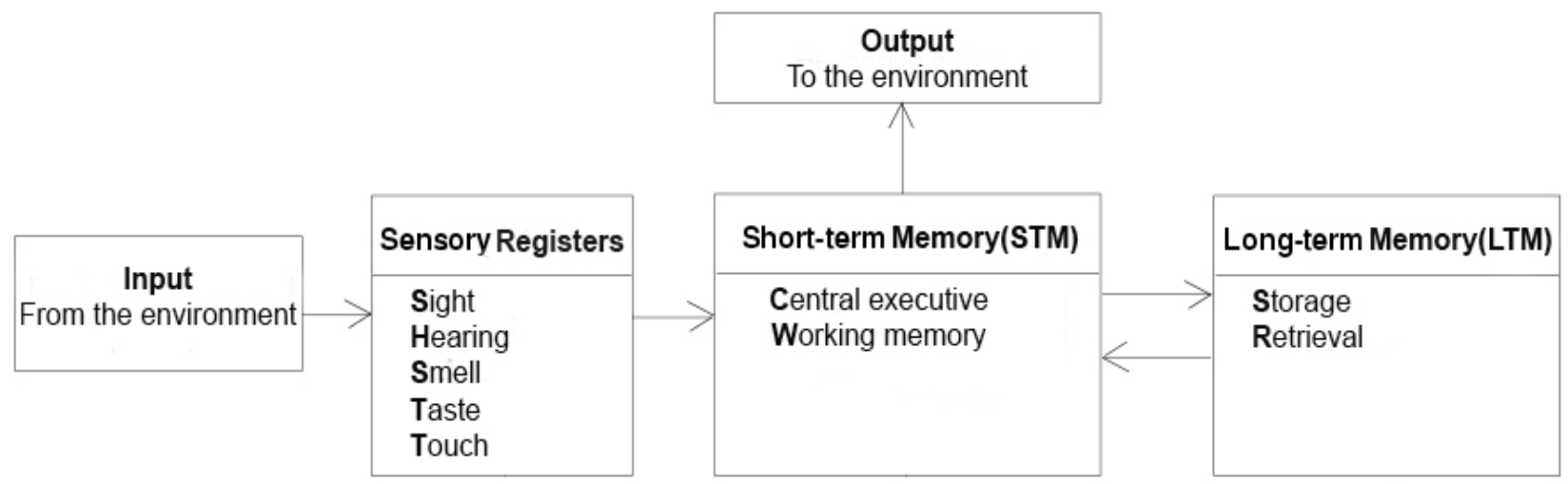

Fig. 2: Graphic derived explanation of a general model of information processing (Roblyer, 2004, p. 58; Walls, 1999, p. 320).

Information processing theory has more than one popular model representing the theoretical internal psychological constructs and stages of human learning (cf. Levels of processing theory, Parallel-distributed processing theory, and Connectionistic processing theory in Huitt, 2003). Perhaps the most widely accepted and popularized model of information processing is the model proposed by Atkinson and Shiffrin (1968) (Roblyer, 2004; Walls, 1999). Atkinson and Shiffrin (1968) proposed a modular stage approach to the psychological processes of human learning involving Sensory Stores (SS), Short Term Stores (STS), and Long Term Stores (LTS) (Fig. 3).

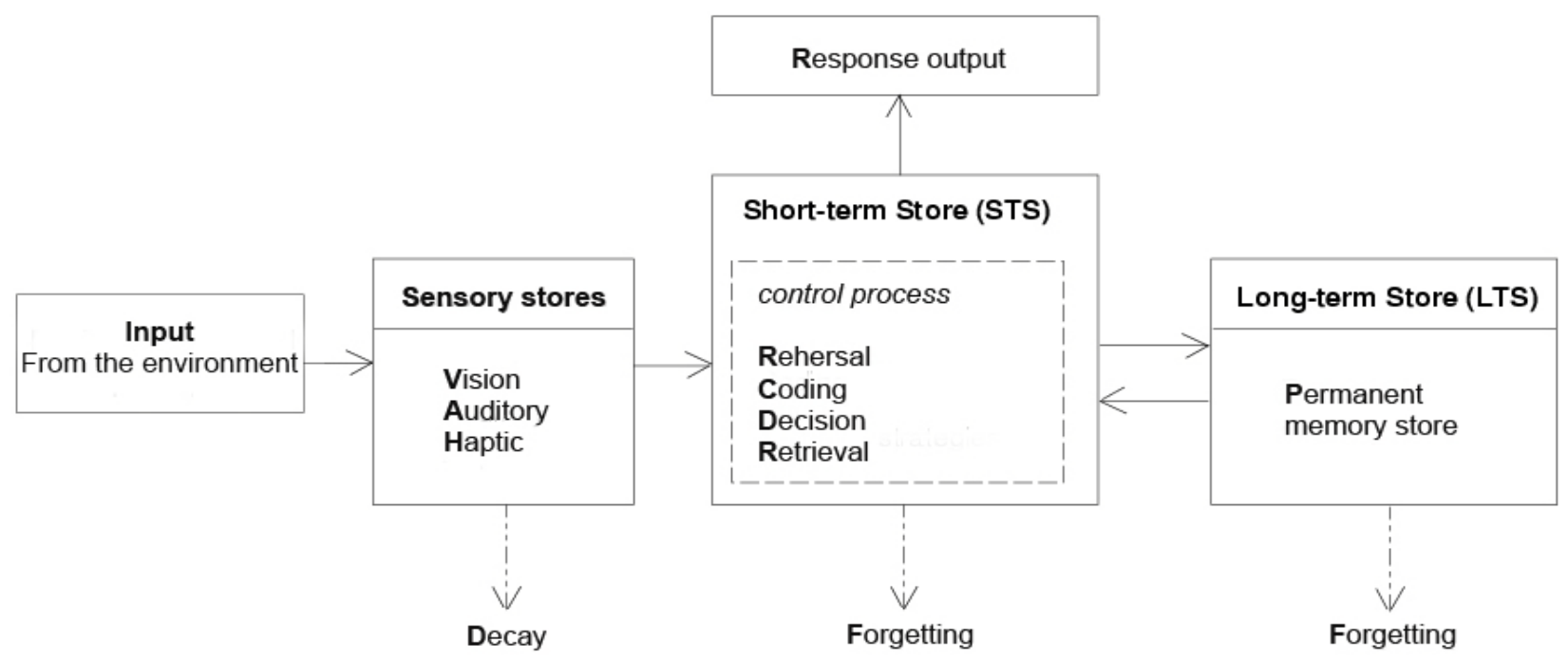

Fig. 3: Atkinson \& Shiffrin model of information processing (1968). 
The Atkinson and Shiffrin (1968) information processing model, in addition to the components of the general information processing model, emphasizes the concept of decay in the SS, the control processes and forgetting in the STS, and forgetting in the LTS. Decay in the SS refers to sensory information that is very short-lived as it is transferred to STS (Shiffrin \& Atkinson, 1969). For example, Sperling (1960, as reported in Shiffrin \& Atkinson, 1969) showed that visual SR information will decay from the SS in a period of several hundred milliseconds as it is transferred to the STS. The emphasis of the control processes of the STS are processes the learner can select and control to govern information flow depending on task (Shiffrin \& Atkinson, 1969). Forgetting in the STS is also referred to as rapid decay of information from the STS. Peterson and Peterson (1959) showed that information in STM decays after 15-30 seconds without rehearsal, or without practicing of information by the subject to keep it fresh in STM. This practice is easily demonstrated in repeating a telephone number over and over after it is read or heard until it is written or dialed, to keep it fresh in STM. Miller (1956) showed that STM also has a limited capacity of approximately $7+/-2$ chunks of information. Information in STM therefore can be forgot, or theoretically replaced with new information if this capacity is exceeded during information input. The capacity of STM and chunking of information is easily demonstrated by a subject glancing at these 16 numbers for a brief 4 seconds (1492177618121945), then trying to recall then without looking at them. The task of remembering 16 bits of information in the STM is impossible for the average subject. However, if the subject is told to remember the years of 4 historic dates from American history that are embedded in the 16 numbers, the task becomes much easier. Another example demonstrates the rate of flow of information capacity through the STM. A subject in this example is told to glance at a written page in a book for a brief time, and then asked to recall the 
information on the page without looking at it. It is impossible for a subject to input all of the words on the page instantly into STM and recall the information because STM does not have the capacity to input and retain all this information for rapid recall. It is simply too much information. However, if the subject begins to read the words on the page, the subject will reach a buffered capacity of information flow from the page to the STM where it is processed. At this stage, the subject should be able to recall and report on the information on the page once it is read. Perhaps not word for word, but accurately. The last emphasis the Shiffrin and Atkinson (1969) model is concerned with is forgetting in the LTS. Forgetting in LTS is described as a phenomenon attributed to failure of the retrieval process to access information accurately as more information is added to LTS. According to Shiffrin and Atkinson (1969), memory in LTS is permanent.

The simulation of the information processing model describes information as coming from the environment of the learning subject (Walls, 1999). Information is input from the environment into the learning subject through the interface of the SR with the environment (Worchel \& Shebilske, 1995). The subject must be aware of and attended to the information coming from the senses (Morrison, Ross \& Kemp, 2004; Walls, 1999). Reiser and Dempsey (2002) state, “[L]earners who fail to pay attention will never receive the information to be learned in the first place...To be most influential to learning, attention must often be directed so that learners heed certain specific aspects of the information they are being asked to learn” (p. 64). Conversely, it is suggested here, if learners are diverted from heeding specific aspects of information they are being asked to learn, learning will not occur either. In the case of efficient learning however, as information is received through touching, feeling, seeing, etc., it resides in the SR for milliseconds as it transfers to the STM (Sperling, 1960, as reported in Shiffrin \& 
Atkinson, 1969). The information in STM is processed as WM (Walls, 1999). WM is a workspace that can be divided between storage and controlling processes (Baddeley \& Hitch, 1974, as reported in Galotti, 2004). WM is a manager of temporary information on a limited capacity between new information coming into the subject through the SR and old information residing in the LTS of the subject (Baddeley \& Hitch, 1974, as reported in Galotti, 2004; Shiffrin \& Atkinson, 1969; Walls, 1999). Through these processes new information enters LTS where it resides permanently as attained knowledge that the subject should be able to demonstrate through some behavior after the fact of learning (Shiffrin \& Atkinson, 1969).

Based on the limitations of STM and WM capacity discovered by researchers such as Miller (1956) and Peterson and Peterson (1959) scientists began considering guidelines for instructional materials that best accommodated these findings (Morrison, Ross \& Kemp, 2004). ID began to focus on minimizing cognitive load on WM and capacity in STM to accommodate learning efficiency. An example is a heuristic that suggests when giving a long list of items to memorize, only present 5 to 9 items at a time rather than a list of two or three hundred (Morrison, Ross \& Kemp, 2004).

CLT gained attention when John Sweller proposed reducing cognitive load through ID strategies that aid students with problem solving skills (Sweller, 1988). Sweller (1988) informed ID of his findings, suggesting cognitive load could be minimized through developing more efficient instructional materials and information delivery techniques. Since that time many implications for ID derived of CLT have been identified (Sweller, 1994). Through the 1990’s researchers focused on CLT and on informing ID of better practices and guidelines for materials development (Chandler \& Sweller, 1992; Moreno \& Mayer, 1999; Mousavi, Low \& Sweller, 1995; Paas, 1992; Paas, Renkl, \& Sweller, 2003). 
Morrison, Ross and Kemp (2004) describe two types of cognitive load and their implications. The first type of cognitive load is intrinsic cognitive load (Morrison, Ross \& Kemp, 2004; Sweller, 1999). The gravity of intrinsic cognitive load is determined by the amount of complexity in the interactivity of the elements of instruction (Morrison, Ross \& Kemp, 2004). Chandler and Sweller (1991) described intrinsic cognitive load as the cognitive processing differences between working a simple calculation (e.g., $2+2$ ) and working a complex equation such as the equation for acceleration (e.g., acceleration $=[$ Final rate - Initial rate]/time) (Morrison, Ross \& Kemp, 2004). Sweller (2006) describes simple calculations as holding low level intrinsic cognitive load and complex equations as holding high level intrinsic cognitive load. The interactivity of the elements of instruction is immutable and cannot be changed by the ID (Chandler \& Sweller, 1991; Morrison, Ross \& Kemp, 2004). However, while intrinsic load is inherent in the interactivity of the instructional elements, ID can effectively reduce the complexity of the interaction of the instructional elements (Morrison, Ross \& Kemp, 2004). Reduction of the complexity of the interaction of instructional elements is accomplished through information delivery strategies and instructional materials that break down the complexity of instruction into low-level intrinsic cognitive load schemata. The schemata are presented as isolated instruction, then reassembled by the learner later as a complex model, reducing overall cognitive load (Chandler \& Sweller, 1991; Sweller, 2006).

The second type of cognitive load Morrison, Ross and Kemp (2004) describe is extraneous cognitive load. Pollock, Chandler and Sweller (2002) describe extraneous cognitive load as the gravity of cognitive processing brought on by the design of instructional materials and the delivery of instruction. This type of cognitive load is not immutable. Morrison, Ross and Kemp (2004) describe reducing extraneous cognitive load for instruction of high-level 
intrinsic cognitive load elements as an ID strategy to reducing overall cognitive load. There are a number of strategies used by instructional designers to accomplish this (Morrison, Ross \& Kemp, 2004; Sweller, 2006). For example, adding concrete visual content to abstract concepts with high levels of intrinsic cognitive load reduces overall cognitive load through providing a concrete visual reference for the terms of the formula, enabling the student to focus on the calculation process (Morrison, Ross \& Kemp, 2004; Sweller, 2006) (Fig. 4).

Lesson materials one: High level of intrinsic and extraneous cognitive load.

Calculate acceleration using the formula.

(acceleration $=[$ Final rate - Initial rate]/time $)$

Lesson materials two: Reduced overall cognitive load through providing complementing visual content. Time from start to finish $=$
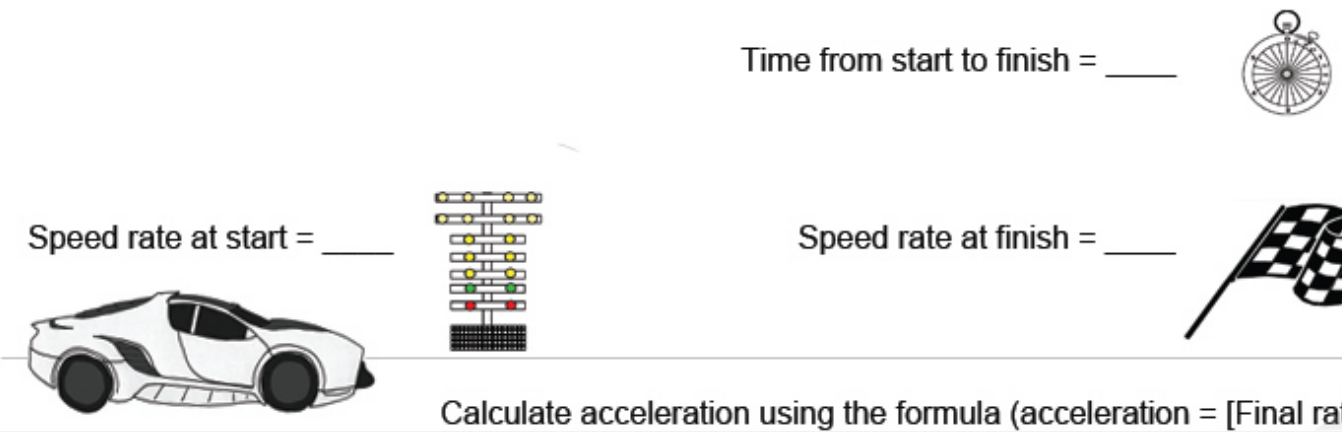

Speed rate at finish $=$

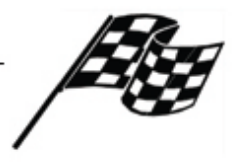

Calculate acceleration using the formula (acceleration $=$ [Final rate - Initial rate]/time)

Fig. 4: Reducing overall cognitive load as explained by Morrison, Ross \& Kemp (2004).

A third type of cognitive described by Sweller, van Merriënboer \& Paas (1998) is germane cognitive load. Germane cognitive load is load focused on productive WM when processing, constructing, and automating schemata. Germane cognitive load is positive cognitive load and desired in the learning processes. Germane cognitive load, such as extraneous cognitive load, is not immutable and can be increased through ID strategies and appropriate content. The goal of ID then is to reduce extraneous cognitive load on complex instruction that has high levels of intrinsic cognitive load, and increase germane cognitive load for efficient 
information processing during learning processes (Sweller, van Merriënboer \& Paas, 1998; Sweller, 2006).

There are numerous learning effects that implicate ID described in the literature that are derived of the study of cognitive load (Chandler \& Sweller, 1992; Moreno \& Mayer, 1999; Mousavi, Low \& Sweller, 1995; Paas, 1992). The learning effect derived of cognitive load that is most important for the present study is called the 'modality effect or modality principle' described by Mayer and Moreno (1998) as part of a theory they developed called multimedia learning theory (MLT). This approach is based on WM and DCT, both of which are also very important to the present research (Baddeley \& Hitch, 1974; Paivio, 1986).

Baddeley and Hitch (1974) proposed a model of STM called the WM model following the Atkinson and Shiffrin (1968) information processing model as an evolution of the information processing model, not as a competing proposal (Baddeley, 1992). WM was described as a more complex model of STM that accounted for manipulating different kinds of information in STM. Whereas Atkinson and Shiffrin (1968) described control processes of general information in STS (Fig. 3), Baddeley and Hitch (1974) described WM as a workspace that can be divided between storage and controlling processes of different kinds of information (Fig. 2) (Baddeley \& Hitch, 1974, as reported in Galotti, 2004). The original simulation model Baddeley and Hitch (1974) proposed as WM consisted of three parts: the central executive, the visuospatial sketch pad, and the phonological loop (Fig. 5) (Galotti, 2004; Walls, 2004). More recently, Baddeley (2000) revised the original simulation model to include the episodic buffer. 


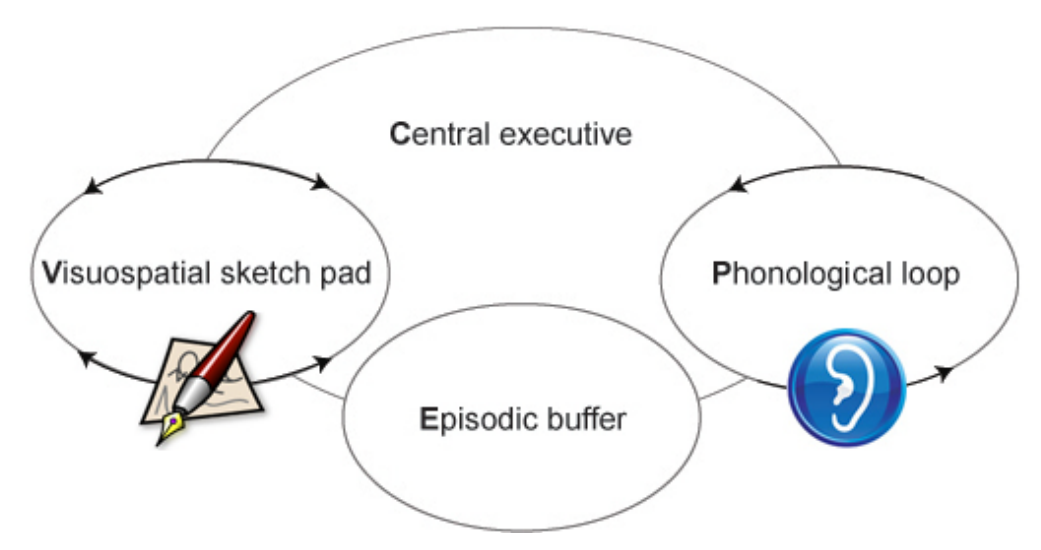

Fig. 5: Working memory as explained by Baddeley (2000), Galotti (2004), and Walls (2004).

Baddeley (1981, 1986, 1990, as reported in Galotti, 2004) described the central executive as the component of STM that directs information flow and selects information to execute into STM processing. Baddeley (1990) describes the central executive as an attentional system that directs the way cognitive resources are allocated to processing tasks. Although the central executive does not retrieve information from the LTS, it is thought to coordinate information that is retrieved from the LTS with information entering STM from the subject's natural environment (Galotti, 2004). One might envision a subject listening to a lecturer in a lecture hall and rapidly selecting new information from the lecturer to coordinate with old information learned from past lectures that is simultaneously retrieved from the LTS into the central executive, then making explicit references to old information with new information in written desk notes.

The phonological loop was described by Baddeley as a STM store that is a separate system devoted to auditory information and verbal information capable of sub-vocal rehearsal (e.g., repeating something to yourself with an inner voice, so that you do not forget it).

The visuospatial sketch pad is also a STM store and separate system devoted to maintaining visual information through visualization (Galotti, 2004). Logie (1995) and more 
recently Klauer and Zhao (2004) suggest the visuospatial sketch pad is composed of two additional subsystems. Baddeley and Andrade (2000) support this idea of two subsystems composing the visuospatial sketch pad. Researchers also suggest the visuospatial sketch pad is to visual information what the phonological loop is to auditory information, maintaining and manipulating visual information in STM (Galotti, 2004).

Coding in cognitive psychology refers to the way information is mentally represented and remembered (Galotti, 2004). A previous example was given of a subject verbally repeating a phone number over and over until it is written or dialed after it was read to maintain the phone number in STM. In this example, even though a phone number is visual information when it is read, it is mentally represented and remembered (i.e., coded) through verbal (i.e., phonological) properties (Conrad, 1964, as reported in Galotti, 2004). DCT was developed by Allan Paivio and describes visual and verbal information as independent systems or channels that mentally represent and remember information differently (Paivio, 1986). This approach parallels the phonological loop and visuospatial sketch pad of the WM model of STM proposed by Baddeley and Hitch (1974). Paivio (1986) views the two systems as potentially complementing each other during information processing or conflicting with each other during information processing. This is because Paivio (1971) views visual information as a naturally occurring observation of analogue information derived of our natural environments, and verbal information as symbolic abstract codes that we construct to represent arbitrary ideas.

Anderson and Bower (1973) showed that verbal information during a learning task can be enhanced when paired with an image that accurately represents the verbal information, or when the subject is asked to imagine an image of the verbal information. Conversely, memory of visual information is enhanced during a learning task when paired with relevant verbal 
information, whether real-world or imagined (Anderson \& Bower, 1973). It appears the two systems also have strengths and weaknesses when compared in certain tasks. For example, Paivio (1969) reported the encoding mechanism for verbal information was more reliable than the encoding mechanism for visual information when recalling the order of information in sequence of presentation during experimentation. While we may prefer verbal codes to remember verbal information we don’t always use them as we may expect (Worchel \& Shebilske, 1995).

An example task that illustrates conflicting visual and verbal information mental coding, and the seemingly superior strength of the verbal coding mechanism for this specific task is evidenced in the Stroop (1935) effect. The Stroop effect demonstrates how verbally encoded information automates in visual perception of adults (Galotti, 2004) (Fig. 6).
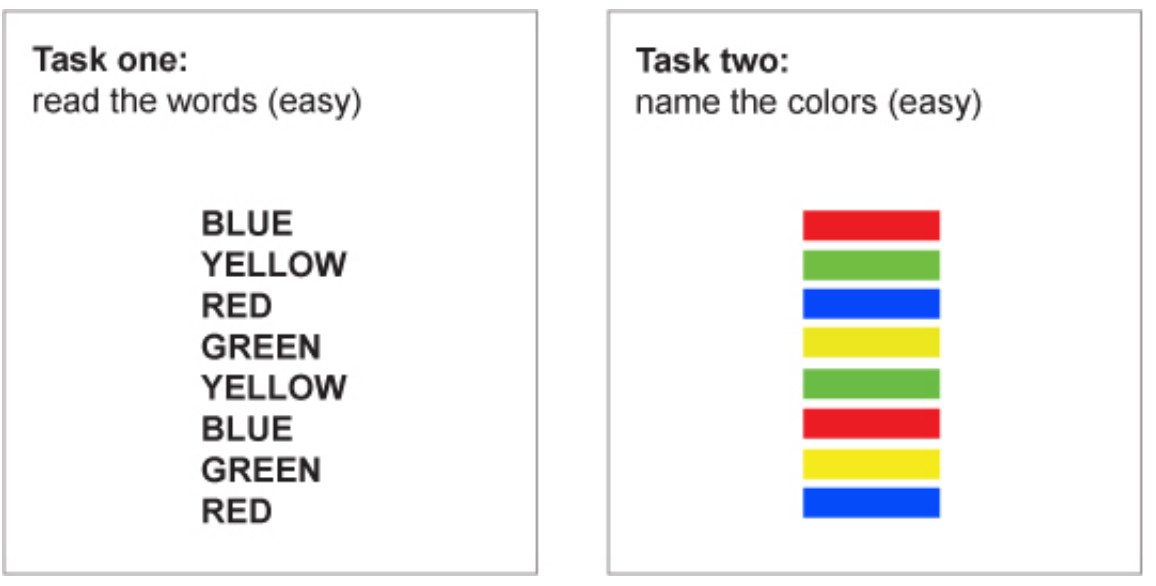

Task three:
try naming the colors of the ink
that the words are printed in
BLUE
YELLOW
RED
GREEN
YELLOW
BLUE
GREEN
RED

Fig. 6: The Stroop (1935) effect, Galotti (2004).

Interestingly, children who have not yet learned to read have little difficulty performing task two and task three. However, adults who have mastered reading find it difficult to rapidly name the colors of the ink that the words are printed in when performing task three. Stroop 
(1935) contends adults read so fluently and quickly that they find it difficult not to read words when they are viewed (Stroop, 1935, as reported in Galotti, 2004).

Posner and Synder (1975, as reported in Galotti, 2004; Worchel \& Shebilske, 1995) call this phenomenon automatic processing. Automatic processing is described as follows:

- It must occur without intention

- It must occur without involving conscious awareness

- It must not interfere with other mental activity

The Mayer and Moreno (1998) MLT model also describes a visual coding mode in conjunction with an auditory coding mode that share information processing capabilities during the human learning process (Cooper, 1998; Mayer, 2003). Considering the multiple sensory processes learners experience in computer-learning environments during information processing and human learning, modern instructional designers seek to understand instructional materials on multiple dynamic levels as either facilitating or impeding effective human learning processes (Mayer \& Moreno, 1998; Moreno, 2006). Modern ID and research development practices include balancing visual and auditory multimedia information to minimize excessive extraneous cognitive load and enhance germane cognitive load during the information processes of human learning (Mayer, 2003; Moreno, 2006; Sweller, 2006).

\section{Study of Visual Memory Systems}

Research into visual systems begins with sensory memory (Galotti, 2004). Walls (2004) reports visual sensory memory was researched as early as 1740 when Swedish scientist Segner discovered iconic memory to last about 100 milliseconds (Mollon, 1970, as reported in Walls 2004). Given crude instruments, Segner was not far off. Today, cognitive psychologists view 
iconic memory as visual mental representations that last from 150 to 200 milliseconds.

Characteristics of iconic memory that can be derived from the research are:

- Glimpsing objects for 50 milliseconds feeds-forward visual information straight to visual memory enabling accurate rapid categorizations (McGovern Institute for Brain Research, 2007). Such as jumping from the forest path at the mere glimpse of a coiled snake

- Viewing a stationary object sends constant analogue visual information of the image directly to visual STM for the duration of viewing. Visual information is more robust, and maintaining it in visual STM following the visual stimulus input is easier

- Viewing an object that moves rapidly leaves traces of the visual information as residue in iconic memory that fades after 200 milliseconds. This is why a torch will create the visual illusion of a complete circle of fire if spun rapidly in the dark

Iconic memory is recoded to a more meaningful code following its 150 to 200 milliseconds life span (Galotti, 2004). The recoded information is placed in visual STM (Walls, 1999). In visual STM we can immediately process new visual information into LTM. Walls (1999) reports visual STM as more durable than iconic visual memory and visual LTM as very durable.

Images we see in our mind's eye, in contrast to viewing with our eyes actively, are called visual imagery (Galotti, 2004). Finke (1989, as reported in Galotti, 2004) describes five principles of visual imagery:

- Implicit encoding: For example, although you probably never sat in a chair and studied the layout and features of your apartment or home, you can close your eyes and vividly walk through it, fixing a picture on the way 
- Perceptual equivalence: visual imagery calls on the same mental processes as visual perception. Therefore when remembering a mental image, the same mental mechanisms are at work, as though you were actually viewing the object

- Spatial equivalence: visual imagery arranges visual elements corresponding to the way objects and features are arranged in real physical space. This is why when you imagined walking through your living space, you probably entered the room through the accurately placed door and walked around the accurately placed coffee table.

- Transformational equivalence: visual images are transformed in the same way as they are perceived in real space (e.g., weight, heights, etc.). For example, rotating a large heavy object takes longer than rotating a small light object in mental visual imagery

- Structural equivalence: visual imagery is derived mentally one object at a time, constructing a complete picture. This is why you can visualize your automobile, and then remove its tire.

One of the most prolific classic researchers contributing to STM and learning studies with visual stimuli is William K. Estes. Estes and Taylor (1964) researched information processing of brief visual displays. Estes and Taylor (1964) targeted information gathered from very brief displays (i.e., fractions of a second) that focused on an upper limit of information retention, or span of apprehension. The experimental visual display was so brief, the participant was unable to move their eyes to visually scan the image from one point to another (e.g., top to bottom, left side to right) before it had disappeared. This typology of research is seen as implicit or recognition research simply because the participant is unable to actively study the stimulus as target learning information (Estes, 1972; Estes, \& Taylor, 1966; Huang \& Pashler, 2005a; Huang 
\& Pashler, 2005b; Maddox \& Estes, 1997; McGovern Institute for Brain Research, 2007;

Pashler, 1984; Pashler, 1988; Shiu \& Pashler, 1995).

The precise processes of learning that occur during visual STM information processing tasks is in debate (Klauer \& Zhao, 2004). O’Shea and Clegg (2006) note the debate between implicit and explicit learning. Klaur and Zhao (2004) also report on a number of threats to previous methods of visual STM research. Controversy concerning visual research does not end there. Galotti (2004) reports on the controversies of LTM visual research also:

- Criticisms of imagery research suggest the experiments enable participants to rely on their personal beliefs and knowledge rather than visual imagery. Intons-Peters (1983, as reported in Galotti, 2004) reported participants in imagery experiments were often cued to response, sensitive to the slightest of unintentional cues given by experimenters, even the intonation and tone of their voice

- Criticisms of the metaphor between images and visual imagery. Nickerson and Adams (1971, as reported in Galotti, 2004) report many people make many mistakes when trying to draw images through visual imagery. Try drawing a penny without looking at one

- Criticisms of visual imagery as a unique independent kind of internal code. This is called propositional theory, which suggests all information is encoded into memory with only one code format (Anderson \& Bower, 1973, as reported in Galotti, 2004).

Despite criticisms of visual research, a vast collection of experiments have been conducted and new areas of research are emerging (Baddeley \& Andrade, 2000; Barker \& Krebs, 1977; Christ, 1975; Galotti, 2004; Horowitz \& Wolfe, 2001; Klauer \& Zhao, 2004; Logie, 1995; 
Smith, 1962; Sperling, Budiansky, Spivak, \& Johnson, 1971). Ideas derived of visual capacity research implicating the utility of colors for searching, identifying, and grouping information have since been applied to the development of computer based environments (Lauer \& Pentak, 2005; Spool, Scanlon, Schroeder, Snyder, \& DeAngelo, 1999).

More recent research has focused on visual attention during STM information processing tasks. One of the most prolific visual attention researchers in the field is Dr Harold Pashler. Pashler has conducted extensive research on divided visual attention. Divided visual attention is described as probing the responses of the STM information processing system, attempting to identify capacity limitations on human ability to perceive multiple visual stimuli simultaneously (Huang \& Pashler, 2005b; Huang, Pashler, \& Junge, 2004; Huang, Treisman, \& Pashler, 2007; Palmer, 1990; Pashler, 1995; Pashler \& Harris, 2001; Põder, 2004). Huang and Pashler (2007) approached the phenomena of visual stimuli STM capacity through a Boolean map theory of visual attention. This research used color as a feature stimulus in conjunction with other multi feature visual stimuli. Participants were reported as capable of attending to one stimulus feature at a glance (i.e., color or shape) while multi feature visual stimuli required more than a glance (i.e., color and shape). Scanning was necessary to interpret the complex information.

Other research has explored color as distracter features in otherwise target visual stimulus environments. Overt visual attention to what we consciously focus on is constantly influenced by the background peripheral environment (Folk, Remington \& Johnston, 1992). In contrast, covert attention is best described at rapid eye movements or saccades that attend to the competing visual stimulus information (Pashler, Carrier \& Hoffman, 1993). Saccades are elicited reactions to extra environmental visual stimuli. The participant engages unwillingly in rapid visual scans of the environment, distracted from attention to target stimuli. Color stimulus 
in digital environments, especially flashing colors such as those described in digital animations may induce saccades and may result in a reduction of learning potential (Becker, Pashler, \& Lubin, 2007; Folk, Remington \& Johnston, 1992; Pashler, 2001; Pashler, Carrier, \& Hoffman, 1993).

In the context of the current research colors and animations are seen as potential distracters, or competing information in the environment. Distracter information in the environment may implicate efficient attention to target stimuli in experimental computerlearning contexts, potentially detracting from maximum information processing during learning tasks.

Research into the advantages and disadvantages of animations as target content in computer-environment learning have also been studied quite extensively, although results are inconclusive (Dwyer \& Dwyer, 2003). Kriz and Hegarty (2007) discovered animations can be used productively for presentations of mechanical models provided students have high prior knowledge of the mechanism. Otherwise, learners gather erroneous information from animations. Lowe (2003) also contends learners must have high prior knowledge and integrate animation into knowledge structures. Lowe (2003) suggests animated visual displays require different information processing demands in contrast to static displays. Meyer, Rasch and Schnotz (2009) contend human visual attention is highly selective, disabling learners from focusing on large animated areas. Learners who do not pay attention to the right place at the right time will not learn from animation (Schnotz \& Lowe, 2008; Weidenmann, 1994, as reported in Meyer, Rasch \& Schnotz (2009). 
The implication for animations and IDT are not well known (Dwyer \& Dwyer, 2003). As with any instructional content, in order to design instructional messages that promote understanding, designing materials based on relevant research-based theory of how people learn is crucial (Bransford, Brown \& Cocking, 1999, as reported in Moreno and Mayer 2002).

The research of Roger Mayer and Roxana Moreno has extensively explored the STM information processes in computer-learning environments through the study of modality. The study of modality within the framework of MLT is an approach to CLT and WM limitations that seeks to identify the right mix (i.e., modes) of multimedia content to provide the most optimal intellectual experiences for learners (Kirschner, 2002; Mayer, 2003; Mayer and Moreno, 1998; Reimann, 2003; Schnotza \& Loweb, 2003). This research includes separating SR information (e.g., visual verse auditory register information) into information processing models (i.e., dual coding models) aimed at understanding the impact of multimedia content through individual and multiple SR during learning tasks (Mayer \& Moreno, 1998; Moreno, 2006). Modern instructional design and research development practices based on these research findings include balancing visual and auditory multimedia information to minimize excessive extraneous cognitive load and enhance germane cognitive load during the information processes of human learning (Mayer, 2003; Moreno, 2006; Sweller, 2006).

While STM research in general has shown strong evidence for a dual coding system in the STM information processes consisting of an auditory system and a visual system (Baddeley \& Hitch, 1974; Mayer \& Moreno, 1998; Moreno, 2006; Paivio, 1969, 1971, 1986), recent visual STM research has provided a simulation model and support of a visual STM system also described as composed of two subsystems (Fig. 7) (Baddeley \& Andrade, 2000; Klauer \& Zhao, 2004; Logie, 1995). The subsystems of visual STM are described by Logie (1995) as: 
- The visual STM store: stores visual information including information about color and shapes

- The inner scribe: rehearses visual information to maintain it in the visual STM store. The visual scribe also transfers information to the central executive for processing, while maintaining STM visual information about movements of objects and perceptual space

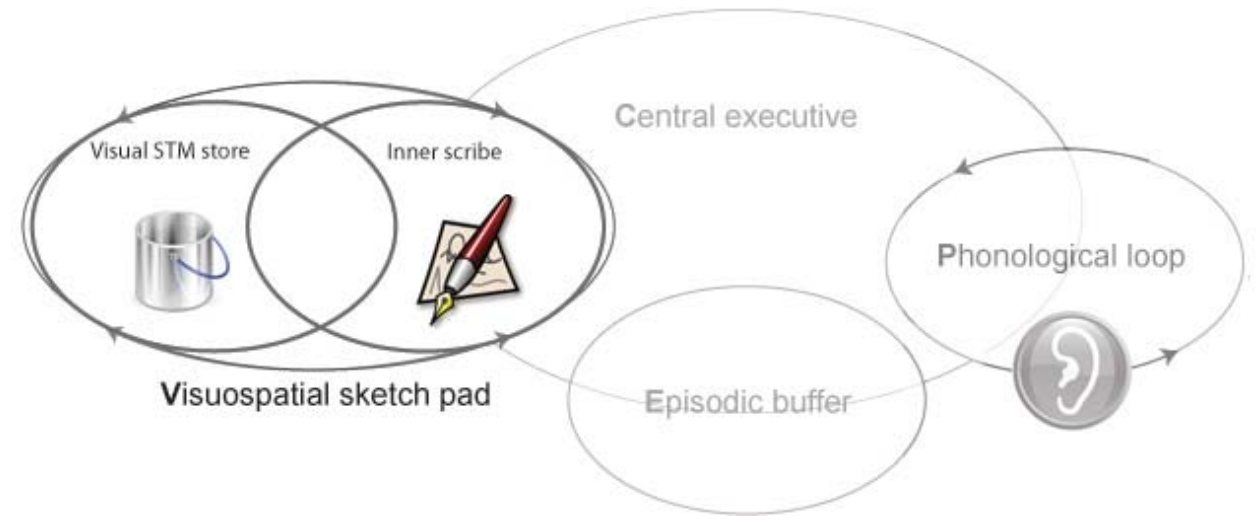

Fig. 7: Visual STM subsystems as explained by Logie (1995).

As research is beginning to explore the new simulation model of visual STM, little is known, much debate is present, and a clear description of the efficiency of the two visual STM subsystems is lacking (Klauer \& Zhao, 2004). Amidst this debate, Klauer and Zhao (2004) reported findings supporting a fractionation of the visual STM system into a visual and a spatial component. Other research supporting a fractionation of visual STM includes Neuroimaging studies that have shown regional variation in the human prefrontal cortex when performing visual verse spatial mental tasks (Baker, Frith, Frackowiak \& Dolan, 1996; Courtney, Ungerleider, Keil \& Haxby, 1996; McCarthy et al., 1996; Nystrom et al., 2000; Owen et al., 1998; Smith et al., 1995, as reported in Klauer \& Zhao, 2004). Mecklinger and Meinshausen (1998, as reported in Klauer \& Zhao, 2004) and Ruchkin, Grafman, Cameron and Berndt (2003) have also produced findings suggesting encoding and retrieval processes for visual and spatial 
information in STM differ. And, Logie and Pearson (1997) demonstrated visual memory and spatial memory tasks differed in their rate of development as a function of participants' age (Baddeley, 2003; Pickering, Gathercole, Hall \& Lloyd, 2001, as reported in Klauer \& Zhao, 2004). Lorsbach and Reimer (2005) also made the same distinction of visual memory and spatial memory tasks differing in their rate of development as a function of participants’ age.

A very important aspect of the Lorsbach and Reimer (2005) research for the present study is the research design methodology. Much previous research exploring a fractionated visual STM system is described by Klauer and Zhao (2004) as dual-task/double dissociations paradigms (Fig. 8).

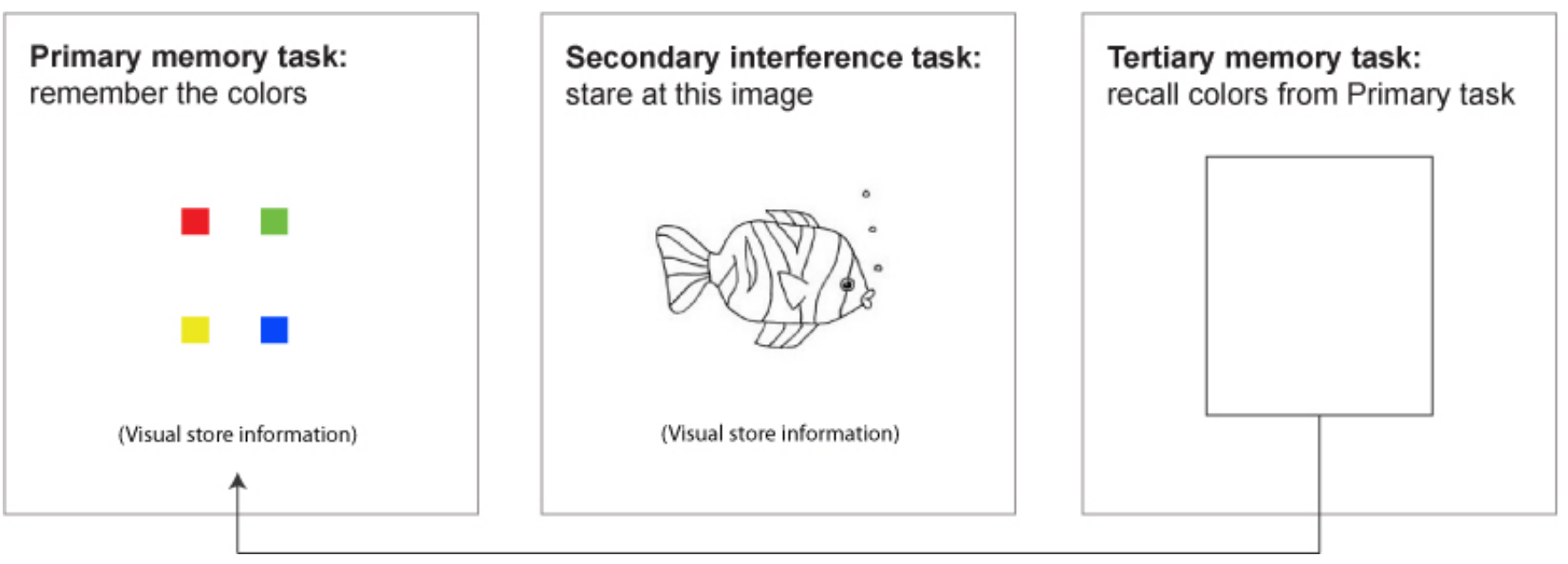

Fig. 8: Dual-task/double dissociations research paradigm as explained by Klauer and Zhao (2004).

The dual-task paradigm is a research design described as involving a primary task (i.e., target stimulus presentation) followed by a secondary task (i.e., interference task) performed during a retention interval (Klauer \& Zhao, 2004). Following the retention interval and interference task, research participants are quizzed on information learned in the primary task. For example, Logie and Marchetti (1991) performed a visual STM memory research study that directed research participants to first quickly remember a sequence of colors (i.e., primary task, 
visual information). Following the primary task, a secondary task of viewing irrelevant black and white drawings on a screen was performed for 10 seconds (i.e., also visual information). Next, following the secondary interference task, research participants were quizzed on their memory of the primary task information (Logie \& Marchetti, as reported in Klauer \& Zhao, 2004). The double dissociations paradigm of the model description is in how primary and secondary tasks are assembled in the dual-task research design. In the example, Logie and Marchetti (1991) discovered participants did not perform well on quizzes of primary task information if both the primary task and the secondary task involved visual information. Logie and Marchetti (1991) report the same negative performances on primary task information quizzes when both primary task and secondary task involved spatial/movement information. Participants performed well on quizzes though when primary task information and secondary task information involved different kinds of information. For example, if the primary task was visual information and the secondary task was spatial/movement information, the participants performed well on primary information quizzes - and vice versa (Logie \& Marchetti, 1991, as reported in Klauer \& Zhao, 2004).

Klauer and Zhao (2004) also report that the Logie and Marchetti (1991) research study was flawed in it did not report individual statistics for each of the experiments. Therefore the result effects were not known. Problems with the double dissociation exist even if the research design is well executed and all findings are reported (Klauer \& Zhao, 2004). Some of the major problems with this research model are described by Klauer and Zhao (2004) as:

- Differential processing: If visual and spatial/movement tasks are not designed analogously they may rely on cognitive resources beyond the scope of visual STM 
- Locus of dissociation: Research designs may not account for whether dissociation (i.e., interference) occurs in the primary task, secondary task, or quiz task

- Similarity based interference: Refers to the extent to which primary and secondary stimuli share many features; strong interference is expected to occur. For example, a red ball and a yellow box have very different features in contrast to a yellow ball and a light orange ball; or a red box and a dark orange box

The problems with the dual-task/double dissociation research designs Klauer and Zhao (2004) describe also have implications for the present research. Because the present research is not as interested in critically defining the visual STM store subsystem or the spatial/movement subsystem of visual STM as much as identifying visual STM memory conflicts as applicable to learning and IDT, the first problem of the dual-task/double dissociation research design is not pressing. Nonetheless, the present experimental design presented visual stimulus separately that have been defined in other research studies as visual STM store information (i.e., hand drawn images) and spatial/movement information (i.e., images placed in different spatial areas, moving from one space to another; and, additional environmental visual movement information in the form of animations) (Klauer \& Zhao, 2004; Logie, 1995). The visual STM store information and spatial/movement information were presented separately in some control environments and simultaneously in others.

The second problem of the dual-task/double dissociation research design Klauer and Zhao (2004) describe is more of a concern for the present study. Real-world learning in computer based environments is fundamentally different from a primary task (i.e., target study information presentation)/ secondary task (i.e., interference information presentation)/ quiz task design. Developing a research design that: 1) presents visual STM target-learning information in 
a real-world order; and 2), fundamentally controls for identifying dissociations (i.e., interference) is critical. Therefore, the present research design is fundamentally different from the dualtask/double dissociation design in a number of ways. The present research design model is very similar to the Lorsbach \& Reimer (2005) research design in that the model utilizes a 'black question mark' (i.e., '?’) during the memory retention interval in contrast to a demanding interference task. The 'black question mark' is not animated and is viewed as minimal ‘verbal information.'

There are several points to make regarding the use of minimal verbal information in the retention interval task phase of the present design. First, the target primary stimulus is visual STM information (i.e., visual STM store information and spatial/movement information). The introduction of minimal verbal information into the memory retention interval task in the present design contrasts dual-task/double dissociation research that has either paired or varied the kinds of visual STM information specifically as interval task information. In this regard, the current research design model is not a classic dual-task/double dissociations design. Secondly, the introduction of minimal verbal tasks in a visual STM research design provides an alternative model to visual STM research designs this study finds valuable.

Although visual STM has been recently described as being composed of two subsystems (i.e., visual STM store and spatial/movement components) the present research design also retains a view of the components of visual STM as an aspect of the general WM model that includes the phonological loop. Much research has ignored the information processes of the phonological loop during visual STM investigations, perhaps assuming they are idle or shut down when visual attention is focused on visual information tasks. The present research design does not make that assumption. Providing the phonological loop a controlled minimal verbal 
task during the visual STM investigations is viewed as a control task that acts to pacify and engage the phonological loop in a consistent WM activity. The verbal control task is equivalent to holding a minimal verbal value in the phonological loop that will likely rapidly transfer to a chunk of consistent verbal information over the first few test trials of a study. The integration of a consistent minimal verbal task in general WM ensures each participant is provided a balanced minimal verbal activity to perform while engaging the visual STM tasks. Without a balanced minimal verbal task during visual STM investigations, it is thought the uncontrolled activity of the phonological loop may engage information beyond the scope of general WM thus impacting the processing of information in STM in general. Ensuring a consistent minimal verbal activity during visual STM investigation is seen as preventing uncontrolled phonological loop information processes from wandering the peripheral environments and potentially engaging unaccountable tasks inadvertently.

In addition to the inclusion of verbal STM tasks in the experimental design, the present research design also considers controlling the presentation sequences of 'interference information.’ Non-target visual information (i.e., interference information) is viewed as appropriately occurring only during the presentation of target visual information in the Primary learning tasks. This model design resembles computer-learning environments more closely that may integrate laden digital information (i.e., non-learning-target content) into the computerlearning environment during learning tasks. Laden digital information in computer-learning environments is characterized by any visual information such as colors or graphics, environmental aesthetics, animations used for advertisements, or any other non-target-learning visual content. The present research design does not integrate a demanding interference task 
during the retention interval, nor does the present research design integrate a demanding interference task during the quiz task (Fig. 9).

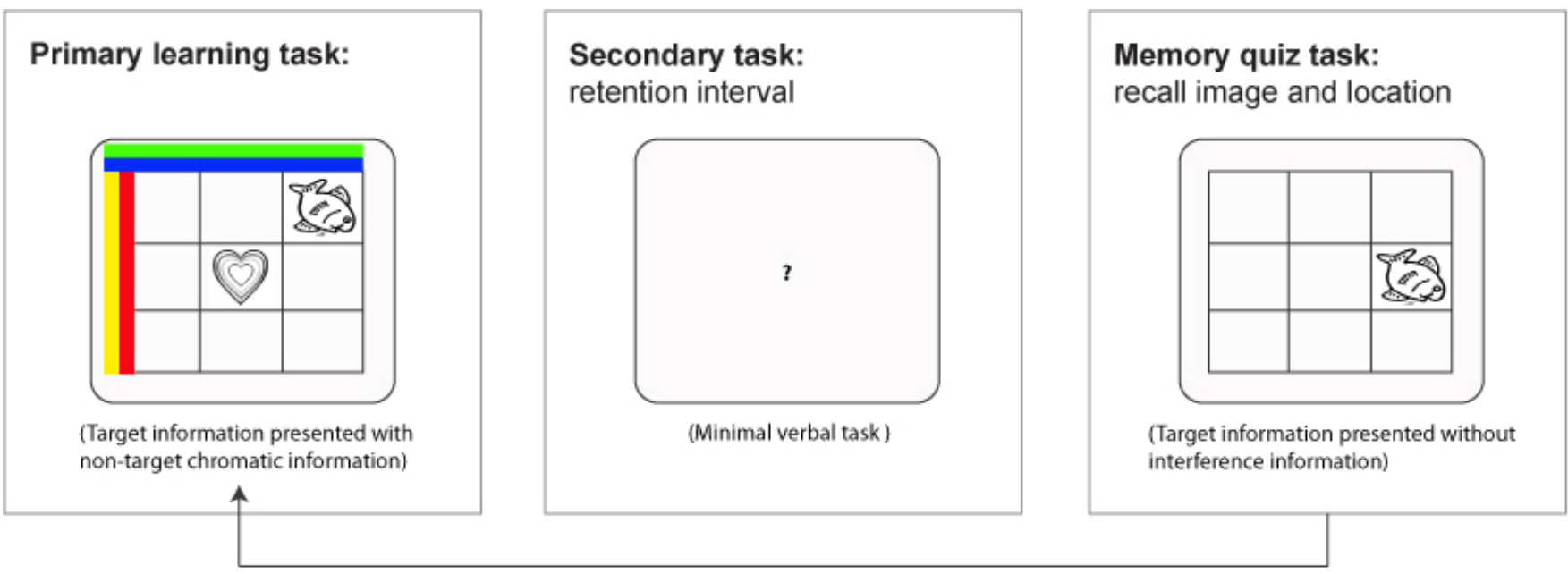

Fig. 9: Interference information during learning tasks only as explained by present research design.

Lastly, the third problem of the dual-task/double dissociation research design Klauer and Zhao (2004) describe is also of concern. Learning more about the characteristics of visual information and the degrees of similarity that impact visual STM negatively is of interest. Better defining specific visual interference information is an important aspect of this research. For example, Hecker and Mapperson (1997) presented achromatic and chromatic information in visual STM computer experiments. The target stimulus presentation was 5 non-repeating color blocks (i.e., approximately $1 \mathrm{~cm} \mathrm{x} 1 \mathrm{~cm}$ ) presented in a random sequence, and placed into random non-repeating positions within a 3 x 3 grid. During the primary target-information presentation distracter-interference-information was also presented in the visual environment. Following the primary presentation, research participants were quizzed for STM of color location and color identity. Distracter-interference-information was also presented in the visual environment during quizzing. The researchers discovered non-target achromatic information (i.e., black and white flickering in the visual environment presented as interference information) interfered with visual 
STM of color location. Conversely, in another trial design, the researchers also discovered nontarget chromatic information (i.e., random colors flickering in the visual environment presented as interference information) interfered with visual STM color identity. However, because the interference information in both conditions was presented to the participants during the initial presentations of target visual stimuli (i.e., learning tasks) and also during the quiz tasks, researchers cannot interpret whether the effects were caused by interference information during the presentation, during the quiz, or a combination of the two. While this research is valuable to the cognitive psychology domain, the findings of this type of research do not necessarily aid in defining explicit parameters of visual STM that readily enable better development of instructional materials through IDT methodology (Fig. 10).
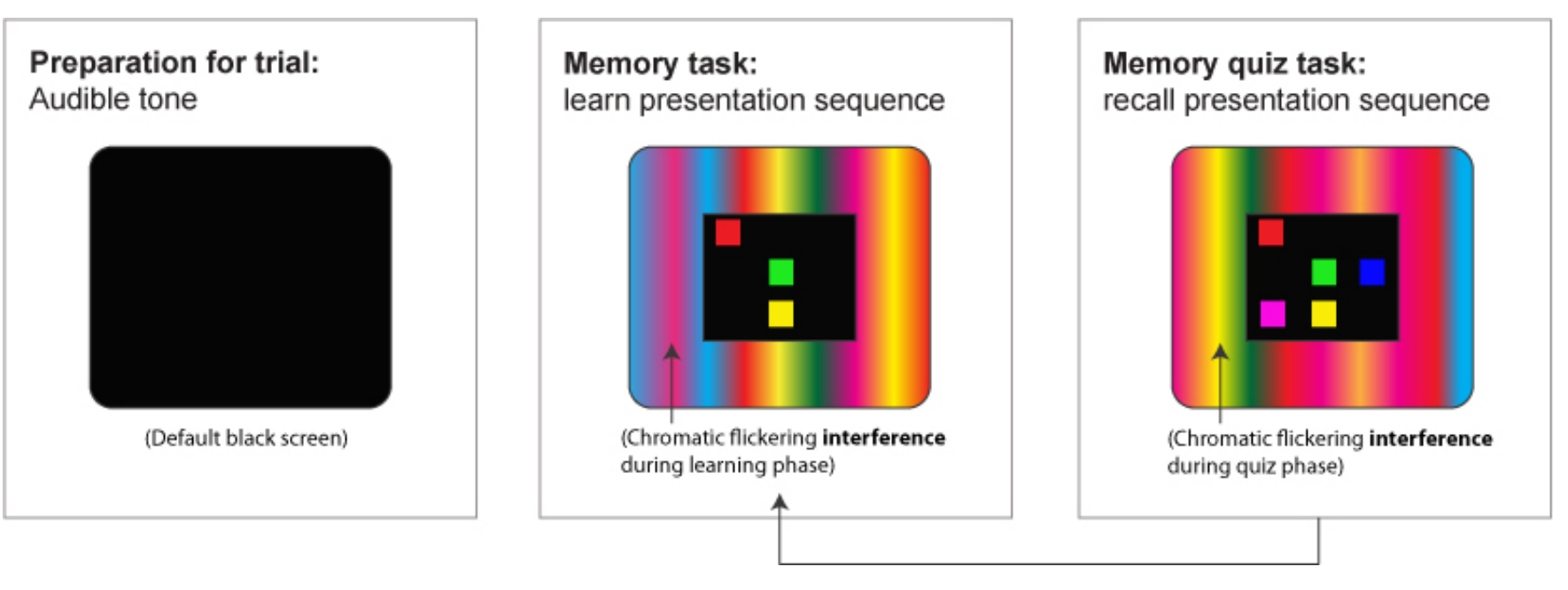

Fig. 10: Interference information during learning tasks and quiz tasks as explained by Hecker and Mapperson (1997). Note: non-target chromatic information (i.e., random colors flickering in the visual environment) interfered with visual STM color identity.

The characteristic distinctions between visual and spatial/movement components of the visual STM system that can be derived of the literature include:

- There is less interference caused between a visual and spatial task in contrast to two visual tasks or two spatial tasks (Klauer \& Zhao, 2004) 
- Results from brain-imaging show that WM tasks with visual objects activate mostly areas in the left hemisphere, whereas tasks with spatial information activate more areas in the right hemisphere (Baker, Frith, Frackowiak \& Dolan, 1996; Courtney, Ungerleider, Keil \& Haxby, 1996; McCarthy et al., 1996; Nystrom et al., 2000; Owen et al., 1998; Smith et al., 1995, as reported in Klauer \& Zhao, 2004)

While research into visual STM such as Klauer \& Zhao (2004) has proven informative to the growing perspectives of cognitive psychology, neuropsychology, and developmental psychology in terms of defining new simulation models that describe how theoretical visual STM components interact in certain conditions, little of this research is applicable to bettering the educational perspectives of content development and IDT. Weaknesses reside especially in research designs and explicit distinctions between visual STM imagery and visual STM spatial/movement components in terms of informing IDT.

Contemporary research has indicated visual STM is negatively influenced by conditions described as conflicts with the visual STM store (i.e., imagery information) and the visuospatial sketch pad (i.e., spatial/movement information) in certain information presentation combinations. Furthering research may better understand visual STM and implications for appropriate IDT applications to developing visual learning environments. Further research may also better understand visual STM properties for the development of computer-learning environment instructional materials from a learning theory perspective.

The nature of visual information in computer-learning environments as developed within the contexts of LMS/LCMS share many of the visual image, visual spatial, and visual animation qualities described as in conflict and interfering with visual STM memory tasks in contemporary 
visual STM research. However, these conflicts are not understood well in terms of applications to IDT. 


\section{CHAPTER III:}

\section{RESEARCH METHOD}

\section{Research Design Overview}

The present research methodology was based on an investigative design that attempts to account for weaknesses of previous visual STM research (Klauer \& Zhao, 2004) to provide information readily applicable to IDT. Additionally, control conditions provided a broad assessment of visual information in STM presentation formats that are more analogous to realworld computer-learning environments.

Hypotheses

This research study explored the effects of color and animation on visual STM in computer-environment learning tasks. Exploring visual STM in experimental environments is thought to provide insight into how a variety of digital visual information environments have an effect on human learning processes.

This research addresses color and animated objects as non-target-learning visual information that may potentially impact the visual STM learning processes of target visual information during learning tasks in computer environments. Learning tasks in black and white environments (i.e., achromatic) in contrast to learning tasks in digital-color-laden environments (i.e., chromatic) with and without animations are of interest. It is thought that the addition of chromatic non-target visual information and non-target animations will cause learning interference and delayed responses. Gaining an understanding of how achromatic interference, chromatic interference, and animation interference impact visual STM in terms of image 
recognition (i.e., visual image STM) and image location recognition (i.e., visual

spatial/movement STM) are also of interest. The research findings inform multiple parameters of visual perception of digital information in computer-learning environments in terms of optimization of visual STM learning.

The research hypotheses under investigation are as follows:

$\mathrm{H}$ 1: When utilizing a repeated measures design are there statistically significant differences in accuracy when comparing levels of STM, color, and animation conditions?

To test this hypothesis the study analyzed the following main effects and interactions: STM conditions, Color conditions, Animation conditions, STM conditions*Animation conditions, Color conditions*Animations conditions and STM conditions*Color conditions*Animation conditions.

H2: When utilizing a repeated measures design are there statistically significant differences in participant response latency when comparing levels of STM, color, and animation conditions?

To test this hypothesis the study also analyzed the following main effects and interactions: STM conditions, Color conditions, Animation conditions, STM conditions*Animation conditions, Color conditions*Animations conditions and STM conditions*Color conditions*Animation conditions.

Independent Variables

There are three main independent variables in the research design: One is the visual stimulus condition, two is the animation condition, and three is the color environment condition (Table 2). The visual stimulus condition has three levels. The three levels are visual STM 
information for: image only (1), location only (2), and combination image + location (3). The animation condition has two levels. The two levels of animation are: no animation (1), and animation (2). Lastly, the color environment condition has three levels also. The three levels of the color environment condition are: black and white, no bars (1), color bars (2), and black and white bars (3).

\section{Dependent Variables}

There are two dependent variables in the research design: One is visual STM accuracy in each condition and the second dependent variable is participant response latency in each condition.

\section{Participants}

Participants were selected non-randomly through a campus newspaper advertisement. Participants were made up of 14 West Virginia University undergraduate and graduate student subjects ranging in age from 19 to 25. Each subject reported having normal to corrected-tonormal visual acuity and no knowledge of color-blindness. Females and males were approximately evenly distributed. Undergraduate and graduate student statuses were also approximately evenly distributed. United States resident students made up approximately half of the participant sample, while two females were from Spain, one male was from China, one male was from Kenya, and two males were from India (Table 1). All participants reported and demonstrated high proficiency with using computers for computer-learning tasks. 
Table 1: Table explanation of participant demographics.

\begin{tabular}{|l|l|l|l|}
\hline Participant number & Gender & Class rank & Nationality \\
\hline 1 & F & Graduate & United States \\
\hline 2 & F & Graduate & United States \\
\hline 3 & F & Graduate & Spain \\
\hline 4 & F & Graduate & Spain \\
\hline 5 & F & Undergraduate & United States \\
\hline 6 & F & Undergraduate & United States \\
\hline 7 & F & Undergraduate & United States \\
\hline 8 & M & Graduate & United States \\
\hline 9 & M & Graduate & Kenya \\
\hline 10 & M & Graduate & India \\
\hline 11 & M & Graduate & India \\
\hline 12 & M & Graduate & China \\
\hline 13 & M & Undergraduate & United States \\
\hline 14 & M & Undergraduate & United States \\
\hline
\end{tabular}

\section{Setting}

The research took place at a major eastern university computer laboratory reserved for research. The computer laboratory is equipped with DELL desk-top computers with Intel Pentium III 2.96 GHz processors, and 4096 Megabytes of Random Access Memory. The computers have DELL 20in flat panel color monitors. An overhead viewer and smart board are provided to present training materials such as power point presentations and dynamic content in 
the laboratory. Chairs in the laboratory are ergonomically adjustable and comfortable. There are four computers at each station and eight stations. The computer laboratory setting is a well lit, quite, roomy, and climate controlled area. Generally, the setting is comfortable and appropriate for focused personal self study activities using computer equipment, as well as for cohort training classes.

\section{Instrument}

Stimuli

Stimuli in this section will be described in terms of physical-visual characteristics and behaviors. Specific stimuli combinations within the context of designed research conditions will be described in the Stimulus Conditions section to follow.

Partial stimuli in the current research study were derived from the Lorsbach and Reimer (2005) study. Target stimuli consisted of a set of common black \& white drawings of a pumpkin, fish, balloons, kite, snowman, lion, frog, and heart (i.e., target visual STM store information). Lorsbach and Reimer (2005) reported the common black and white drawings did not possess any obvious categorical relationships. Additionally, ratings of the objects in terms of their familiarity, visual complexity, and name agreement were very similar among pervious research participant groups (Cycowicz, Friedman \& Rothstein, 1997; Snodgrass \& Vanderwart, 1980, as reported in Lorsbach \& Reimer, 2005). Although the images used in the present study were not the exact images used in the Lorsbach and Reimer (2005) study, they were very similar (Fig. 11). 


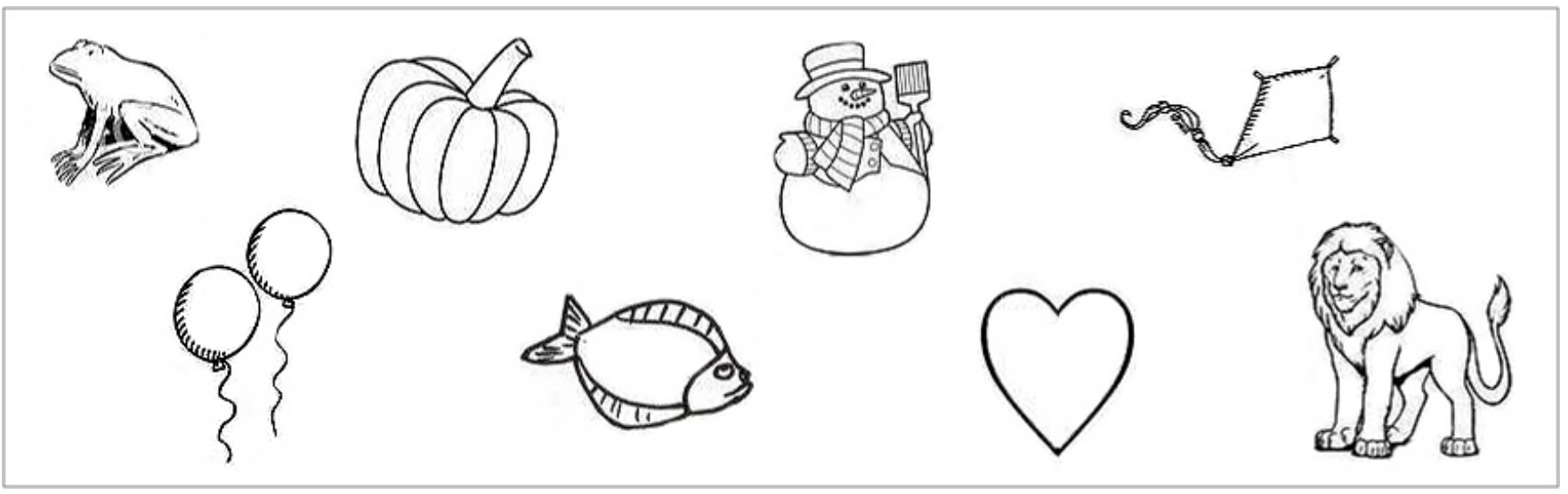

Fig. 11: Target visual information objects used in present study. Note: Objects appear as they did in the present research study presentations.

Additional target stimuli derived of the Lorsbach and Reimer (2005) study included a 3 x 3 black \& white grid 17cm x 17cm (Fig. 12). Unlike the Lorsbach and Reimer (2005) study which did not utilize the center block of the black and white 3 x 3 grid, the present research design utilized the center block for non-target visual information only. The remaining eight locations on the $3 \times 3$ grid equate to the eight line drawings described above. The remaining eight locations of the $3 \times 3$ grid were target visual STM stimuli (i.e., spatial/movement visual STM information). These remaining eight target locations were used specifically for random placement of target visual STM store information during the study (Figs. 12, 16). Therefore a combination of visual STM store information (e.g., balloons) and visual STM spatial/movement information (e.g., top right corner) could be presented at the same time as target stimulus (Fig. 12). 


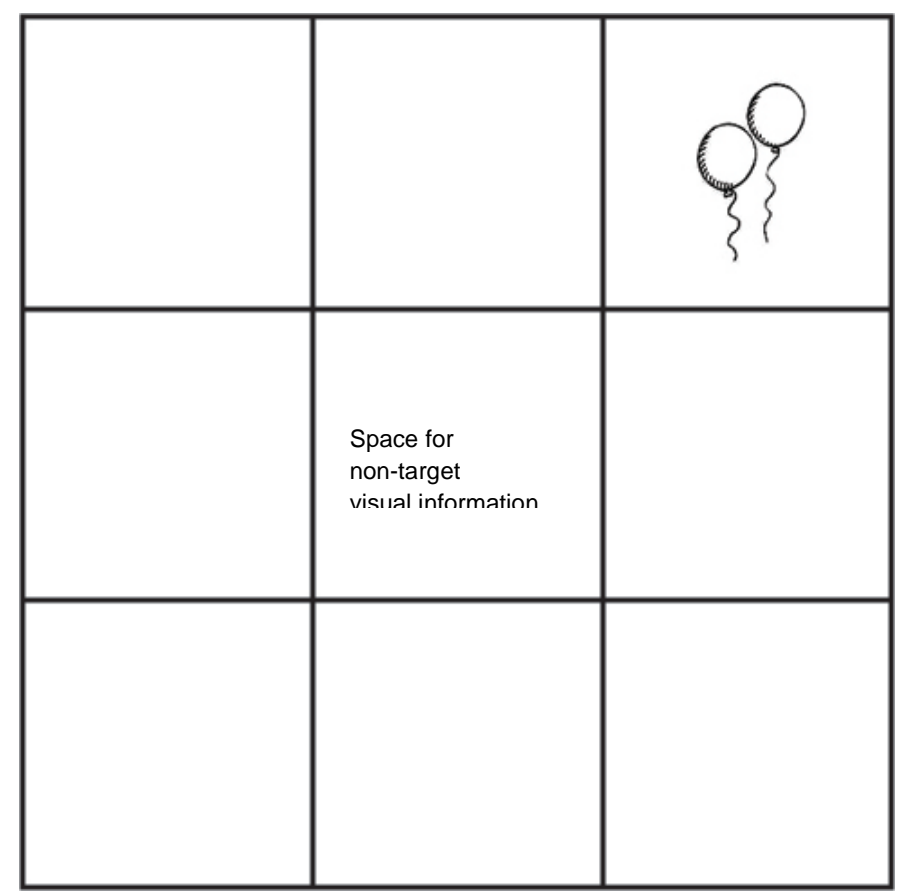

Fig. 12: 3 X 3 grid used in present study. Note: Actual size of grid was $17 \mathrm{~cm} \mathrm{X} 17 \mathrm{~cm}$.

The last visual stimulus derived from the Lorsbach and Reimer (2005) study was a black box. The black box was only used during the quizzing phase of a spatial/movement visual STM (e.g., top right corner) research trial. The box provided the participant a reference to the location without the use of a target information image (Fig. 13). 


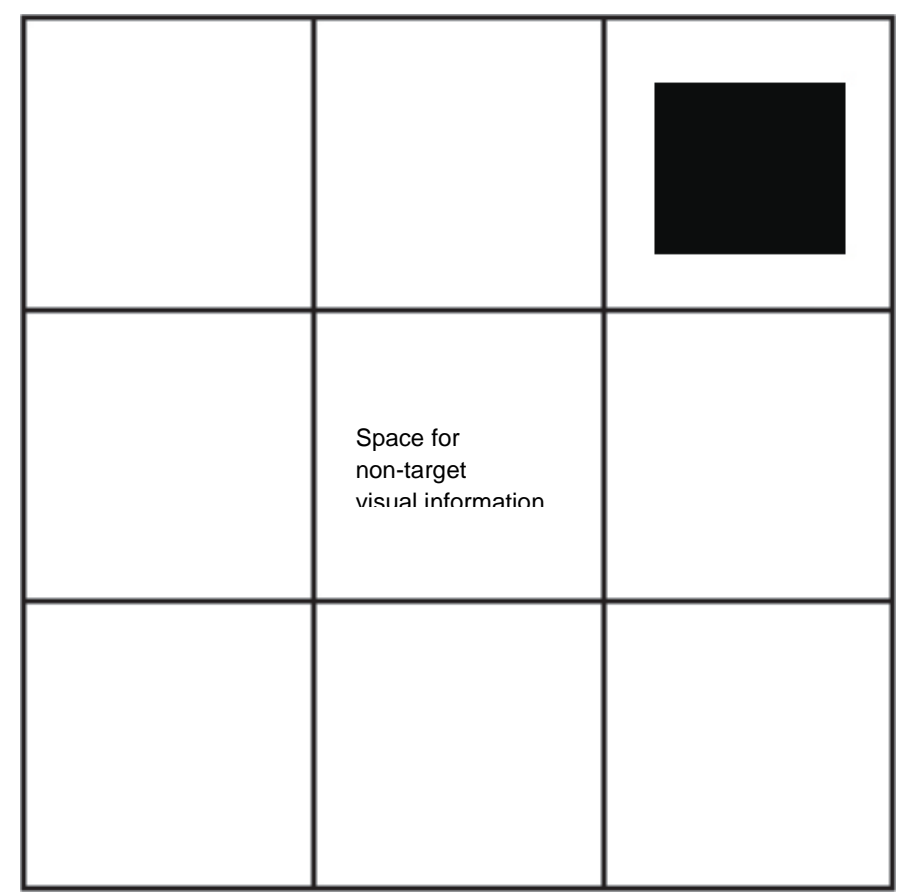

Fig. 13: 3 X 3 grid and spatial/movement visual STM black box used in present study. Note: Actual size of grid was $17 \mathrm{~cm} \mathrm{X} 17 \mathrm{~cm}$.

Non-target chromatic stimuli included 16 color bars derived of the eight rainbow colors (i.e., red, orange, yellow, green, blue, indigo, violet, and pink) (i.e., non-target chromatic visual information). Their color mode was Red-Green-Blue, and the hexadecimal codes of the colors were in the ranges of 'FF0000’ (red), 'FF6600' (orange), 'FFFF00' (yellow), '339900’ (green), '0000FF' (blue), ‘3333FF' (indigo), ‘6600FF' (violet), and ‘FF00CC’ (pink). Dependent upon research condition, color bars were randomly placed into positions on the left margin and top header areas of the 3 x 3 grid. Eight bars were designed for vertical positioning (i.e., left margin), and eight bar were designed for horizontal positioning (i.e., top header). Four of eight bars were randomly placed into each of four positions on the 3 x 3 grid, two side-by-side positions on the left margin area, and two stacked positions on the top header area (Fig. 14). Color bars placed randomly on the left margin area of the $3 \times 3$ grid had a width of $.5 \mathrm{~cm}$ and a height of $17 \mathrm{~cm}$. Color bars placed randomly on the top header area of the $3 \mathrm{x} 3$ grid had a width of $18 \mathrm{~cm}$ and a height of $.5 \mathrm{~cm}$. Colors were not duplicated in any instance of presentation. 
Therefore, each of the four color bar instances during any presentation was randomly placed and each was a different color from the others presented during the same instance of presentation.

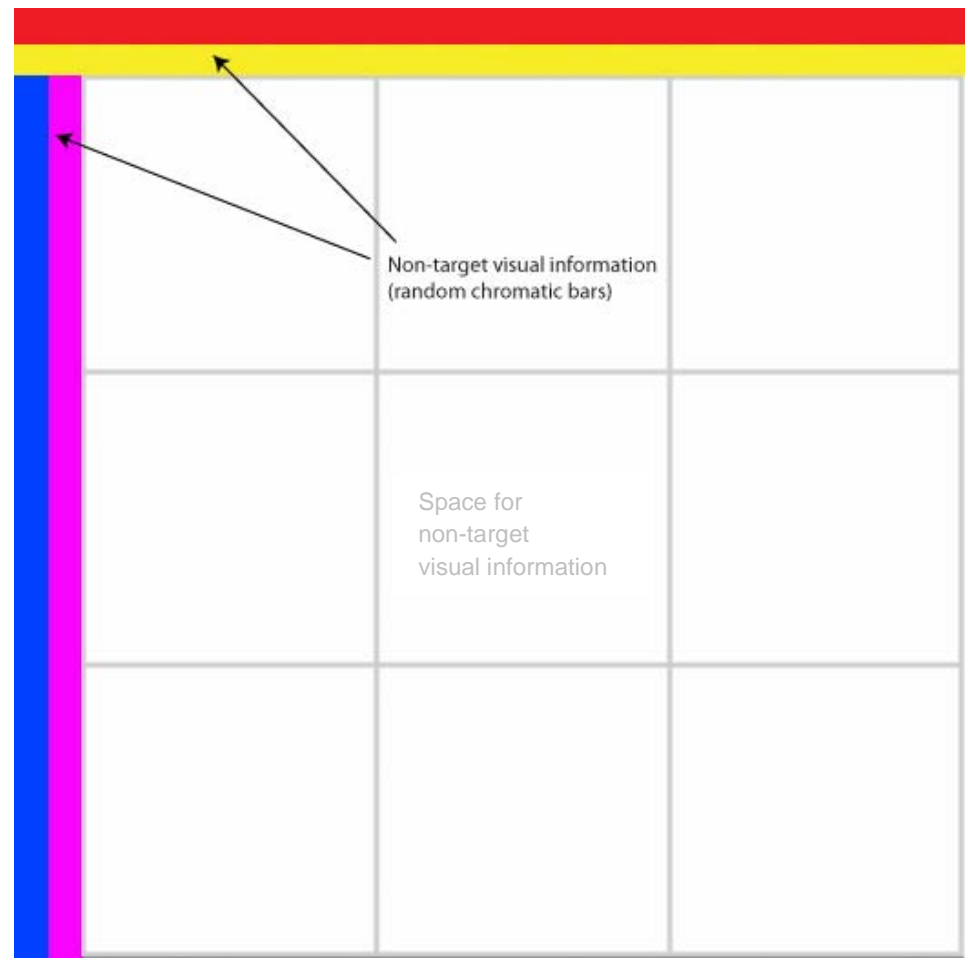

Fig. 14: 3 X 3 grid and non-target information color bar placement areas used in present study. Note: Actual size of grid was $17 \mathrm{~cm}$ X $17 \mathrm{~cm}$.

Non-target achromatic stimuli included 16 black and white bars. Dependent upon research condition, black and white bars were randomly placed into positions on the left margin and top header areas of the 3 x 3 grid. Eight bars were designed for vertical positioning (i.e., left margin), and eight bar were designed for horizontal positioning (i.e., top header). Four of eight bars were randomly placed into each of four positions on the 3 x 3 grid, two side-by-side positions on the left margin area, and two stacked positions on the top header area. Black and white bars placed randomly on the left margin area of the $3 \times 3$ grid had a width of $.5 \mathrm{~cm}$ and a height of $17 \mathrm{~cm}$. Black and white bars placed randomly on the top header area of the $3 \times 3$ grid had a width of $18 \mathrm{~cm}$ and a height of $.5 \mathrm{~cm}$. Black and white bars were randomly selected from a pool. Therefore, in any presentation any combination of black and white bars could potentially 
display during the same instance of presentation, including all black bars or all white bars (Fig. 15).

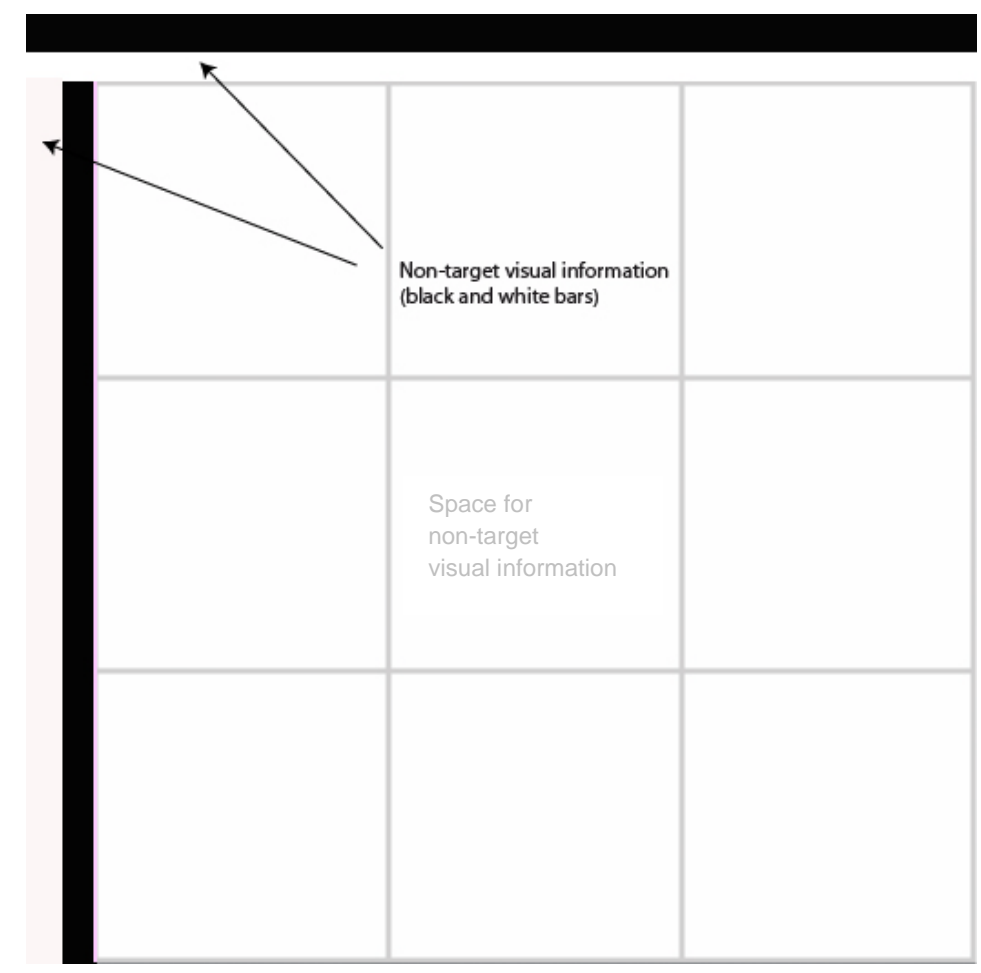

Fig. 15: 3 X 3 grid and non-target information black and white bar placement areas used in present study. Note: Actual size of grid was $17 \mathrm{~cm} \mathrm{X}$ $17 \mathrm{~cm}$.

The remaining non-target achromatic stimuli included both static and animated black \& white drawings of a pumpkin, fish, balloons, kite, snowman, lion, frog, and heart. The static images were duplicates of the target stimuli images described previously. The animated images were also duplicates of the target stimuli images with the exception of their animation. The pumpkin bounced, the fish swam, the balloons lifted and floated, the kite lifted and bounced, the snowman turned a circle, the lion charged and retreated, the frog hopped, and the heart pulsed. Dependent upon the condition, static images or animated images were randomly placed in the center block of the 3 x 3 grid. The center block, as previously described, was utilized for non- 
target visual information only. Therefore, any information placed in that area on the grid, whether static or animated, was non-target visual information (Fig. 16).

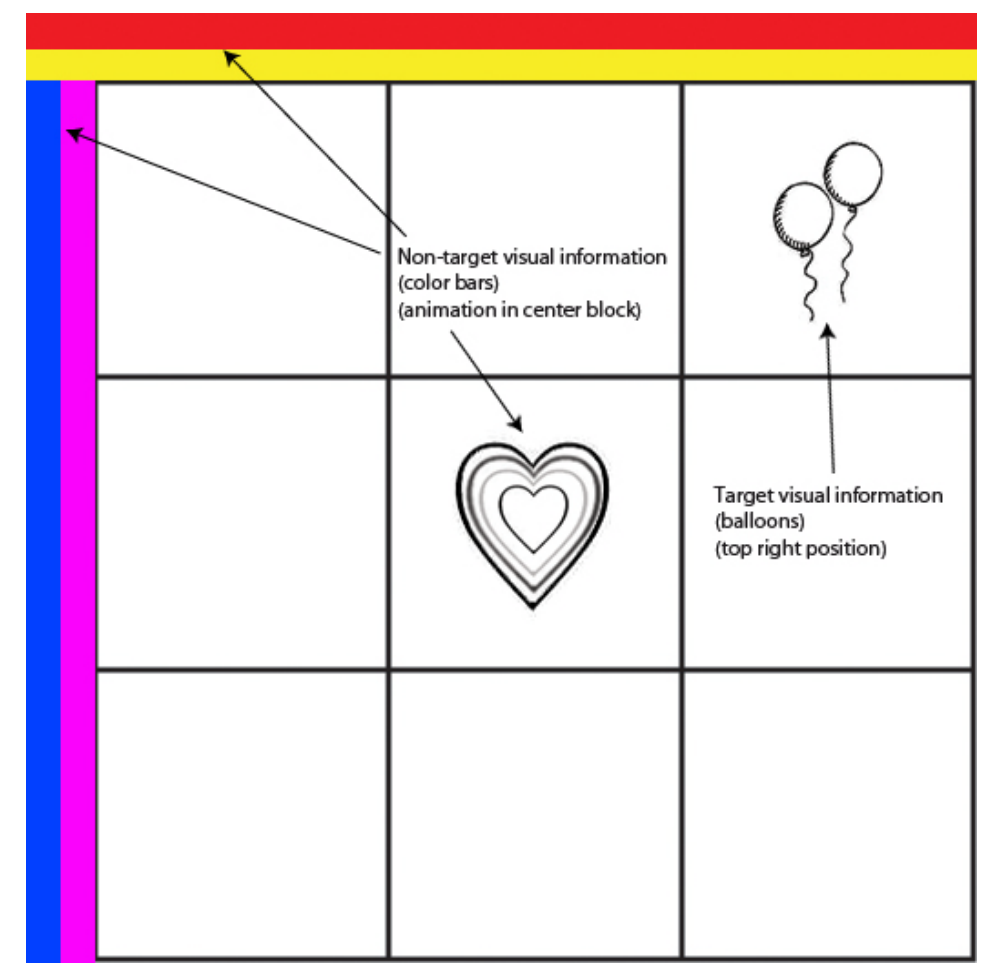

Fig. 16: 3 X 3 grid, non-target information color bar placement, non-target information animation in center block, and target information used in present study. Note: Actual size of grid was $17 \mathrm{~cm} \mathrm{X} 17 \mathrm{~cm}$.

\section{Stimulus Conditions}

The present research design consisted of eighteen different stimulus conditions. Each of these conditions will be explained in this section thoroughly from least complex in terms of visual stimuli to most complex. The order in which the conditions were presented to participants and the explicit trial sequences will be explained in detail in the Experimental Design section to follow.

Eighteen presentation conditions (i.e., study task conditions) of the research design were described and labeled as: (1) Black and white (no bars), image, no animation, (2) Black and 
white (no bars), image, animation, (3) Black and white (no bars), location, no animation, (4) Black and white (no bars), location, animation, (5) Black and white (no bars), combination, no animation, (6) Black and white (no bars), combination, animation, (7) Color bars, image, no animation, (8) Color bars, image, animation, (9) Color bars, location, no animation, (10) Color bars, location, animation, (11) Color bars, combination, no animation, (12) Color bars, combination, animation, (13) Black and white bars, image, no animation, (14) Black and white bars, image, animation, (15) Black and white bars, location, no animation, (16) Black and white bars, location, animation, (17) Black and white bars, combination, no animation, (18) Black and white bars, combination, animation (Table 2).

Table 2: Table derived explanation of eighteen stimulus conditions of present research design.

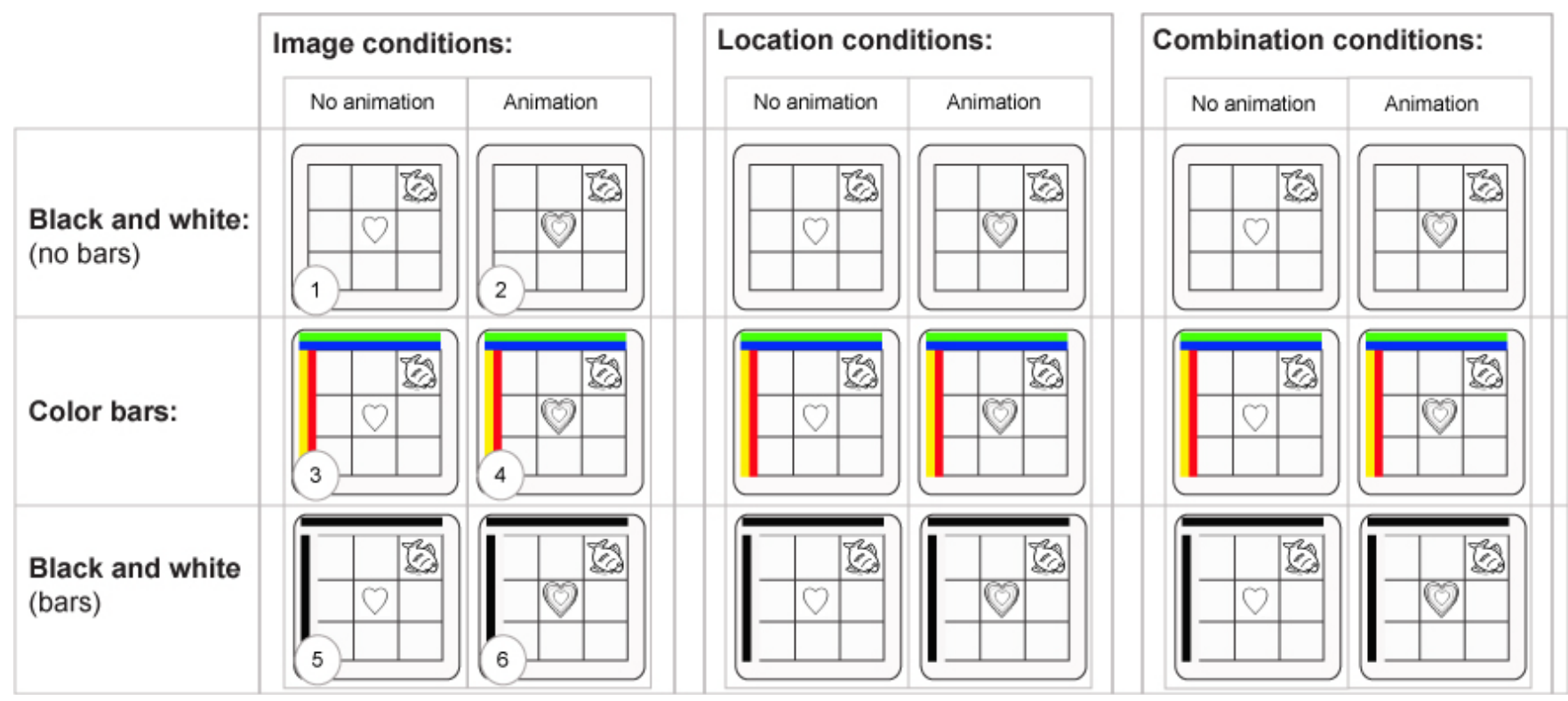

After viewing the specifics of Table 2 the reader will realize six presentation formats were repeated three times for each of three main study task conditions (i.e., image conditions, location conditions, and combination conditions). Note: even though Table 2 describes six presentation formats repeated three times for each of the main conditions, Table 2 does not describe the underlying random nature of the presentation mechanism. Note: images, placement 
locations, animations, color bar combinations, and black and white bar combinations were all random; therefore, even though the formats are presented as three duplicates for each of the three main conditions for clarity, the real-world presentation of stimuli potentially never duplicate the same image, animation, and bars combinations during a set of trial experiments.

The specific differentiation of the eighteen described study task conditions becomes clear and evident with the description of the memory quiz task stimulus environment. The memory quiz task environments were described and labeled as: 'Image only’ (i.e., visual STM store) (1), 'Location only’ (i.e., visual spatial/motion STM) (2), and 'Combination’ (i.e., visual STM store and visual spatial/motion STM combined) (3). The memory quiz task for image only presented one image in the center of the computer monitor. Either the image was accurate (Fig. 17) or inaccurate (Fig. 18). The memory quiz task for location only presented the $3 \mathrm{x} 3$ grid and a black box placed in a location on the grid. Either the location was accurate (Fig. 19) or inaccurate (Fig. 20). The memory quiz task for the combination condition presented the $3 \times 3$ grid and an image placed in a location on the grid. Both the image and location were accurate (Fig. 21) or inaccurate (Fig. 22). 


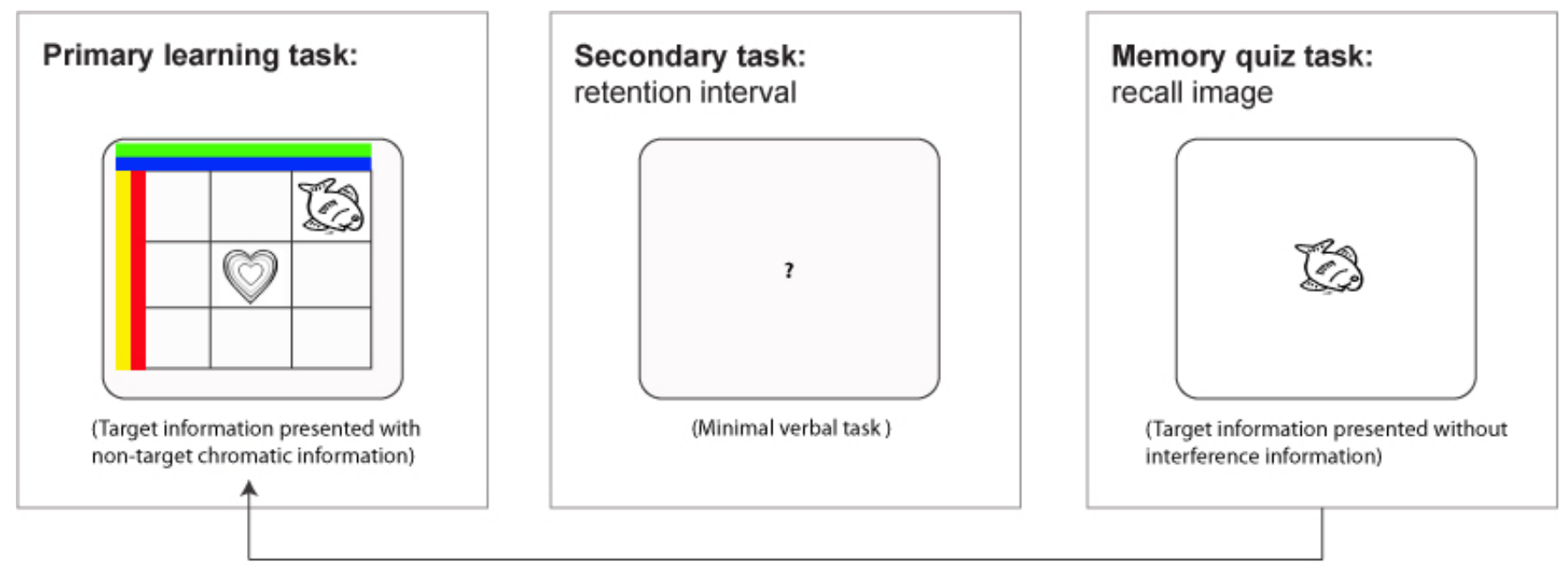

Fig. 17: Graphic derived explanation of color bars, image only, and animation condition 'accurate.'

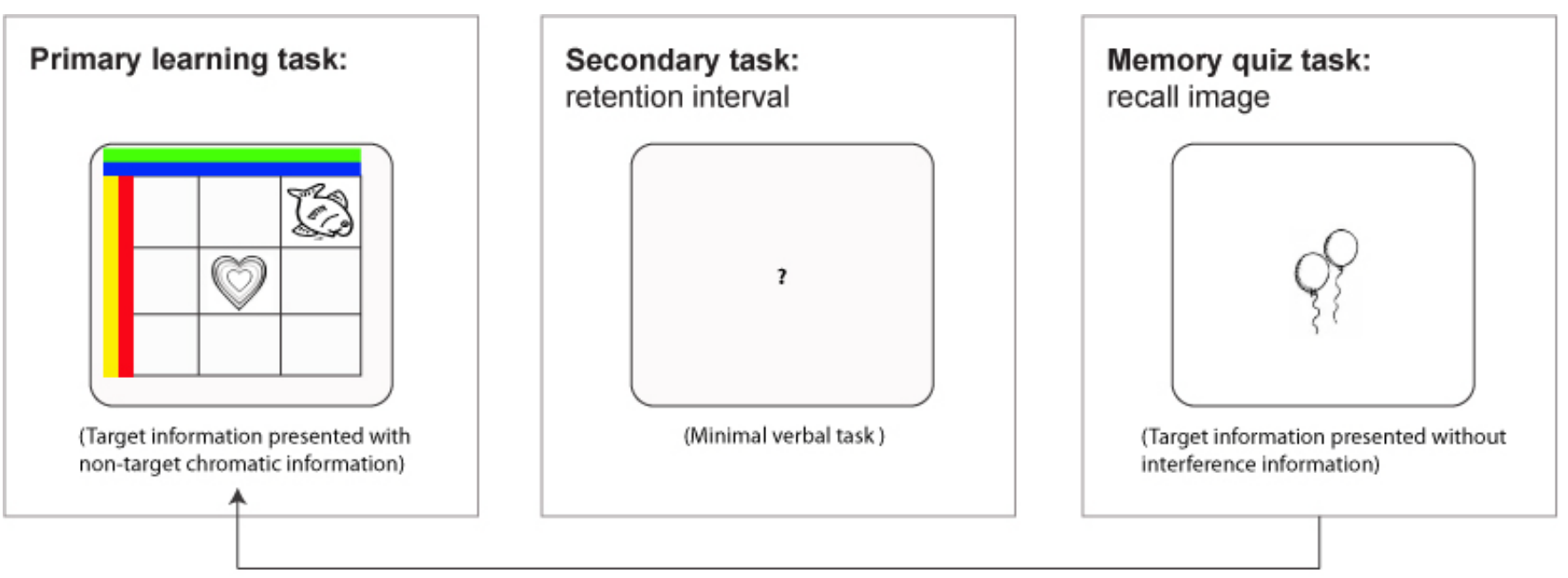

Fig. 18: Graphic derived explanation of color bars, image only, and animation condition 'inaccurate.' 


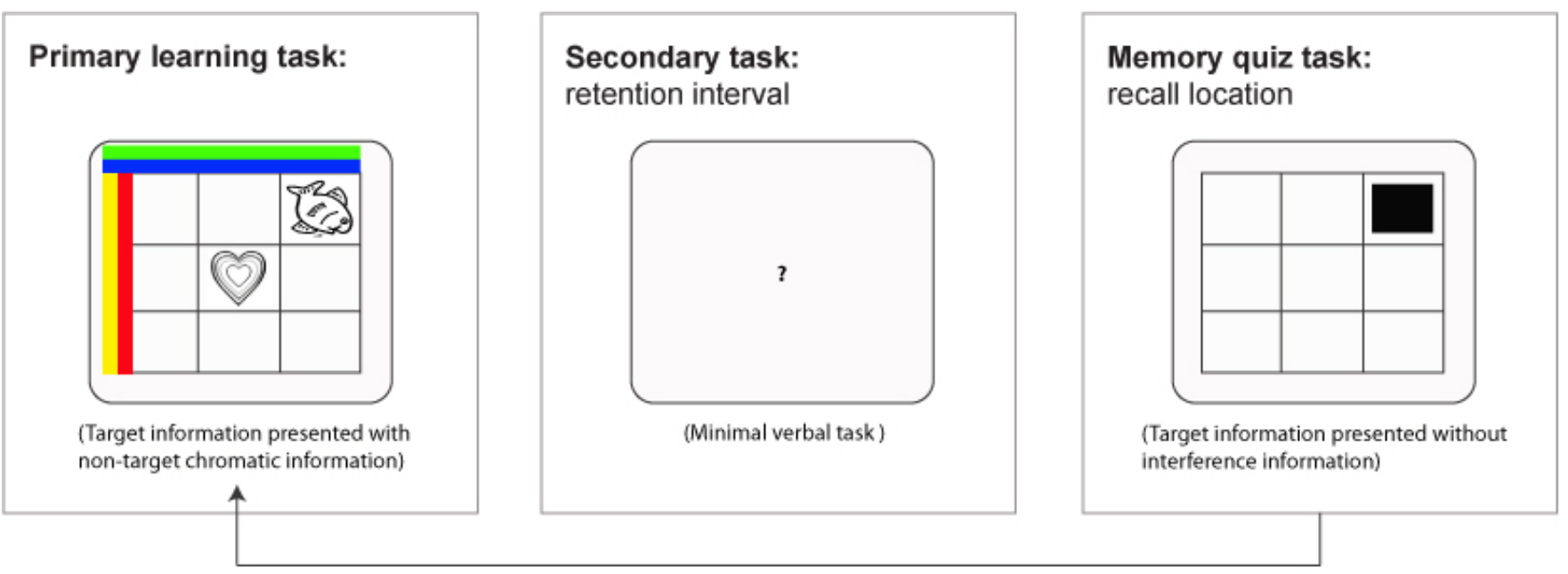

Fig. 19: Graphic derived explanation of color bars, location only, and animation condition 'accurate.'

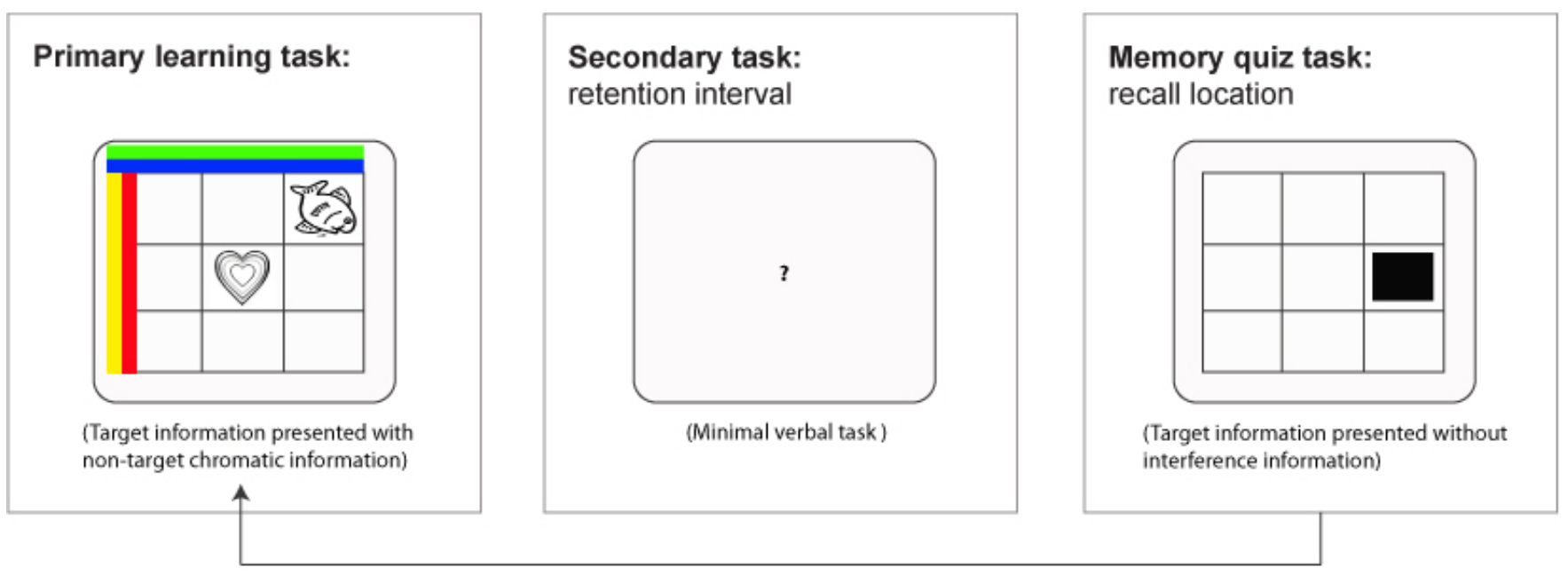

Fig. 20: Graphic derived explanation of color bars, location only, and animation condition 'inaccurate.' 


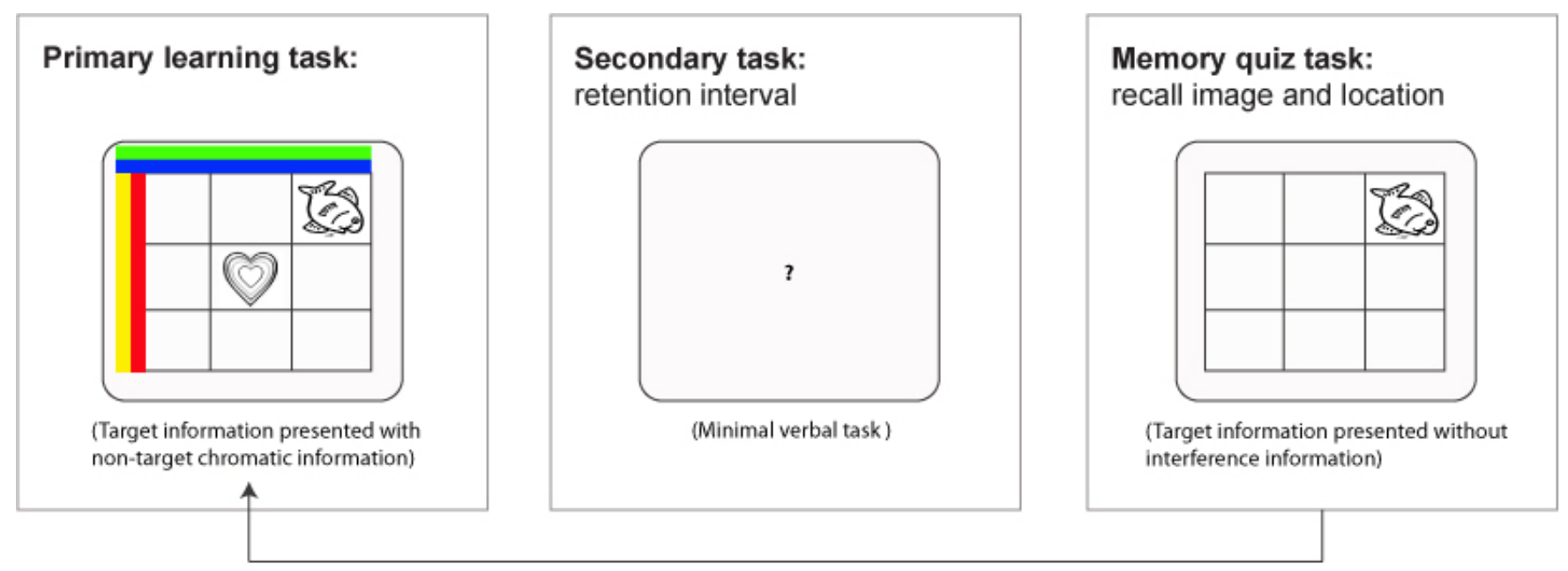

Fig. 21: Graphic derived explanation of color bars, combination, and animation condition 'accurate.'

Primary learning task:

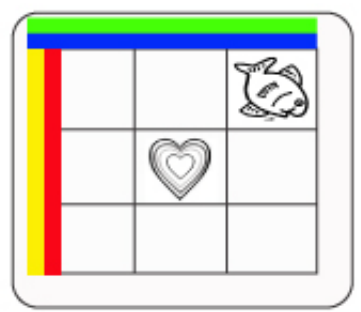

(Target information presented with non-target chromatic information)

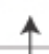

\section{Secondary task:} retention interval

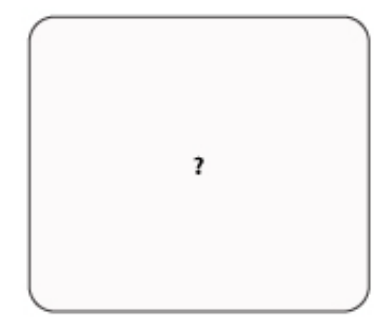

(Minimal verbal task)
Memory quiz task:

recall image and location

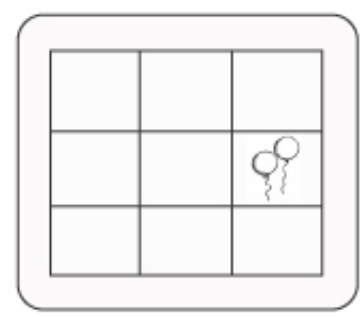

(Target information presented without interference information)

Fig. 22: Graphic derived explanation of color bars, combination, and animation condition 'inaccurate.'

\section{Experimental Design}

The experimental design of the study presented visual STM information as memory tasks and recorded participant response data in a series of 36 separate trials. Each of the eighteen conditions was tested two times randomly (Table 2). All participants completed each condition of the experimental design. Each of the 36 trials had 12 study condition presentation sequences, 
each one followed by 12 memory quiz tasks for each sequence. The 12 study condition presentations represented 6 random memory quiz tasks requiring a YES response for accuracy, and 6 random memory quiz tasks requiring a NO response for accuracy. There were a total of 432 study condition presentations and memory quiz tasks for each participant. The sequence of the study conditions were as follows:

- Beginning of study condition: Word STUDY was presented in black letters in center of a white background on the computer monitor screen for 500ms (i.e., minimal verbal STM information)

- Study buffer: A white blank screen with no information was presented for 1 sec

- Study information (1): A black and white 3 x 3 grid $17 \mathrm{~cm}$ x $17 \mathrm{~cm}$ was presented for 3 secs in the center of the computer monitor screen

- Study information (2): During the 3 sec presentation of the black and white $3 \times 3$ grid described in study information (1), three random target visual STM images (i.e. visual STM store information) were presented one at a time for $1 \mathrm{sec}$ each

- $\quad$ Study information (3): During the 3 sec presentation of the black and white $3 \times 3$ grid described in study information (1), three random target visual STM spatial/motion (i.e. visual STM visuospatial information) locations on the $3 \mathrm{x} 3$ grid contained one random target image for 1 sec each

Note: random images and random locations on the 3 x 3 black and white grid were never duplicated during the 3 sec visual STM presentation sequences

- Retention interval: Following the 3 sec presentation of the black and white 3 x 3 grid, and the three random target visual STM images, and the three random target visual STM location presentations, a question mark (i.e., ?) was presented in black in 
the center of a white background on the computer monitor screen for 8 secs (i.e., minimal verbal STM information)

- Test condition: Following the 8 sec retention interval the word TEST was presented in black letters in center of a white background on the computer monitor screen for 500ms (i.e., minimal verbal STM information)

- Test buffer: A white blank screen with no information was presented for $1 \mathrm{sec}$

- Memory quiz task: Following the $1 \mathrm{sec}$ test buffer one of three random memory quiz conditions was presented (i.e., 'Image only,' 'Location only,' or 'Combination') (Figs. 17-22).

- Following participant response : Immediate return to beginning of study condition for eleven more study conditions within each trial for a total of twelve

- Following study condition twelve of a given trial sequence the participant was informed the trial had ended. The words TRAIL HAS ENDED was presented in black letters in center of a white background on the computer monitor screen and remained there until participant closed the trial page manually

Each of the 12 study condition presentation sequences within a trial sequence utilized one of six presentation format patterns continuously (Table 2). Each presentation format pattern was used two times for each of the main study conditions randomly, for a total of six times over 36 total trials. Each of six presentation format patterns within a given trial had a precise and repeated presentation methodology of visual STM information and minimal verbal STM information (i.e., phonological loop). The presentation methodology included controlling for specific information presented for a specific amount of time during each of the stimulus 
conditions. The sequence of each study condition was as follows (Figs. 23-28 in APPENDIX) (also refer to Table 2):

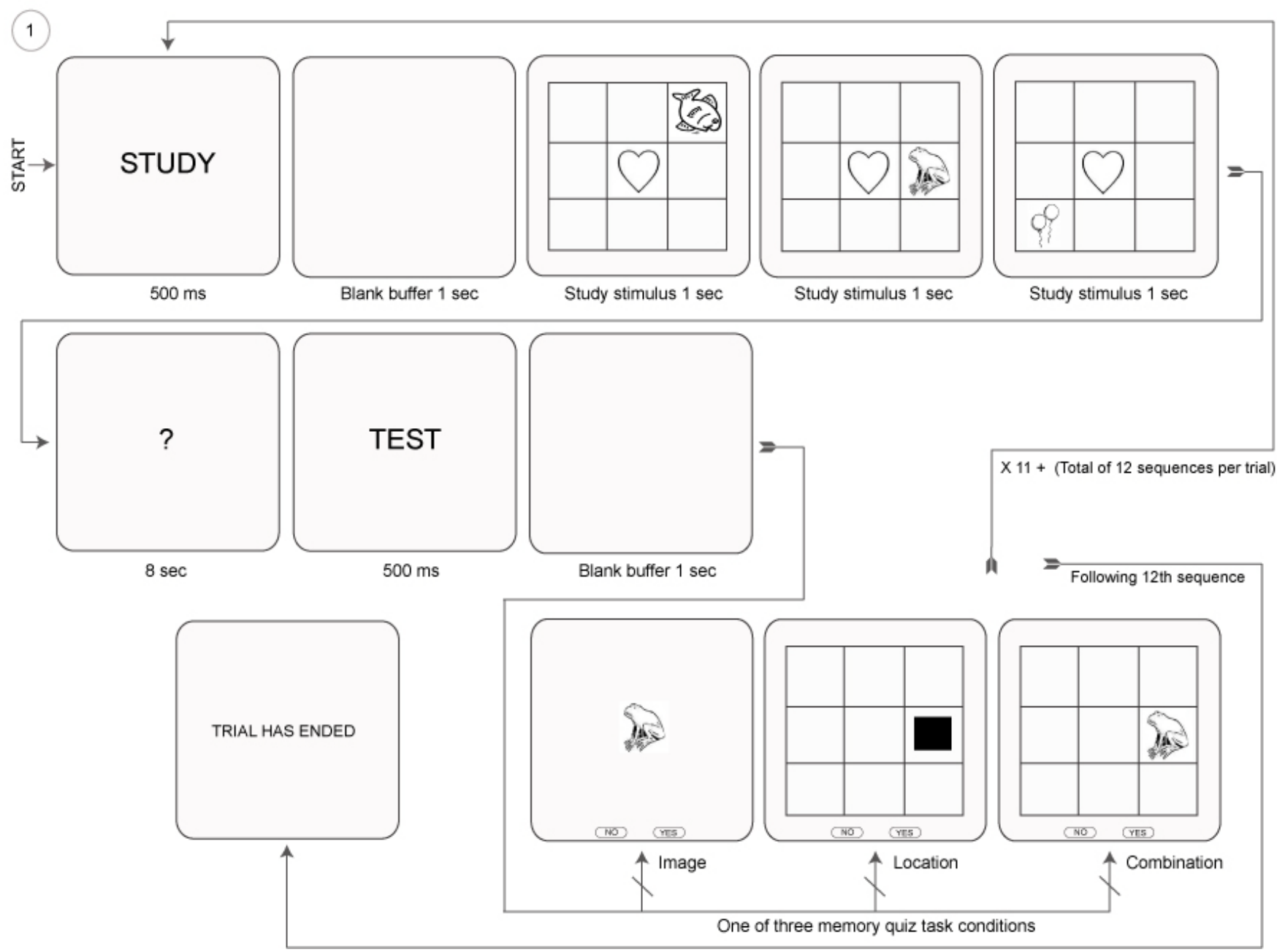

Fig. 23: Stimulus condition one (Black and white, no bars, no animation). Note: Static non-target image in center block does not change during study stimulus presentations.

The research design enabled each of the 36 separate trials to be initiated by the individual participants through clicking buttons on a main user interface. The main user interface also enabled the participants to monitor their progress through the 36 separate trials. There were seven different main user interfaces, each differing only by their individual program to deliver a different random sequence of trials (i.e., Participant 1, Participant 2, Participant 3, etc.). Of 14 
participants, two participants each were randomly assigned to one of seven main user interfaces. As the participants advanced through the 36 separate random trials the user interface buttons for the appropriate following random trial would automatically activate (Fig. 29 in APPENDIX). Therefore, a given participant was required to finish a given trial before moving forward to the following random trial.

Once a participant initiated a trial sequence by clicking on an activated sequence button on the main user interface, the trial sequence loaded into the computer monitor. The participant maximized the browser windows and enabled active X content. Next, the participant clicked two gateway buttons to start the trial sequence. The gateway buttons were designed to enable the participant to prepare for the rapid delivery of the trial sequences’ visual information. Each gateway button page presented the participant a different minimal verbal message (Figs. 30-31 in APPENDIX). Once a participant entered the second gateway page the trial sequence of 12 study condition presentations began (Figs. 23-28 in APPENDIX). Following the $12^{\text {th }}$ sequence of a given trial the participant was informed the trial sequence had ended (Fig. 32 in APPENDIX). Each trial sequence required approximately three minutes to complete depending on each participant’s individual speed. All 36 trial sequences required approximately one hour 50 minutes.

\section{Apparatus Program Design}

The superficial design methodology of the research instrument was based on the research instrument of Lorsbach and Reimer (2005). The Lorsbach and Reimer (2005) research instrument measured adult response accuracy for visual STM of images, locations, and combination of images/locations in a black and white environment. The Lorsbach and Reimer 
(2005) research instrument was void of non-target visual information such as colors and animations. Lorsbach and Reimer (2005) reported adults performed equally well in all three black and white conditions, and their performance was exceptional. The goals of the current research instrument design were not to simply duplicate the Lorsbach and Reimer (2005) instrument. The goals were to introduce additional visual STM stimuli into a research instrument similar in function and performance to the Lorsbach and Reimer (2005) instrument. Based on the Lorsbach and Reimer (2005) approach, the current design sought to gain an understanding of adult learning performances in computer-learning environments that introduce non-learning-target information in the form of additional visual objects, colors, and animations. Additionally, the Lorsbach and Reimer (2005) research instrument design was analogous to realworld academic computer-learning environments. Other visual STM research designs introduce methods that do not lend to real-world computer-environment learning; therefore they do not lend readily to informing IDT (e.g., Hecker \& Mapperson, 1997; Klauer \& Zhao, 2004).

The reasoning of the inquiry was one that considered the human computer interfacing environment and the cognitive processes of learning. Specifically the visual STM learning processes. In order to understand more about visual STM learning in computer environments it was necessary to construct computer environments and control them dynamically in experimental tests.

The functional requirements of the research instrument were to consistently and randomly present learning information as visual STM stimulus in experimental computerlearning environments. The research instrument was required to also gather participant response data during experimental learning tasks. Specific data to be gathered were 'accuracy of responses' to memory quiz prompts following visual STM stimulus trials, and 'time or latency of 
response' behaviors measured from visual STM stimulus onset to memory quiz prompt response. Records of multiple participants had to be archived in a format applicable to subsequent statistical analysis.

To accomplish the needs of research instrument design the researcher developed the instrument through utilizing Adobe Flash ${ }^{\circledR}$ Actionscript 2.0 (2009), the php programming language (Lerdorf, 1995), and a MySQL (Widenius \& Axmark, 1995) data base.

All visual aspects of the research instrument were accomplished in the Adobe Flash ${ }^{\circledR}$ (2009) environment. Adobe Flash ${ }^{\circledR}$ (2009), through Actionscript 2.0, also provided the underlying programming environment that enabled all of the functions of the experimental design, including the presentation of visual stimuli according to the experimental design, and the capturing of participant responses according to the experimental design.

Adobe Flash ${ }^{\circledR}$ (2009) communicated with a php (Lerdorf, 1995) middleware program for ease of program infrastructure. Adobe Flash ${ }^{\circledR}(2009)$ sent individual participant response data for accuracy and latency to a php (Lerdorf, 1995) program. The program processed the response data and sent it to a MySQL (Widenius \& Axmark, 1995) data base where the data were archived. The MySQL (Widenius \& Axmark, 1995) data base was capable of outputting the data set to a Microsoft Office Excel $®$ (2006) file format. Subsequently, the Microsoft Office Excel ${ }^{\circledR}$ (2006) file was imported into SPSS (Nie, 1968) software for statistical analysis (Fig. 33) 


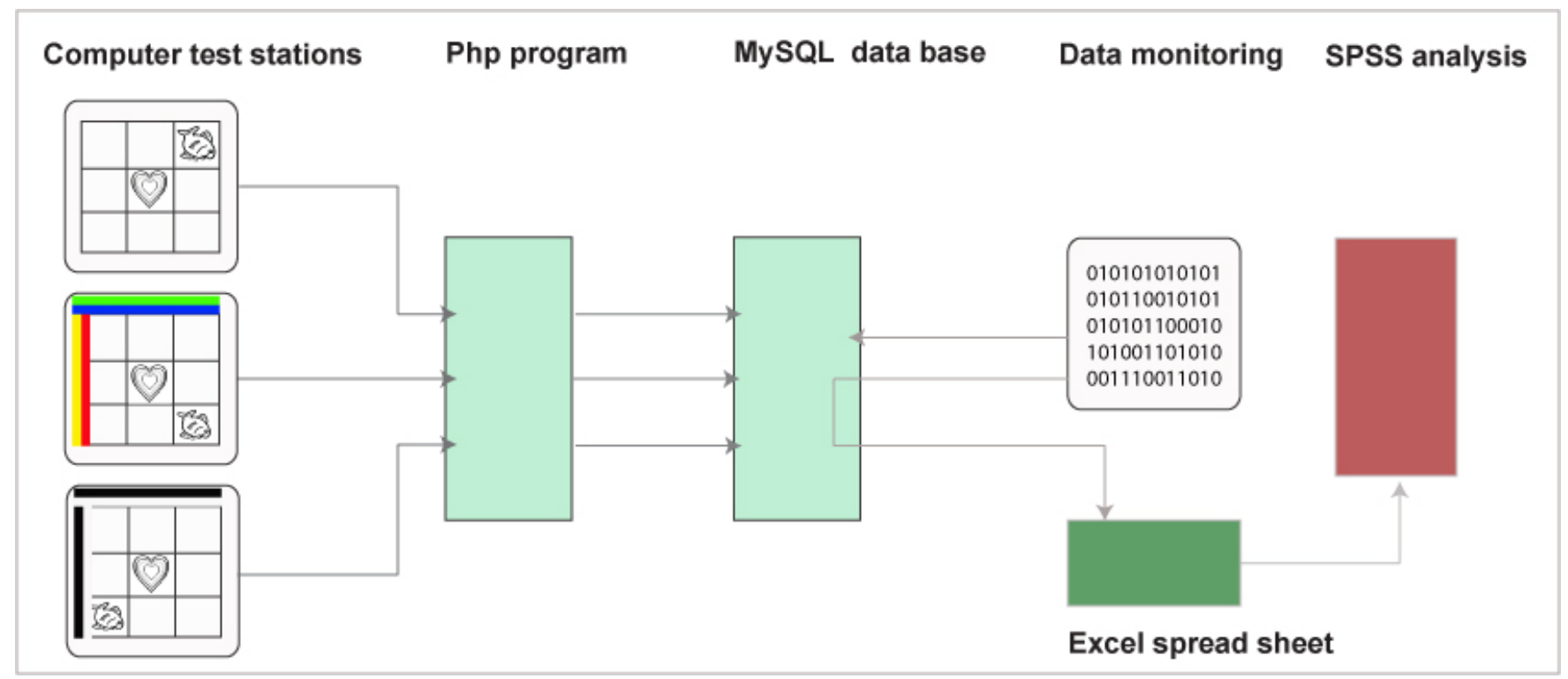

Fig. 33: Apparatus infrastructure.

This was a precision instrument calculating time to the $1000^{\text {th }}$ of a second. The research instrument functioned as an online tool. However, the instrument would not be impaired by network lag. For each response transmission (i.e., 432 transmissions per participant), the response data were calculated and encoded on the local machine, then the accurate response data were transmitted to a php (Lerdorf, 1995) program via the Internet. If the transmission encountered unexpected network lag, the accuracy of data calculated on the local machine would maintain its integrity.

\section{Limitations of Experimental Design and Apparatus}

Although the experimental design and research instrument approached many dynamic visual STM learning environments, there are many others to consider. The STM visual parameters under investigation are a small part of the whole scope of visual STM and STM in general. The present experimental design can only attempt to explore a fraction of these areas. 
The experimental design was also limited in the nature of the randomness of the 36 research trials. Each trial presented the participant 12 sequences of visual STM stimuli followed by 12 memory quiz tasks. Although each trial was randomly presented to the participants based on seven instruments, the sequences programmed into the trials were all one of six presentation patterns. Therefore, following the first sequence of a given trial, the participant would learn what the following 11 sequences in the trial set were targeting for response (i.e., image, location, or combination of image/location). A future design may eliminate this limitation through developing a program to randomly deliver all sequences independently of a trial set.

The requirement of participants to maximize browser windows and enable active $\mathrm{X}$ content as well as clicking through gateways of each trial set may also be described as a potential limitation. The current research design is not a conventional visual STM study though. Although requiring the participants to navigate through minimal verbal information and perform two minimal tasks (i.e., clicking two entry buttons) in order to begin each trial, the environment is more analogous to a real-world computer-learning environment in contrast to an apparatus specifically attempting to control for target visual STM processes. Future designs may consider this limitation and develop an alternative.

\section{Materials}

Each research participant was trained prior to engaging the research study. Cohort and individual training of participants was conducted with a power point presentation and brief lecture (Figs. 34-35 in APPENDIX). Participants were provided a question and answer period during training. 


\section{Procedure}

Participants were randomly assigned to computer workstations. Although participants were in the same computer research lab, each participant was separated from other participants to provide a comfortable independent environment. Following a brief power point presentation and lecture instructing the participants on the nature of the research study and the instruments, a brief question and answer session was held. Participants were explicitly instructed on each aspect of the performance requirements required to engage the research instrument. Participants were instructed to answer the memory quiz tasks as accurately and as quickly as possible by clicking the response buttons (i.e., YES or NO). Participants were instructed on how to complete the 36 trail sets of the experiment through the utility of the main user interface. Participants then had an opportunity to run a pre-research trial of the research instrument to become accustomed to it. Participants were instructed to take breaks at their leisure between trial sets. However, it was suggested not to take more than 5 breaks lasting more than 5 minutes. None of the participants took more than a few short breaks during the experimentation. The research experiment took approximately 140 minutes to complete.

\section{Statistical Method}

The statistical method of the experimental research design called for a Factorial Analysis of Variance (ANOVA) 3 × 2 x 3 totally-within repeated-measures design. The choice of ANOVA was made instead of MANOVA because the dependant variables of accuracy of scores and participant response latency were assessed to see if either independent variable, or both, was sensitive to the impact of the independent variables. 
The research design utilized the experimental design analysis software program $\mathrm{G} *$ Power 3.0.10 for an a priori analysis. G*Power 3.0.10 analysis findings were derived of the specific parameters of the research experimental design. Based on an ANOVA totally-within factors, repeated measures design, 18 conditions, near medium effect of .25 , and a critical $F$ of 1.669 , G*Power 3.0.10 suggested a total sample size of 14 (Table 3) (Fig. 33).

Table 3: Table derived explanation of G*Power 3.0.10 a priori analysis output.

F tests - ANOVA: Repeated measures, within factors

Analysis: A priori: Compute required sample size

Input:

Effect size $\mathrm{f}$

$\alpha$ err prob

Power (1- $\beta$ err prob)

Repetitions

Corr among rep measures

Nonsphericity correction $\varepsilon$

Output: Noncentrality parameter $\lambda$

Critical F

Numerator df

Denominator df

Total sample size

Actual power
$=0.25$

$=0.05$

$=0.95$

$=18$

$=0.5$

$=1$

$=31.500000$

$=1.669171$

$=17.000000$

$=221$

$=14$

$=0.954666$

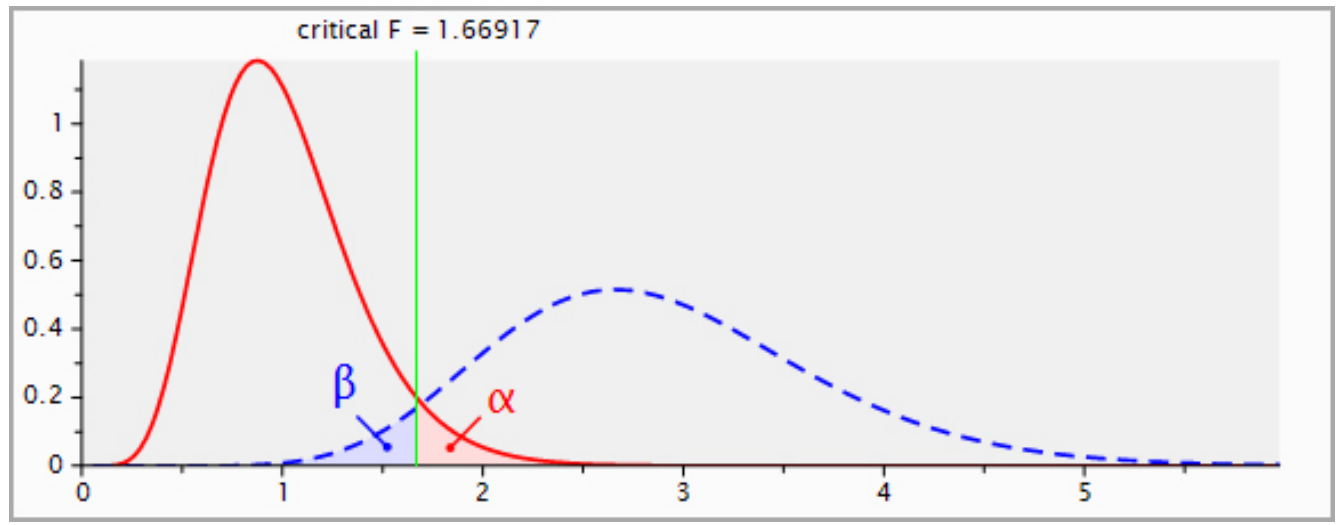

Fig. 33: G*Power 3.0.10 a priori analysis critical $F$ output graph. 


\section{Data Collection}

Data was collected in real time as the research experiments took place. Each participant response was recorded from the Adobe Flash ${ }^{\circledR}$ (2009) computer research environment through a php (Lerdorf, 1995) program into a data base. The data base was monitored by the facilitator as data were gathered during the experimentation (Fig. 33). There were no missing data sets. 


\section{CHAPTER IV:}

\section{RESULTS}

\section{Data Analysis}

Data were statistically evaluated using SPSS (Nie, 1968) software for Windows version 17.0. A Factorial ANOVA $3 \times 2 \times 3$ totally-within repeated-measures design was carried out for each of the two dependant variables (i.e., accuracy of scores, participant response latency). Post hoc Bonferroni adjustment for multiple comparisons tests were also carried out for the main effects. Statistical significance was found in STM conditions, color conditions, and the interaction of animation conditions*STM conditions (Table 4, and APPENDIX II Tables 5, 6).

Table 4: Table explanation of statistically significant findings.

\begin{tabular}{|c|c|c|}
\cline { 2 - 3 } \multicolumn{2}{c|}{} & \multicolumn{2}{c|}{ Accuracy } & \multicolumn{1}{c|}{ Latency } \\
\cline { 2 - 3 } & & \\
\hline STM cond. & Statistical significance & No statistical significance \\
\hline Color cond. & Statistical significance & No statistical significance \\
\hline Animation cond. & No statistical significance & No statistical significance \\
\hline Interactions & & No statistical significance \\
\hline STM cond.*Color cond. & No statistical significance & No statistical significance \\
\hline STM cond.*Animation cond. & Statistical significance & No statistical significance \\
\hline Color*Animation cond. & No statistical significance & No statistical significance \\
\hline STM cond.*Color*Animation & No statistical significance & \\
\hline
\end{tabular}


Main Effects on Accuracy

STM conditions.

Mauchly’s test indicated no violation of sphericity for the main effect of STM conditions on accuracy. The main effect of the STM conditions on accuracy of scores was significant at ( $p$ $<.05, F(2,26)=10.63)$. This means, if we ignore the color conditions and the animation conditions, participants still scored significantly differently within the STM conditions (Fig. 34). A post hoc Bonferroni adjustment for multiple comparisons revealed a significant main effect ( $p$ $<.01$ ) indicating a difference between STM combination condition and STM location condition. The post hoc Bonferroni adjustment for multiple comparisons also revealed a significant main effect $(p<.01)$ indicating a difference between STM image condition and STM location condition.

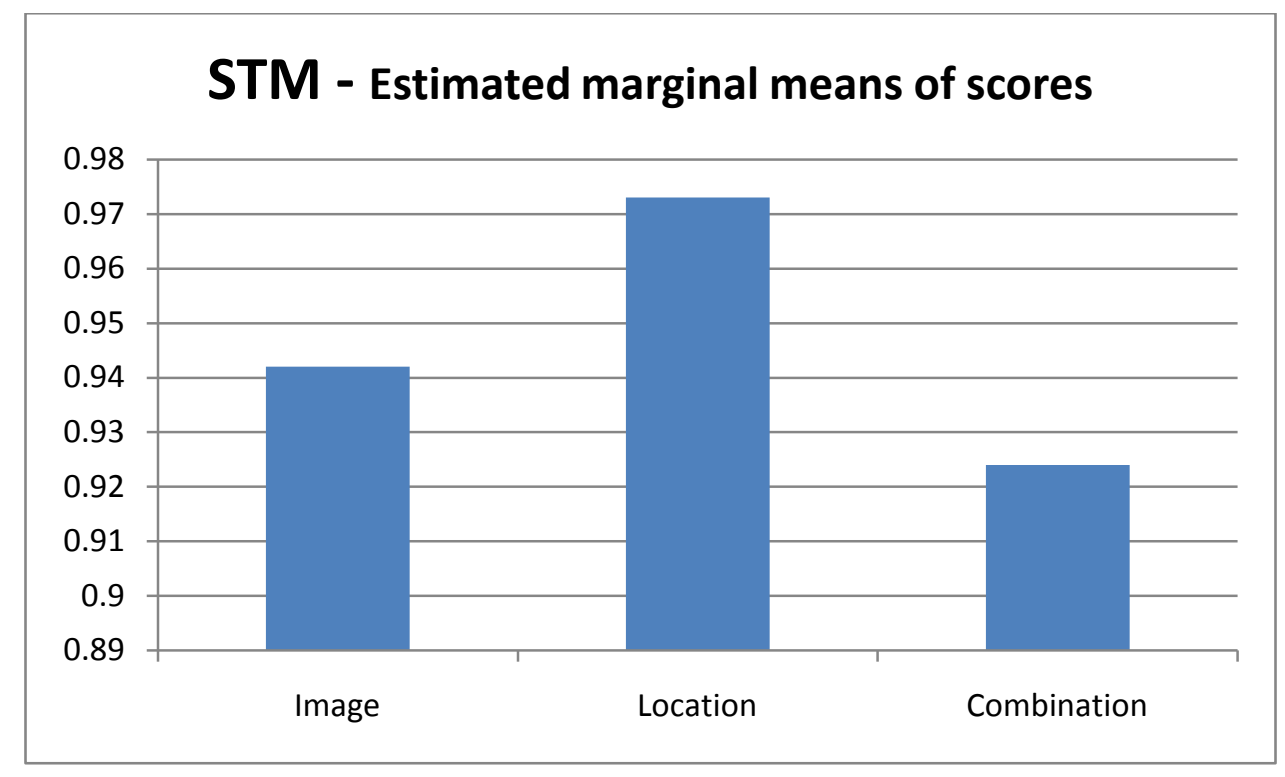

Fig. 34: STM conditions - Estimated marginal means of scores. Note: Image $=.942 \%$, location $=.973 \%$, and combination $=.924 \%$. Note: truncated axes. Note: Also see APPENDIX II for estimated means. 


\section{Color conditions.}

Mauchly’s test indicated no violation of sphericity for the main effect of type of color condition on accuracy. There was a significant main effect of type of color conditions on accuracy of scores, $(p<.05, F(2,26)=6.88)$. This means, if we ignore the STM conditions and the animation conditions, participants still scored significantly differently within the STM conditions according to the type of color condition participants were subjected to (Fig. 35). Participants scored significantly higher in the black and white condition and in the color bars condition.

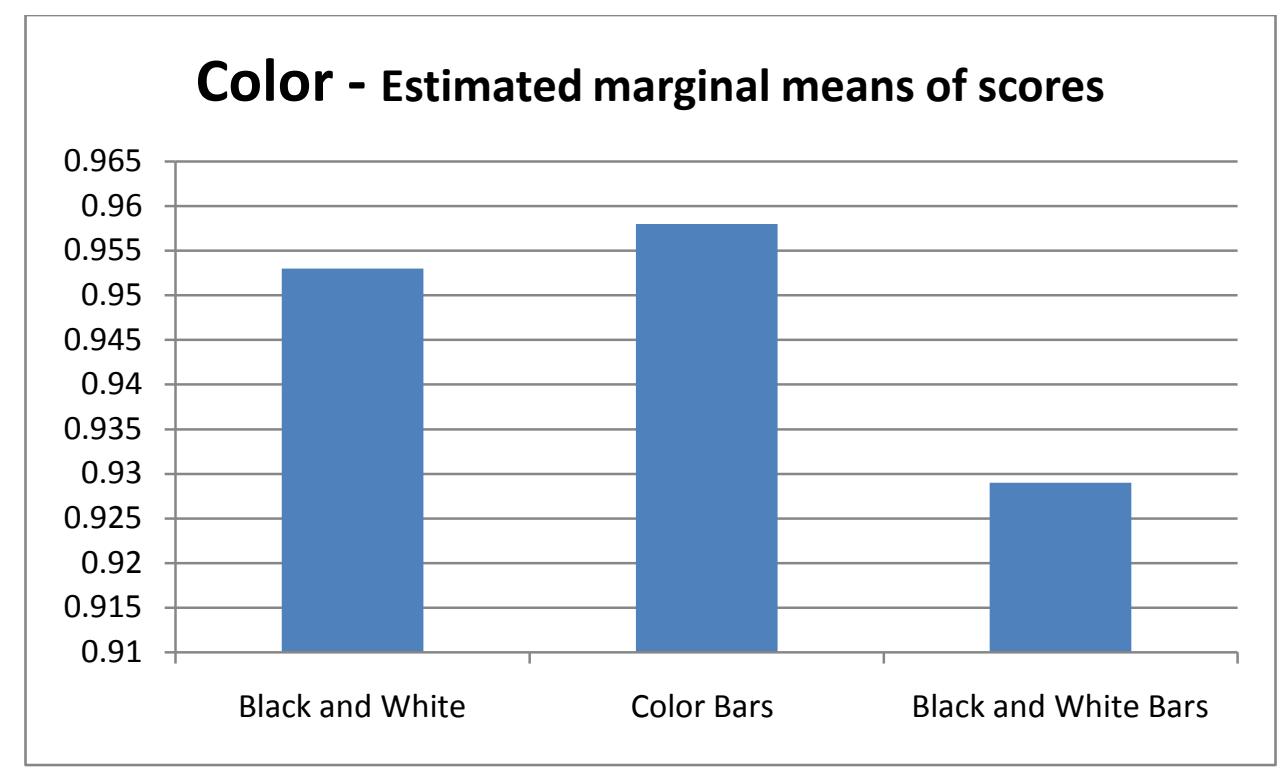

Fig. 35: Color conditions - Estimated marginal means of scores. Note: Black and white $=.953 \%$, color bars $=.958 \%$, and black and white bars $=.929 \%$. Note: truncated axes. Note: Also see APPENDIX II for estimated means.

Animation conditions.

There was no significant main effect of type of animation condition on accuracy to report $(p>.05)$. For a comprehensive report of these findings please see APPENDIX II. 
Interaction Effects on Accuracy

STM conditions*color conditions.

There was no significant interaction effect of STM*Color conditions on accuracy to report $(p>.05)$. For a comprehensive report of these findings please see APPENDIX II.

\section{STM conditions*animation conditions.}

There was a significant interaction effect between the STM conditions and animation conditions on accuracy of scores, $(p<.05, F(2,26)=3.62)$. This indicates that animation conditions when combined with STM conditions had different effects on participants' accuracy of scores. Looking at the interaction graph (Fig. 36), these effects reflect that level two ‘animation condition’ compared to level one ‘no animation condition' lowered participant accuracy scores significantly when combined with the combination STM condition as compared to the Image STM condition.

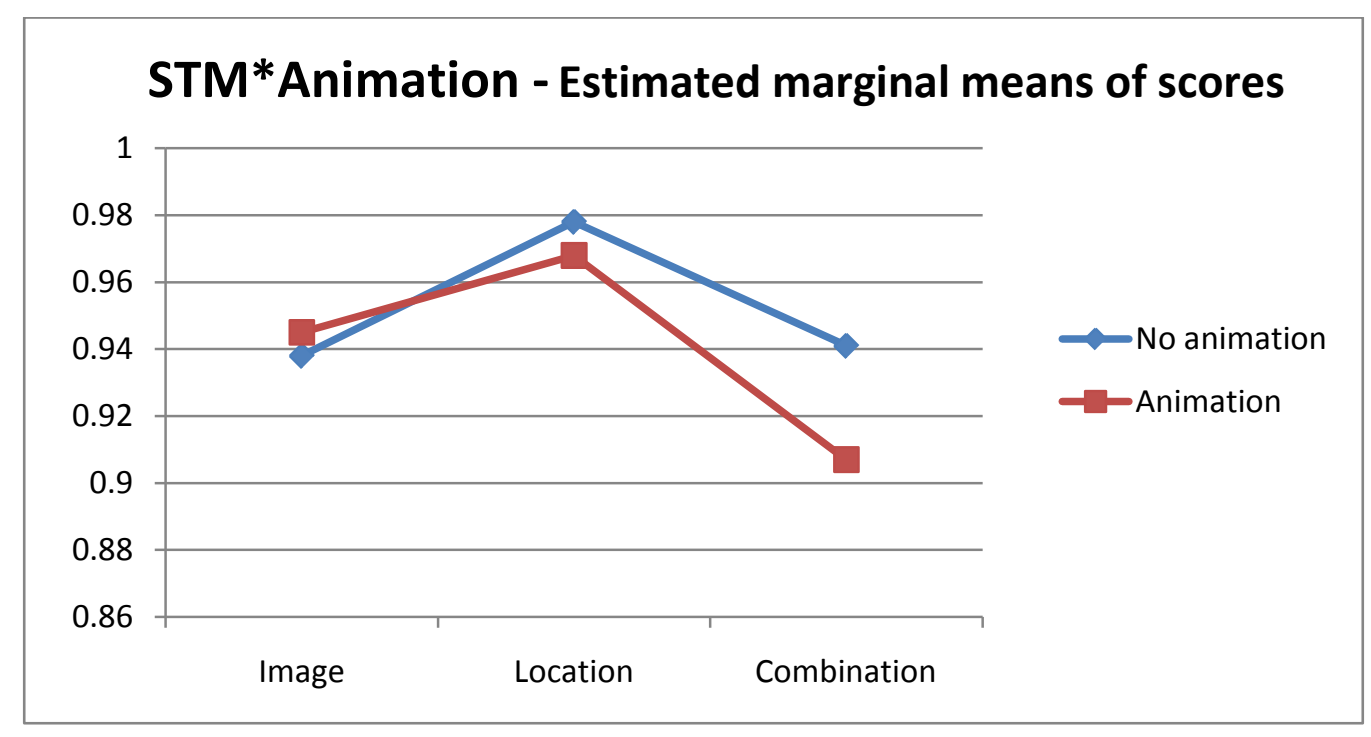

Fig. 36: STM conditions*Animation conditions - Estimated marginal means of scores. Note: Image*no animation $=.938 \%$, location*no animation $=.978 \%$, combination*no animation $=.941 \%$, and image*animation $=.945 \%$, location*animation $=.968 \%$, combination*animation $=.907 \%$. Note: truncated axes. Note: Also see APPENDIX II for estimated means. 


\section{Main Effects on Latency}

There were no significant main effects on latency to report $(p>.05)$. For a comprehensive report of these findings please see APPENDIX II.

Interaction Effects on Latency

There were no significant interaction effects on latency to report $(p>.05)$. For a comprehensive report of these findings please see APPENDIX II.

\section{Findings Based on Research Questions}

\section{Research Question 1: Analysis and Findings}

RQ1: Is there a significant difference in visual STM learning-task response-accuracy between black and white digital learning environments and digital learning environments laden with colors? There was a significant main effect $(p<.05, F(2,26)=6.88)$ indicating color conditions had an impact on visual STM learning-task response-accuracy; therefore, the null hypothesis was rejected.

Research Question 2: Analysis and Findings

RQ2: Is there a significant difference in visual STM learning-task response-latency between black and white digital learning environments and digital learning environments laden with colors? There was no significant main effect $(p>.05, F(2,26)=1.23)$ to indicate color conditions had an impact on visual STM learning-task response-latency; therefore, the findings failed to reject the null hypothesis. 
Research Question 3: Analysis and Findings

RQ3: Is there a significant difference in visual STM learning-task response-accuracy between black and white digital learning environments with animation and digital learning environments laden with colors and animation? There was no significant main interaction effect ( $p>.05, F(4$, $52)=1.05)$ to indicate STM conditions*color conditions*animation conditions had an impact on visual STM learning-task response-accuracy; therefore, the findings failed to reject the null hypothesis. However, there was a significant main effect with a medium to large effect size ( $p<$ $.05, F(2,26)=3.62)$ indicating STM conditions*animation conditions had an impact on visual STM learning-task response-accuracy. The failure to reject the main 3-way interaction hypothesis does not diminish the interaction effects between STM conditions*animation conditions. The finding is significant and important for the goals of this research.

\section{Research Question 4: Analysis and Findings}

RQ4: Is there a significant difference in visual STM learning-task response-latency between black and white digital learning environments with animation and digital learning environments laden with colors and animation? There was no significant main interaction effect $(p>.05, F(4$, $52)=1.35)$ to indicate STM conditions*color conditions*animation conditions had an impact on visual STM learning-task response-latency; therefore, the findings failed to reject the null hypothesis.

\section{Summary}

The research goals of this study were to gain a better understanding of the effects of color and animation on visual STM in computer-environment learning tasks. Through the experimental design information was sought to aid in the better development of computer- 
learning-environment-specific ID models derived from the psychological processes of learning. The findings of this research will provide for informing specific psychometric parameters of effective visual instructional content in computer-learning environments.

Findings that will aide in developing models of ID specific to computer-learning environments, considering a theoretical model based on learning theory include:

1) Specific color parameters that facilitate visual STM learning tasks.

2) Specific color parameters that impede visual STM learning tasks.

3) Specific animation parameters that impede visual STM learning tasks. 


\section{CHAPTER V:}

\section{CONCLUSIONS}

The research study proposal addressed color and animated objects in computer environments as non-target visual information that may potentially impact the visual STM learning processes during learning tasks. Visual learning tasks in black and white environments (i.e., achromatic) in contrast to visual learning tasks in digital-color-laden environments (i.e., chromatic) with and without animations were the focus of interest. Gaining an understanding of how achromatic interference, chromatic interference, and animation interference impact visual STM in terms of image recognition (i.e., visual image STM) and image location recognition (i.e., visual spatial/movement STM) was explored. The research findings have provided information on multiple parameters of visual perception of digital information in computer-learning environments in terms of optimization of visual STM learning.

\section{Conclusions Based on Research Conditions}

\section{STM Conditions}

The STM conditions findings revealed the combination (i.e., visual STM store and visual spatial/motion STM combined) learning tasks were most difficult in contrast to visual STM store or visual spatial/motion STM tasks in isolation. This finding is somewhat surprising as Lorsbach and Reimer (2005) did not report significant differences between STM condition learning tasks among adults $(p>.14)$. The current study integrated additional information into the visual learning environment the Lorsbach and Reimer (2005) study did not integrate that may account for the emergent significant differences in the current study. The additional information integrated into the visual learning environment in the current study was a random static or 
animated image that remained in the center block of the $3 \times 3$ grid during the duration of target visual stimuli presentations (Figs. 23-28). The implications of this finding will be discussed further in the following section addressing suggestions for future research.

\section{Color Conditions}

The color conditions findings revealed the black and white bars condition was the most difficult condition for participants to achieve accuracy of all three STM conditions. This finding is an achromatic visual information effect deserving critical considerations. This finding is important for considerations of further research.

In consideration of IDT development of visual information for computer-learning environments, it is first important to understand the physical presence of visual information within the computer-learning environment. The development of effective visual information derived of the findings is directly relational to the experimental research design, and the physical information presented within the design. The dynamic visual information elements to consider are: color (i.e., chromatic or achromatic), visual objects, visual space, target-information, and non-target information.

The achromatic visual information effect description considers all visual information (i.e., visual objects, visual space, target-information, and non-target information) as sharing a global achromatic value. The nature of this value warrants considerations of further research into IDT designing principles.

Much research has supported chromatic visual environments as aiding in locating specific visual objects and in grouping visual information (Barker \& Krebs, 1977; Galotti, 2004). In contrast the achromatic visual information effect essentially removes the positive properties of 
information filtering chromatic environments provide. In the achromatic visual information environment the learner is faced with visual information that has no immediate distinct visual features to distinguish it as either target information or as non-target information.

Why did the black and white condition not have the same achromatic visual information effect as the black and white bar environment? There is no explicit clear answer. There are two main considerations.

First, the research findings for color conditions revealed the accuracy scores in the black and white conditions and the color bars conditions were significantly higher than the accuracy scores in the black and white bars conditions. The target and non-target visual information displayed in the black and white environment was localized to a 3 x 3 grid though, and minimized visual distraction information to the center block. Saccades or covert eye movement may have been limited because the non-target visual information display was consistent in image instance (e.g., frog) and location (i.e., center block). The addition of the random black and white bars in the black and white bars environment created a visual non-target information environment that was: not localized to the 3 x 3 grid and was not consistent as a single instance of an image. The black and whites bars environment essentially broadened the visual field of distracter information, potentially resulting in higher instances of saccades, and less focused attention on target information.

The achromatic bars additionally shared chromaticity values with the target visual information, presenting a conflict between visual non-target and target information. The achromatic visual information effect disabled immediate visual information features that provide for information filtering. In contrast, the color bars environment did not exhibit the same effect. 
The color bars environment provided an immediate visual information descriptor that enabled visual information to be immediately focused on or immediately disregarded. Even though color bars were dynamic and random, they were immediately disposable in the visual environment, perhaps because the properties of their chromaticity were immediately distinguishable from the chromaticity properties of the target visual information. I am naming the achromatic visual information effect as a potential aspect of a Minimal Differential Content Theory, which contends non-target information with little characteristic difference from target information impedes attention to target information, increases extraneous cognitive load, and lowers germane cognitive load. The idea of a Minimal Differential Content Theory will be discussed more in suggestions for further research.

Second, although the findings suggest there was no main effect in the black and white environment to report, it is important to reconsider the findings of the STM conditions mentioned above. The STM conditions by nature of the experimental design were conducted in an achromatic visual environment. It was previously mentioned that the STM conditions findings of the current study were considerably different from the Lorsbach and Reimer (2005) findings also. The current study reports the STM conditions findings revealed the combination (i.e., visual STM store and visual spatial/motion STM combined) learning tasks were most difficult in contrast to visual STM store or visual spatial/motion STM tasks in isolation. Reviewing the findings, the post hoc Bonferroni adjustment for multiple comparisons also revealed a significant main effect $(p<.01)$ indicating a difference between STM image condition and STM location condition. Therefore, the STM image condition was also significantly lower than the STM location condition (i.e., spatial/motion). What does this mean? It may mean the previously described achromatic visual information effect was also present in the black and white 
environment. Although distracter visual information was limited to the $3 \times 3$ grid, the distracter information may have been impacting accuracy scores in the image STM condition and the combination STM condition.

Interestingly, the STM conditions findings support previous dual task/double dissociations research. If we consider the distracter information was always an image in STM condition environments it explains why image only conditions (i.e., image and combination) were negatively impacted and why location conditions were not negatively impacted. Recall, in the dual task/double dissociations research, image distracter information interfered with image target information; spatial distracter information interfered with spatial target information; however, distracter image information did not interfere with target spatial information, and distracter spatial information did not interfere with target image information.

These additional latter considerations support the strategic and consistent use of color in visual information environments to distinguish target and non-target information presentations. Also supported in these additional considerations is the use of specific target visual information (i.e., image) that is not conflicted with by non-target visual information sharing similar visual characteristics (i.e., non-target image).

\section{STM Conditions*Animation Conditions}

The STM conditions*animation conditions revealed the combination of complex visual learning tasks (i.e., visual STM combination environment) when combined with non-target animated visual distracter information impeded participant accuracy scores. The animations in the current experimental design were only used as distracter information though, and therefore their utility as target information is unknown. Further the animations were 2 dimensional 
redundant-pattern animations and not complex visual information. While Dwyer and Dwyer (2003) suggest the use of animation for instructional purposes is not conclusive, Mayer and Moreno (2002) suggest complex animations in proper contexts can be beneficial to CAI if designed properly. Mayer and Moreno (2002) derived seven principles to guide the use of target information animation. These principles include: the multimedia principle (explicit instructional content utilizing both animation and complimenting verbal information), the modality principle (visual dynamic information is complemented better by audio narration than by written text), the temporal contiguity principle (presenting visual and verbal information simultaneously), and the spatial contiguity principle (presentations of complimenting verbal information should appear near animations). All of the principles Mayer and Moreno (2002) provide point to the balancing of target visual information with target verbal information appropriately to minimize intrinsic and extraneous CL and to maximize germane CL.

\section{Significance of Findings Considerations}

It is important to understand that while the findings of the current research study are statistically significant the real numbers they represent are very minimal. Statistically significant differences in participant accuracy scores across conditions were all differences of a few percentage points and all greater than 90 percent (Figs. 34, 35, and 36). Therefore, it is difficult to solidly support formation of IDT principles for CAI environmental development, and any IDT design considerations are made with caution. In context of the previous research literature there are several considerations suggesting these findings may warrant further explorations. These include the findings impact on dual coding theory, MLT, and the potential impact on children as participants. These will be discussed in detail in the following Suggestions for Further Research section. Also important to understand about these minimal findings is the length at which they 
were attained. Each participant was subjected to 432 total questions over approximately 140 minutes of study time. One may argue that fatigue was the cause of the minimal variation, and not visual STM processing complications derived of non-target visual information. This is a very good argument and deserves attention in further research,

Important to reiterate at this time, these findings were derived from a study on visual STM. This was a focused research design that did not comprehensively consider implications for other cognitive models of memory. Visual STM is not a whole memory system model. However, it is important to understand how the visual STM component of a whole model system interacts with other components. It is easily argued the slight variations reported by these findings were derived from some memory component other than the visual STM system.

\section{IDT Design Considerations}

\section{The Achromatic Visual Information Effect}

The first cautious design consideration for informing IDT based on the research findings are those derived of the achromatic visual information effect. What does this mean for IDT development of visual information for computer-learning environments? In a general sense of effective visual information for computer-learning environments (i.e., visual STM of objects, space, and combination), designing visual information utilizing distinguishing chromatic contexts is supported. Information that is not chromatic may be difficult to process immediately in visual STM when it consists of both target and non-target information. This statement is made partially based on the findings of Lorsbach and Reimer (2005) who reported no significant differences and high rates of accuracy among STM conditions for adult participants. Based on Lorsbach and Reimer (2005), achromatic visual information is not problematic for visual STM 
learning tasks if all the visual field information is target information. However, the present study findings suggest an introduction of non-target achromatic visual information among achromatic target visual information causes a slight statistically significant variation for visual STM learning processes. Therefore as previously mentioned, based on these findings, it is difficult to justify specific IDT color parameters that facilitate visual STM learning tasks and impede visual STM learning tasks because the variation is very minimal.

\section{Chromatic Visual Information}

Chromatic visual information environments enable immediate visual references for organizing visual information as attention focusing information and as visual information to be displaced (i.e., disregarded for task). Therefore, it can be suggested to use color strategically and consistently to organize visual information appropriately. Consistency is considered here because non-consistent color information use may arguably also disable the positive properties of information filtering chromatic environments can provide. This will be discussed more in suggestions for future research.

\section{Target Visual Information Conflicts}

The experimental design of the current research study explicitly considered the limitations of a dual task/double dissociations research design in terms of information presentation that remains consistent with real-world computer-learning environment information presentations. Even though this consideration was made, similar findings emerged consistent with dual task/double dissociations research. While dual task/double dissociations research present interference information during a distracter task following the primary-learning task (Fig. 8), the present experimental design presented interference information during the primary- 
learning task. The current research found distracter visual STM-image information interferes with target visual STM-image information, supporting double dissociations findings (Hecker \& Mapperson, 1997; Klauer \& Zhao, 2004). However, the spatial information subsystem of visual STM was not informed in the current research design. These findings suggest non-target visual STM-image information interferes with target visual STM-image information. Therefore, limiting image presentations in the visual information field to target image information only can also be suggested.

\section{Animation Use}

As mentioned, the STM*animation conditions revealed the combination of complex visual learning tasks (i.e., visual STM combination condition) when combined with non-target animated visual distracter information are significantly impeded in terms of accuracy scores. In considerations of these findings it is clear non-target animated visual information somewhat slightly interferes with visual learning tasks, therefore the use of non-target animated visual information can be discouraged. What does this mean for animations used as target visual information in computer learning environments? Animation information has been shown to improve learning of mechanical processes (e.g., machines) and other processes if the learner has background knowledge of the processes under study (Kriz \& Hegarty, 2007; Lowe 2003). Because the current study did not report on animation visual information as target visual information more research would be required to answer that question.

\section{Suggestions for Further Research}

There are many new considerations worth exploring based on the findings of the current research study. Research considerations include the impact on DCT (Paivio, 1971, 1986), MLT 
(Mayer \& Moreno, 1998), single task paradigms, and the potential impact on children as participants.

Dual coding theory (Paivio, 1971, 1986), as previously discussed describes visual and verbal information as independent systems or channels that mentally represent and remember information differently (Paivio, 1986). This approach parallels the phonological loop and visuospatial sketch pad of the WM model of STM proposed by Baddeley and Hitch (1974). Paivio (1986) views the two systems as potentially complementing each other during information processing or conflicting with each other during information processing.

However, the role of DCT within CAI has primarily been limited to research such as that conducted by Mayer and Moreno $(1998,2002)$ within the context of MLT. This research points to balancing target visual information with target verbal information appropriately to minimize intrinsic and extraneous CL and to maximize germane CL.

The current research study has explored the visual STM systems (i.e., image STM store, inner scribe) in a real-world single task paradigm (Fig. 17) that represents a fundamentally different approach to this type of research and research goals. Interestingly the current study's real-world single paradigm supports dual tasks/double dissociations research findings (i.e., nonbalanced visuospatial information impedes visual STM). In considerations of DCT (Paivio, 1971, 1986), and MLT (Mayer \& Moreno, 1998, 2002), research exploring whether balancing appropriate visuospatial information in digital learning environments may also prove beneficial to effective visual learning tasks (Fig. 37). It is therefore suggested, in reference to Mayer and Moreno (2002) who have already shown balancing visual STM and phonological STM information reduced extraneous CL and increases germane CL, that a remaining question for 
further exploration is whether balancing visual STM information also reduces extraneous CL and increases germane CL. A suggested model is to compare visual learning of 2D information (i.e., no spatial information balance) in contrast to 3D information (i.e., spatial information balanced). A suggested directional hypothesis is $3 \mathrm{D}$ visual information will be more beneficial to visual learning than 2D visual information.

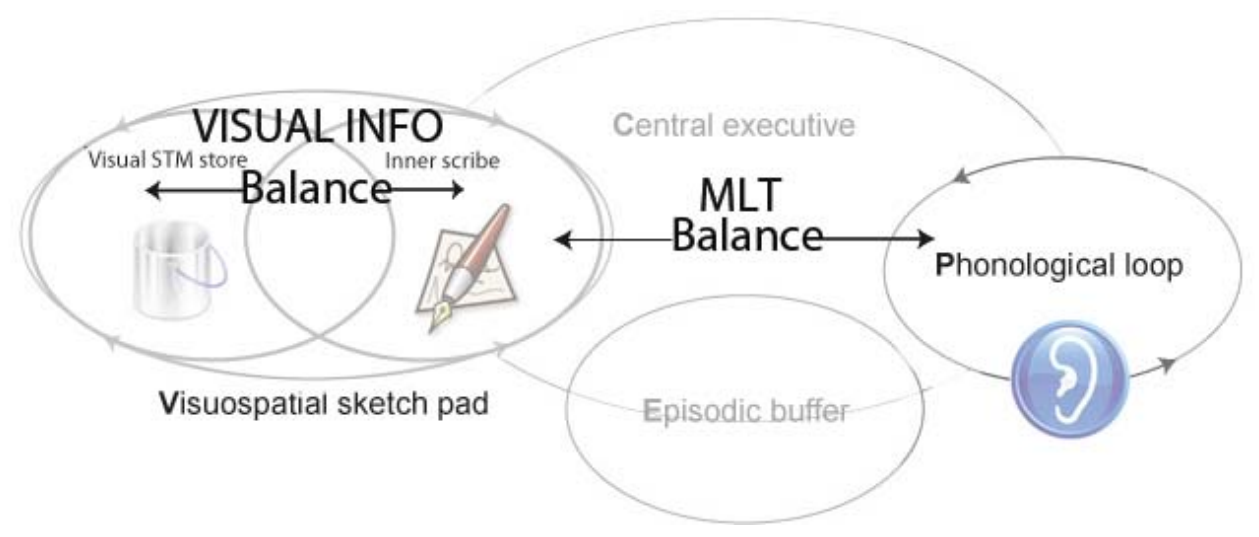

Fig. 37: Visual STM subsystems considering MLT and balancing information delivery for effective STM information processing.

Research that explores the implications for current findings among children is also suggested. This suggestion is based on limitations of the current findings. The current findings are somewhat surprising as Lorsbach and Reimer (2005) did not report significant differences between STM condition learning tasks among adults $(p>.14)$. As previously mentioned, this may be a result of the addition of visual information in the visual learning environment the current study presented that the Lorsbach and Reimer (2005) study did not present. We must also consider further that these significant differences may also be a result of population differences the research has not accounted for. Even though Lorsbach and Reimer (2005) describe their adult participants as college undergraduate students ( $M$ age $=21.11$ years), enough information is not given to fully account for comparing the Lorsbach and Reimer (2005) population with the current research study population. Given this limitation, the Lorsbach and 
Reimer (2005) study also included two groups of children ( $M$ age $=9.24$ years, and $M$ age $=$ 12.07 years). Both groups of children had results with statistically significant differences between STM conditions. While it is difficult to explain why the current study found a minimal significant difference between STM conditions for adults, it is suggested that the minimal current findings may be dramatically different among children. A directional hypothesis is minimal variation found in the current study is amplified among children. Given this assumption, further research in this area is suggested.

Lastly, the current experimental research design utilized minimal verbal information as part of the STM information presentations. It is suggested further research considering the role of verbal information and other aspects of the STM processes during focused STM component studies will provide valuable findings. The current research study considered STM as a system composed of both the visual STM subsystems and auditory (i.e., phonological loop) STM subsystems. Considering the whole STM system when developing control environments may prove a valuable approach to understanding individual components of the STM system, and the STM system as a whole system engaged in information processing.

The integration of verbal information into visual STM research such as this research has done, as a balancing control STM activity is just a beginning though. The current focus has been specifically visual STM information in computer learning environments. Integration of verbal information as target information in a variety of visual layout designs integrating colors and shapes is also an exciting area to consider for further research. The current researcher has planned an experimental design that integrates verbal information as target information within computer learning environment contexts that are laden with colors and animations. 


\section{Conclusion}

The goals of this research were to gain a better understanding of the effects of color and animation on visual STM in computer-environment learning tasks. The research findings were successful in providing information that informs development of computer-learningenvironment-specific ID models stemming from the psychological processes of learning. This research has provided for informing specific psychometric parameters of effective visual instructional content in computer-learning environments. The statistically significant findings reported very minimal variations though. Therefore, more exploration is encouraged.

The largest impacts of this research may be described as successfully approaching the study of visual STM in a real-world single task paradigm. In order to understand how visual STM conditions impact CAI and provide information for IDT models derived from the psychological processes of learning, approaching the study from a fundamental real-world paradigm is seen as crucial. While the statistically significant findings are minimal, they provide for considerations of research explorations beyond the scope of the current study. Most notable are explorations of balancing visuospatial information in CAI environments to minimize intrinsic and extraneous CL and maximize germane CL, and explorations that learn how visual learning among children is impacted by the current findings.

This research has only begun to scratch the surface of the properties of visual STM derived of computer learning environments. While minimal findings are encouraging, the research was successful in additionally stating a case that may have been previously trivial to IDT development of computer learning environments. Specifically, colors, space, and objects in computer learning environments do impact learning experiences. It is clear considerations of 
these visual elements are beneficial to IDT and development of effective computer learning environments. 


\section{References}

Abutarbush, S.M., Naylor, J.M., Parchoma, G., D’Eon, M., Petrie, L., \& Carruthers, T. (2006). Evaluation of traditional instruction versus a self-learning computer module in teaching veterinary students how to pass a nasogastric tube in the horse. Journal of Veterinary Medical Education, 33(3), 447-454.

Adobe Flash (2009). (Version 8.0) [Computer software]. NY: Adobe Systems Incorporated.

Allen, I.E., \& Seaman, J. (2008). Staying the course: Online education in the United States, 2008. Needham, MA: Sloan Consortium. Retrieved May 15, 2009, from http://www.sloanconsortium.org/publications/survey/pdf/staying_the_course.pdf

Ally, M. (2004). Foundations of educational theory for online learning. In T., Anderson, \& E. Fathi (Eds.), Theory and practice of online learning (Chap.1). Athabasca, Alberta, Canada: Athabasca University. Retrieved May 15, 2009, from http://cde.athabascau.ca/online_book/ch1.html.

Anderson, J.R., \& Bower, G.H. (1973). Human associative memory. Washington, DC: Winston.

Atkinson, R.C., \& Shiffrin, R.M. (1968). Human memory: A proposed system and its control processes. In K.W. Spence \& J.T. Spence (Eds.), The psychology of learning and motivation: Advances in research and theory (Vol. 2). New York: Academic Press.

Baddeley, A.D. (1990). The development of the concept of working memory: Implications and contributions of neuropsychology. In G. Vallar \& T. Shallice (Eds.), Neuropsychological Impairments of Short-Term Memory (pp. 54-73). Cambridge: Cambridge University Press.

Baddeley, A.D. (1992). Working memory. Oxford: Oxford University Press. 
Baddeley, A.D. (2000). The episodic buffer: a new component of working memory? Trends in Cognitive Science, 4, 417-423.

Baddeley, A.D. (2003). Double dissociations: Not magic, but still useful. Cortex, 39, 129-131.

Baddeley, A.D., \& Andrade, J. (2000). Working memory and the vividness of visual imagery. Journal of experimental psychology: General, 129, 126-145.

Baddeley, A.D., \& Hitch, G.J. (1974), Working Memory. In G.A. Bower (Ed.), The psychology of learning and motivation: advances in research and theory (pp. 47-89). New York: Academic Press.

Barker, E., \& Krebs, M.J. (1977). Color coding effects on human performance: An annotated bibliography. Springfield, VA: National Technical Information Service. (DTIC No. ADA039318).

Basile, A., \& D’Aquila, J.M., (2002). An experimental analysis of computer-mediated instruction and student attitudes in a principles of financing course. Journal of Education for Business, 137-143.

Becker, M.W., Pashler, H., \& Lubin, J. (2007). Object-intrinsic oddities draw early saccades. Journal of Experimental Psychology: Human Perception and Performance, 33(1), 20-30.

Bersin \& Associates. (2009). Top trends in e-learning and corporate training. Retrieved May 15, 2009, from http://www.hrmreport.com/article/Issue-5/Executive-Education/Top-trendsin-e-learning-and-corporate-training/

Brünken, R., Plass, J.L., \& Leutner, D. (2003). Direct measurement of cognitive load in multimedia learning. Educational Psychologist, 38, 53-61. 
Caldwell, E.C. (1985). Dangers of PSI. Teaching of Psychology, 12(1), 9-12.

Caldwell, E.C., Bissonnettee, K., Klishis, M.J., Ripley, M., Farudi, P.P., Hochstetter, et al. (1978). Mastery: The Essential essential in PSI. Teaching of Psychology, 5(2), 59-65.

Catani, M.B., \& Biers, D.W. (1998). Usability evaluation and prototype fidelity: Users and usability professionals. Proceedings of the Human Factors and Ergonomics Society 42nd Annual Meeting, (pp. 1331-1335). Santa Monica, CA: HFES.

Center for Curriculum Transfer and Technology, (2000). Online educational delivery applications: A web tool for comparative analysis. Retrieved May 15, 2009, from http://www.edutools.info/course

Chandler, P., \& Sweller, J. (1991). Cognitive load theory and the format of instruction. Cognition and Instruction, 8(4), 293-332.

Chandler, P., \& Sweller, J. (1992). The split-attention effect as a factor in the design of instruction. British Journal of Educational Psychology, 62, 233-246.

Christ, R.E. (1975). Review and analysis of color coding research for visual displays. Human Factors, 17(6), 542-570.

Clark, R.C., \& Lyons, C. (1999). Using Web-based training wisely. Training, 36(7), 51-56.

Cooper, G. (1998). Research into Cognitive Load Theory and Instructional Design at UNSW. Sydney, Australia: University of New South Wales (UNSW). Retrieved May 15, 2009, from http://education.arts.unsw.edu.au/staff/sweller/clt/index.html

Dabbage, N., \& Bannan-Ritland, B. (2005). Online learning: Concepts, strategies, and applications. Upper Saddle River, NJ: Pearson. 
Derry, J. (2007). Epistemology and conceptual resources for the development of learning technologies. Journal of Computer Assisted Learning, 23, 503-510

Dwyer, F., \& Dwyer, C. (2003). A Systematic Assessment of the Contributions of Animation to Knowledge Acquisition. In D. Lassner \& C. McNaught (Eds.), Proceedings of World Conference on Educational Multimedia, Hypermedia and Telecommunications 2003 (pp. 1112-1117). Chesapeake, VA: AACE.

Edmundson, A. (Ed.). (2007). Globalized e-learning cultural challenges. Hershey: Idea Group Inc.

Estes. W.K. (1972). Interactions of signal and background variables in visual processing. Perception and Psychophysics, 12(3), 278-286.

Estes, W.K., \& Taylor, H.A. (1964). A detection method and probabilistic models for asses- sing information processing from brief visual displays. Proceedings of the National Academy of Sciences, 52, 446-454.

Estes, W.K., \& Taylor, H.A. (1966). Visual detection in relation to display size and redundancy of critical elements. Perception and Psychophysics, 1, 9-16.

Folk, C.L., Remington, R.W., \& Johnston, J.C. (1992). Involuntary covert orienting is contingent on attentional control settings. Journal of Experimental Psychology: Human Perception and Performance, 18(4), 1030-1044.

Fritz, M. (2006). Get enriched quick: The rise of rapid elearning. EContent, 29(4), 38-43.

Frommann, U., \& Phan Tan, T.T. (2005). On the didactical potential of e-learning courseware. In G. König, H. Lehmann, \& R. Köhring (Eds.), Proceedings of the International Society of 
Photogrammetry and Remote Sensing: Vol. 36. Tools and techniques for e-learning. Potsdam, Germany: Institute of Geodesy and Geoinformation Science.

Galizt, W.O. (2007). The essential guide to user interface design: An introduction to GUI design principles and techniques ( $3^{\text {rd }}$ ed.). Indianapolis, IN: Wiley Publishing.

Galotti, K.M. (2004). Cognitive psychology: In and out of the laboratory ( $3^{\text {rd }}$ ed.). Belmont, CA: Wadsworth/Thompson.

George, C.A. (2005). Usability testing and design of a library website: An iterative approach. OCLC Systems \& Services, 21(3), 167-180.

Harasim, L., Hiltz, S.R., Teles, L., \& Turoff, M. (2001). Learning networks: A field guide to teaching and learning online. Cambridge, MA: MIT Press.

Hecker, R., \& Mapperson, B. (1997). Dissociation of visual and spatial processing in working memory. Neuropsychologia, 35(5), 599-603.

Herrot, A.M., Bishop, J.A., \& Truby, H. (2004). The development and evaluation of student training, education and practice of dietetics CD-ROM: A computer-assisted instruction programme for dietetic students. The British Dietetic Association: Journal of Human Nutrition and Dietetics, 17, 35-41.

Horowitz, T.S., \& Wolfe, J.M. (2001). Search for multiple targets: Remember the targets, forget the search. Perception and Psychophysics, 63(2), 272-285.

Horton, S. (2000). Web teaching guide: A practical approach to creating course websites. London: Yale University Press. 
Howarth, J., Andre, T., \& Hartson, R. (2007). A structured process for transforming usability data into usability information. Journal of Usability Studies, 3(1), 7-23.

Huang, L., \& Pashler, H. (2005a). Expectation and repetition effects in searching for featural singletons in very brief displays. Perception \& Psychophysics, 67(1), 150-57.

Huang, L., \& Pashler, H. (2005b). Quantifying object salience by equating distractor effects. Visual Research, 45, 1909-1920.

Huang, L., \& Pashler, H. (2007). A Boolean map theory of visual attention. Psychological Review, 114(3), 599-631.

Huang, L., Pashler, H., \& Junge, J.A. (2004). Are there capacity limitations in symmetry capacity? Psychonomic Bulletin \& Review, 11(5), 862-869.

Huang, L., Treisman, A., \& Pashler, H. (2007). Characterizing the limits of human visual awareness. Science, 317, 823-825.

Huitt, W. (2003). The information processing approach to cognition. Educational Psychology Interactive. Valdosta, GA: Valdosta State University. Retrieved May 15, 2009, from http://chiron.valdosta.edu/whuitt/col/cogsys/infoproc.html

Jacoby, C.G., Smith, W.L., \& Albanese, M.A. (1984). An evaluation of computer-assisted instruction in radiology. American Journal of Radiology, 143, 675-677.

Kantowitz, B.H., \& Roediger, H.L. (1980). Memory and information processing. In G. M. Gazda \& R. J. Corsini (Eds.), Theories of Memory: A Comparative Approach. Itasca, IL: F. E. Peacock Publishers, Inc. 
Kim, H., \& Yoon, W.C. (2005). Supporting the cognitive process of user interface design with reusable design cases. International Journal of Human-Computer Studies, 62, 457-486.

Kirschner, P.A. (2002). Cognitive load theory: Implications of cognitive load on the design of learning. Learning and Instruction, 12, 1-10.

Klauer, K.C., \& Zhao, Z. (2004). Double dissociations in visual and spatial short-term memory. Journal of Experimental Psychology: General, 133(3), 355-381.

Kriz, S., \& Hegarty, M. (2007). Top-down and bottom-up influences on learning from animations. International Journal of Human-Computer Studies, 65, 911-930.

Lauer, D.A., \& Pentak, S. (2005). Design basics. Boston, MA: Wadsworth/Thompson.

Lerdorf, R. (1995). Php (Version 4.0) [Computer software]. http://www.php.net/contact.php: The PHP Group.

Linn, R.L., \& Miller, M.D. (2005). Measurement and assessment in teaching ( $9^{\text {th }}$ ed.). Upper Saddle River, NJ: Pearson Prentice Hall.

Logie, R.H. (1995). Visuo-spatial working memory. Hove, UK: Lawrence Eribaum Associates.

Logie, R.H., \& Marchetti, C. (1991). Visuo-spatial working memory: Visual, spatial or central executive? In R.H. Logie, \& M. Denis (Eds.), Mental images in human cognition (pp. 105-115). Amsterdam: North-Holland.

Logie, R.H., \& Pearson, D.G. (1997). The inner eye and the inner scribe of visuo-spatial working memory: Evidence from developmental fractionation. European Journal of Cognitive Psychology, 9(3), 241-257. 
Lorsbach, T.C, \& Reimer, J.F. (2005). Feature binding in children and young adults. The Journal of Genetic Psychology, 166(3), 313-327.

Lowe, R.K. (2003). Animation and learning: Selective processing of information in dynamic graphics. Learning and Instruction, 13, 157-176.

Lynch, P.J., \& Horton, S. (2008). Web Style Guide: Basic Design Principles for Creating Web Sites ( $3^{\text {rd }}$ ed.). Retrieved May 15, 2009, from http://www.webstyleguide.com/index.html

Maddox, W.T., \& Estes, W.K. (1997). Direct and indirect stimulus-frequency effects in recognition. Journal of Experimental Psychology: Learning, memory, and cognition, 23(3), 539-559.

Marx, A.N. (1994). Using metaphor effectively in user interface design. Human Factors and Computer Systems. Conference (4th. 1994), Conference companion on Human factors in computing systems (pp. 379-380). New York: ACM Press.

Maughan, G.R. (Ed.). (2001). Technology leadership: Communication and information systems in higher education. San Francisco, CA: Jossey-Bass.

Mayer, R.E. (2001). Multimedia learning. New York: Cambridge University Press.

Mayer, R.E. (2003). The promise of multimedia learning: Using the same instructional design methods across different media. Learning and Instruction, 13(2), 125-139.

Mayer, R.E., \& Moreno, R. (1998). A split-attention effect in multimedia learning: Evidence for dual processing systems in working memory. Journal of Educational Psychology, 90, $312-320$. 
Mayer, R.E., \& Moreno, R. (2002). Aids to computer-based multimedia learning. Learning and Instruction, 12(1), 107-119.

Mayer, R.E., \& Moreno, R. (2003). Nine ways to reduce cognitive load in multimedia learning. Educational Psychologist, 38(1), 43-52.

McGovern Institute for Brain Research. (2007). First impressions: Computer model behaves like humans on visual categorization task. Retrieved May 15, 2009, from http://web.mit.edu/mcgovern/html/News_and_Publications/0703_poggio.shtml

Mehlenbacher, B., Bennett, L., Bird, T., Ivey, M., Lucas, J. Morton, J., et al. (2005). Usable elearning: A conceptual model for evaluation and design. Proceedings of HCI International 2005: 11th International Conference on Human-Computer Interaction, Vol. 4. Theories, Models, and Processes in HCI. Las Vegas, NV: Mira Digital, 1-10.

Meyer, K., Rasch, T., \& Schnotz, W. (2009). Effects of animation's speed of presentation on perceptual processing and learning. Learning and Instruction, 20, 1-10.

Microsoft Office Excel (2006). (Version 12.0) [Computer software]. Redmond, WA: Microsoft Corporation.

Miller, G.A. (1956). The magical number seven. The Psychological Review, 63, 81-97.

Minoli, D. (1996). Distance learning technology and applications. Boston: Artech House.

Moreno, R. (2006). Does the modality principle hold for different media? A test of the method affects learning hypothesis. Journal of Computer Assisted Learning, 22(3), 149-158. 
Moreno, R., \& Mayer, R.E. (n.d). A learner-centered approach to multimedia explanations: Deriving instructional design principles from cognitive theory. Interactive Multimedia Electronic Journal of Computer-Enhanced Learning. Retrieved May 15, 2009, from http://imej.wfu.edu/articles/2000/2/05/index.asp\#6

Moreno, R. \& Mayer, R.E., (1999). Visual presentations in multimedia learning: Conditions that overload visual working memory. In D.P. Huijsmans, \& A.W.M. Smeulders (Eds.), Lecture Notes in Computer Science: Visual Information and Information Systems (pp. 793-800). Berlin: Springer Verlag.

Moreno, R. \& Mayer, R.E. (2002). Learning science in virtual reality multimedia environments: Role of methods and media. Journal of Educational Psychology, 94, 598-610.

Morrison, G.R., Ross, S.M., \& Kemp, J.E. (2004). Designing effective instruction. Hoboken, NJ: John Wiley \& Sons, Inc.

Mousavi, S., Low, R., \& Sweller, J. (1995). Reducing cognitive load by mixing auditory and visual presentation modes. Journal of Educational Psychology, 87(2), 319-334.

Mullen, E.M., \& Love, R.L. (1980). An evaluation of the use of mini-computers for computer assisted instruction in allied health curricula. Journal of Allied Health, 9(1), 33-40.

Nie. N. (1968). Statistical Package for Social Sciences (SPSS) (Version 17.0) [Computer software]. Armonk, NY: International Business Machines Corporation - IBM.

Nielsen, J., \& Loranger, H. (2006). Prioritizing web usability. Berkeley, CA: New riders.

Norman, D. (2002). The design of everyday things. New York: Basic Books. 
Olsen, L., \& Di Fazio, R. (1983). The shoemaker’s children: How Digital uses interactive video to train computer technicians. Training \& Development Journal, 37(12), 32-34.

Oosterhof, A., Conrad, R-M., \& Ely, D.P. (2008). Assessing learners online. Upper Saddle River, NJ: Pearson Prentice Hall.

O’Shea, G., \& Clegg, B.A. (2006). Stimulus and response chunking in the Hebb digits task. Psychological Research, 70, 180-192.

Paas, F. (1992). Training strategies for attaining transfer of problem-solving skill in statistics: A cognitive-load approach. Journal of Educational Psychology, 84, 429-434.

Paas, F, Renkl, A., \& Sweller, J. (2003). Cognitive load theory and instructional design: Recent developments. Educational Psychologist, 38(1), 1-4.

Paivio, A. (1969). Mental Imagery in associative learning and memory. Psychological Review, 76(3), 241-263.

Paivio, A. (1971). Imagery and verbal processes. New York: Holt, Rinehart \& Winston.

Paivio, A. (1986). Mental representations: a dual coding approach. Oxford, England: Oxford University Press.

Palmer, J. (1990). Attentional limits on the perception and memory of visual information. Journal of Experimental Psychology, 16(2), 332-350.

Pashler, H. (1984). Evidence against late selection: Stimulus quality effects in previewed displays. Journal of Experimental Psychology, Human Perception and Performance, 10(1), 429-448. 
Pashler, H. (1988). Familiarity and visual change detection. Perception and Psychophysics, 44(4), 369-378.

Pashler, H. (1995). Attention and Visual Perception: Analyzing Divided Attention. Retrieved May 15, 2009, from http://www.pashler.com/Articles/Pashler_AttnVisPerception1995.pdf

Pashler, H. (2001). Involuntary orienting to flashing distractors in delayed search? In C.L. Folk, \& B. Gibson (Eds.), Attraction, Distraction, and Action: Multiple Perspectives on Attentional Capture. Advances in psychology. Elsevier Science.

Pashler, H., Carrier, M., \& Hoffman, J. (1993). Saccadic eye movements and dual-task interference. The Quarterly Journal of Experimental Psychology, 46A(1), 51-82.

Pashler, H., \& Harris, C. (2001). Spontaneous allocation of visual attention: Dominant role of uniqueness. Psychometric Bulletin \& Review, 8(4), 747-752.

Paperny, D.M., \& Starn, J.R. (1989). Adolescent pregnancy prevention \& health education computer games: Computer-assisted instruction of knowledge and attitudes. Pediatrics, 83(5), 742-752.

Peterson, L.R., \& Peterson, M.J. (1959). Short-term retention of individual verbal items. Journal of Experimental Psychology, 58, 193-198.

Picciano, A.G., \& Seaman, J. (2009). K-12 online learning: A follow-up of the survey of U.S. school district administrators. Newburyport, MA: The Sloan Consortium. Retrieved May 15, 2009, from http://www.sloan-c.org/publications/survey/pdf/k12_online_learning_2008.pdf 
Picciano, A.G. (2002). Beyond Student Perceptions: Issues of Interaction, Presence, and Performance in an Online Course. Journal for Asynchronous Learning Networks, 6(1), 21-40.

Põder, E. (2004). Role of attention in visual information processing. (Doctorial dissertation, Tallinn Pedagogical University, 2004). Trükitud: OÜ VALI PRESS.

Pollock, E., Chandler, P., \& Sweller, J. (2002). Assimilating complex information. Learning and Instruction, 12, 61-86.

Predavec, M. (2001). Evaluation of e-rat, a computer-based rat dissection, in terms of student learning outcomes. Journal of Biological Education, 35(2), 75-80.

Reimann, P. (2003). Multimedia learning: beyond modality. Learning and Instruction, 13, 245252.

Reiser, R.A., \& Dempsey, J.V. (2002). Trends and issues in instructional design and technology. Upper Saddle River, NJ: Pearson Merrill Prentice Hall.

Reiser, R., \& Gagne, R. (1983). Selecting media for instruction. Englewood Cliffs, NJ: Educational Technology Publications.

Richey, R.C., \& Klein, J.D. (2007). Design and development research. Mahwah, NJ: Lawrence Erlbaum Associates, Publishers.

Roblyer, M.D. (2004). Integrating educational technology into teaching ( $3^{\text {rd }}$ ed.). Upper Saddle River, NJ: Pearson Merrill Prentice Hall. 
Ruchkin, D.S., Grafman, J., Cameron, K., \& Berndt, R.S. (2003). Working memory retention systems: A state of activated long-term memory. Behavioral and Brain Sciences, 26, 709777.

Säde, S., Nieminen, M., \& Riihiaho, S. (1998). Testing usability with 3D paper prototypesCase Halton system. Applied Ergonomics, 29(1), 67-73.

Saettler, P. (Ed.). (2000). The evolution of American educational technology. Charlotte, NC: Information Age Publishing.

Sangster, A. (1992). Computer-based instruction in accounting education. Accounting Education, 1(1), 13-32.

Schnotza, W., \& Loweb, R. (2003). External and internal representations in multimedia learning. Learning and Instruction, 13, 117-123.

Shiffrin, R.M., \& Atkinson, R.C. (1969). Storage and retrieval processes in long-term memory. Psychological Review, 76(2), 179-193.

Shelton, K. \& Saltsman, G. (2005). An administrator's guide to online education. Greenwich, CT: Information Age.

Shiu, L-P., \& Pashler, H. (1995). Spatial attention and vernier acuity. Vision Research, 35(3), 337-343.

Skinner, B.F. (1954). The science of learning and the art of teaching. Harvard Educational Review, 24(2), 86-97. 
Smith, S. L. (1962). Color coding and visual search. Journal of Experimental Psychology, 64(5), 434-440.

Snyder, C. (2003). Paper prototyping. San Francisco, CA: Morgan Kaufmann Publishers.

Sperling, G., Budiansky, J., Spivak, J. G., \& Johnson, M. (1971). Extremely rapid visual search: The maximum rate of scanning letters for presence of a numeral. Science, 174, 307-311.

Spool, J.M., Scanlon, T., Schroeder, W., Snyder, C., \& DeAngelo, T. (1999). Web site usability: A Designer's guide. San Francisco, CA: Morgan Kaufmann Publishers.

Steel, D.F., Johnson Palensky, J.E., Lynch, T.G., Lacey, N.L., \& Duffy, S.W. (2002). Learning preferences, computer attitudes, and student evaluation of computerized instruction. Medical Education, 36, 225-232.

Stroop, J.R. (1935) Studies of interference in serial verbal reactions. Journal of Experimental Psychology, 18, 643-662.

Sweller, J. (1988). Cognitive load during problem solving: Effects on learning. Cognitive Science, 12(2), 257-285.

Sweller, J. (1994). Cognitive Load Theory, learning difficulty, and instructional design. Learning and Instruction, 4, 295-312.

Sweller, J. (1998). Can we measure working memory without contamination from knowledge held in long-term memory? Behavioral and Brain Sciences, 21, 845-846.

Sweller, J. (1999). Instructional Design in Technical Areas. ACER:Melbourne. 
Sweller, J. (2003). Evolution of human cognitive architecture. In B. Ross (Ed.), The Psychology of Learning and Motivation (Vol. 43, pp. 215-266). San Diego: Academic Press.

Sweller, J. (2006). The worked example effect and human cognition. Learning and Instruction, 16(2) 165-169.

Sweller, J., Van Merriënboer, J., \& Paas, F. (1998). Cognitive architecture and instructional design. Educational Psychology Review, 10, 251-296.

Tomei, L.A. (2002). The technology façade. Boston: Allyn and Bacon.

Van Dusen, G.C. (2000). Digital dilemma. San Francisco, CA: Jossey-Bass.

Uceta, F.A., Dixon, M.A., \& Resnick, M.L. (1998). Adding interactivity to paper prototypes. Proceedings of the Human Factors and Ergonomics Society $42^{\text {nd }}$ Annual Meeting. Chicago, IL: HFES, 506-510.

Vatrapu, R., \& Pérez-Quinoñes, M.A. (2006). Culture and usability evaluation: The effects of culture in structured interviews. Journal of Usability Studies, 1(4), 156-170.

Walls, R. T. (1999). Psychological foundations of learning. (Available from Doctor Richard T. Walls, Department of Educational Psychology, West Virginia University, 806E Allen Hall, PO Box 6122, Morgantown, WV 26506).

Walls, R. T. (2004). Memory: Notes and notations. (Available from Doctor Richard T. Walls, Department of Educational Psychology, West Virginia University, 806E Allen Hall, PO Box 6122, Morgantown, WV 26506). 
Widenius, M., \& Axmark, D. (1995). MySQL (Version 4.0) [Computer software]. Santa Clara, CA: MySQL AB Company.

Wilson, B.G. (2004). Designing E-Learning Environments for Flexible Activity and Instruction. Educational Technology Research \& Development, 52(4), 77-84.

The Wired Campus - The Chronicle of Higher Education. NYU establishes a center for videogame design and research. (December 15, 2008). Retrieved May 15, 2009, from http://chronicle.com/wiredcampus/

Worchel, S., \& Shebilske, W. (1995). Psychology: Principles and applications. Englewood Cliffs, NJ: Prentice Hall. 


\section{APPENDIX}

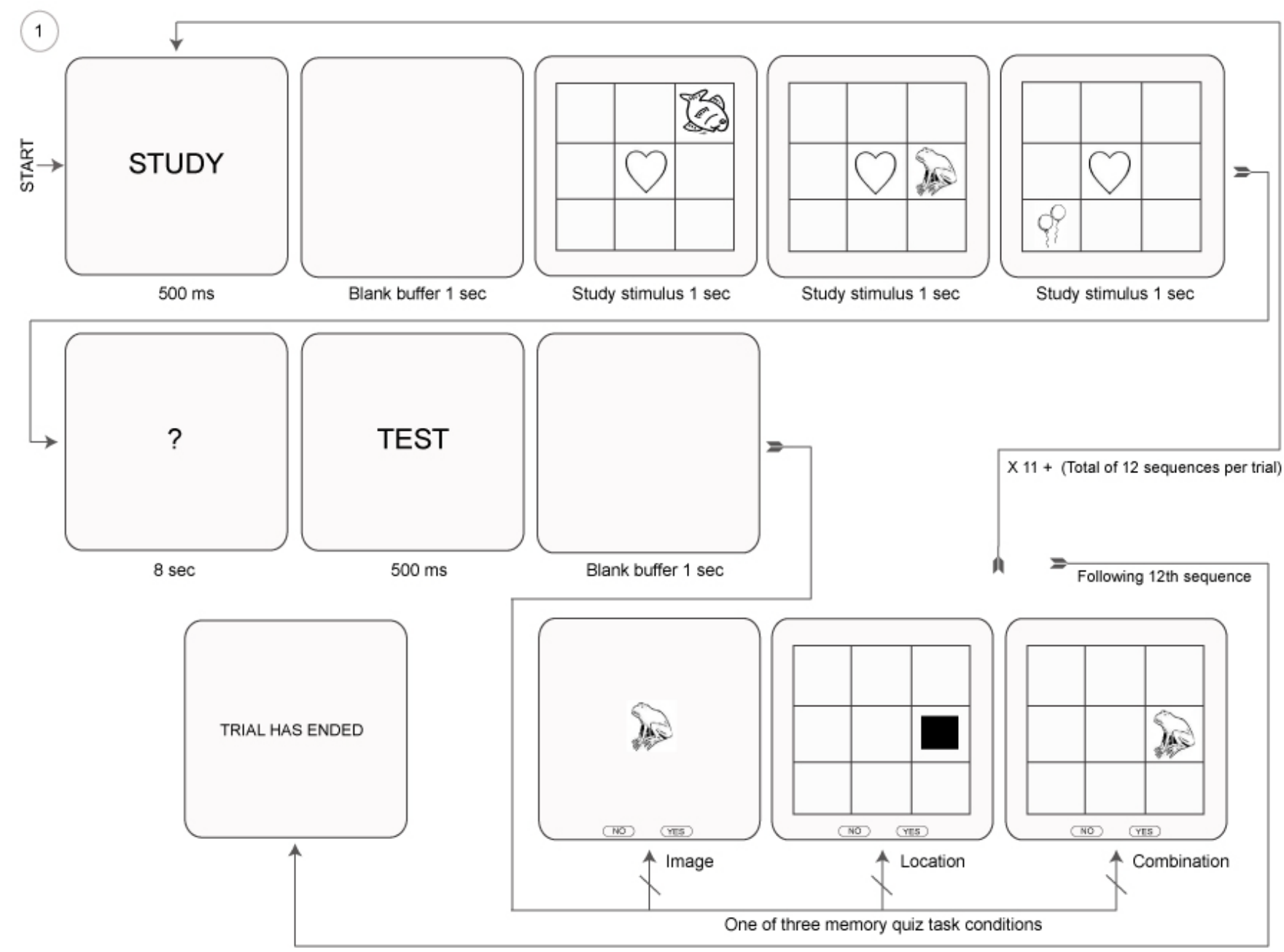

Fig. 23: Stimulus condition one (Black and white, no bars, no animation). Note: Static non-target image in center block does not change during study stimulus presentations. 


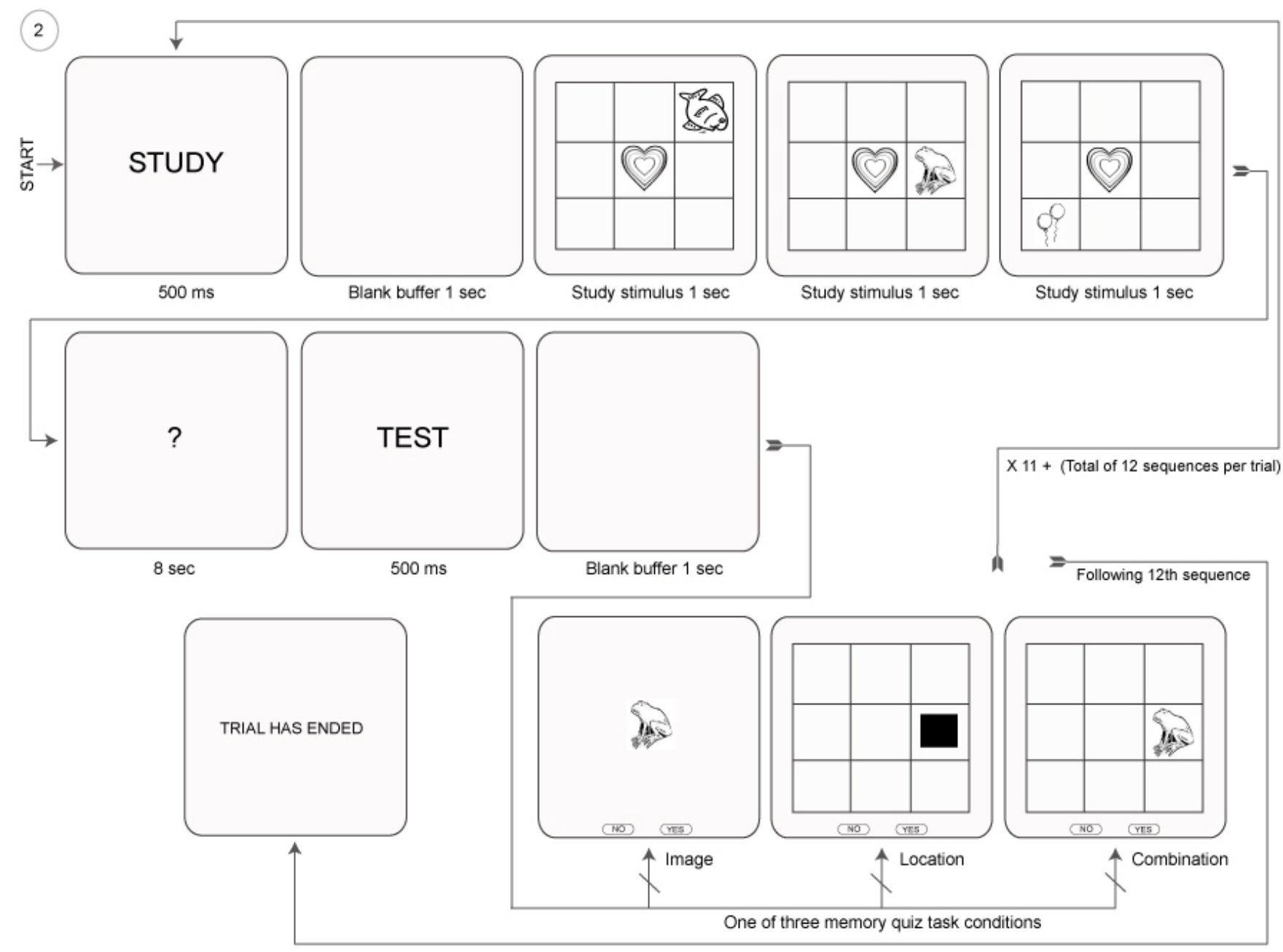

Fig. 24: Stimulus condition two (Black and white, no bars, animation). Note: Animated non-target image in center block does not change during study stimulus presentations. 


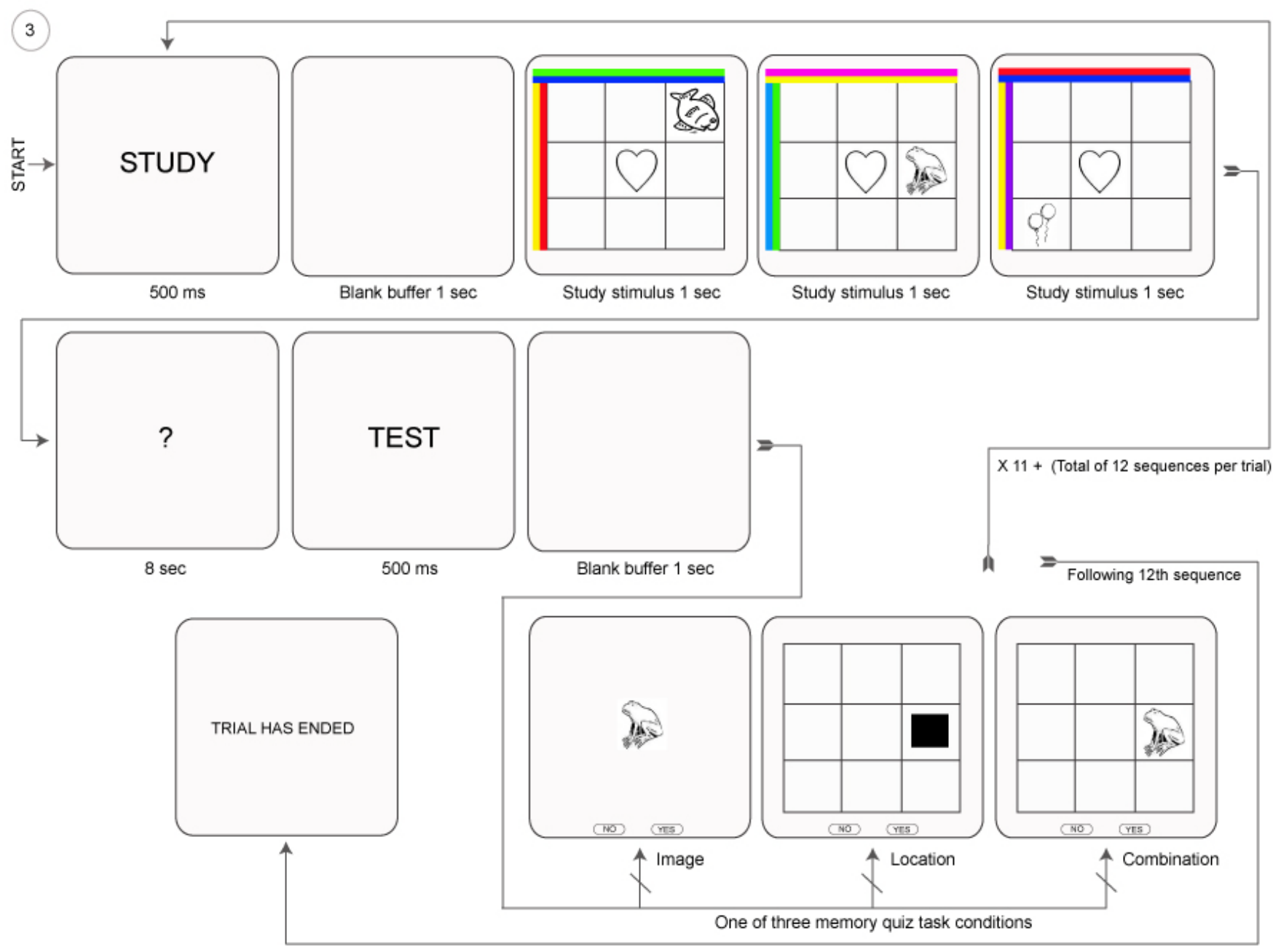

Fig. 25: Stimulus condition three (Color bars, no animation). Note: Static non-target image in center block does not change during study stimulus presentations. Note: Color bars do randomly change during study stimulus presentations. 


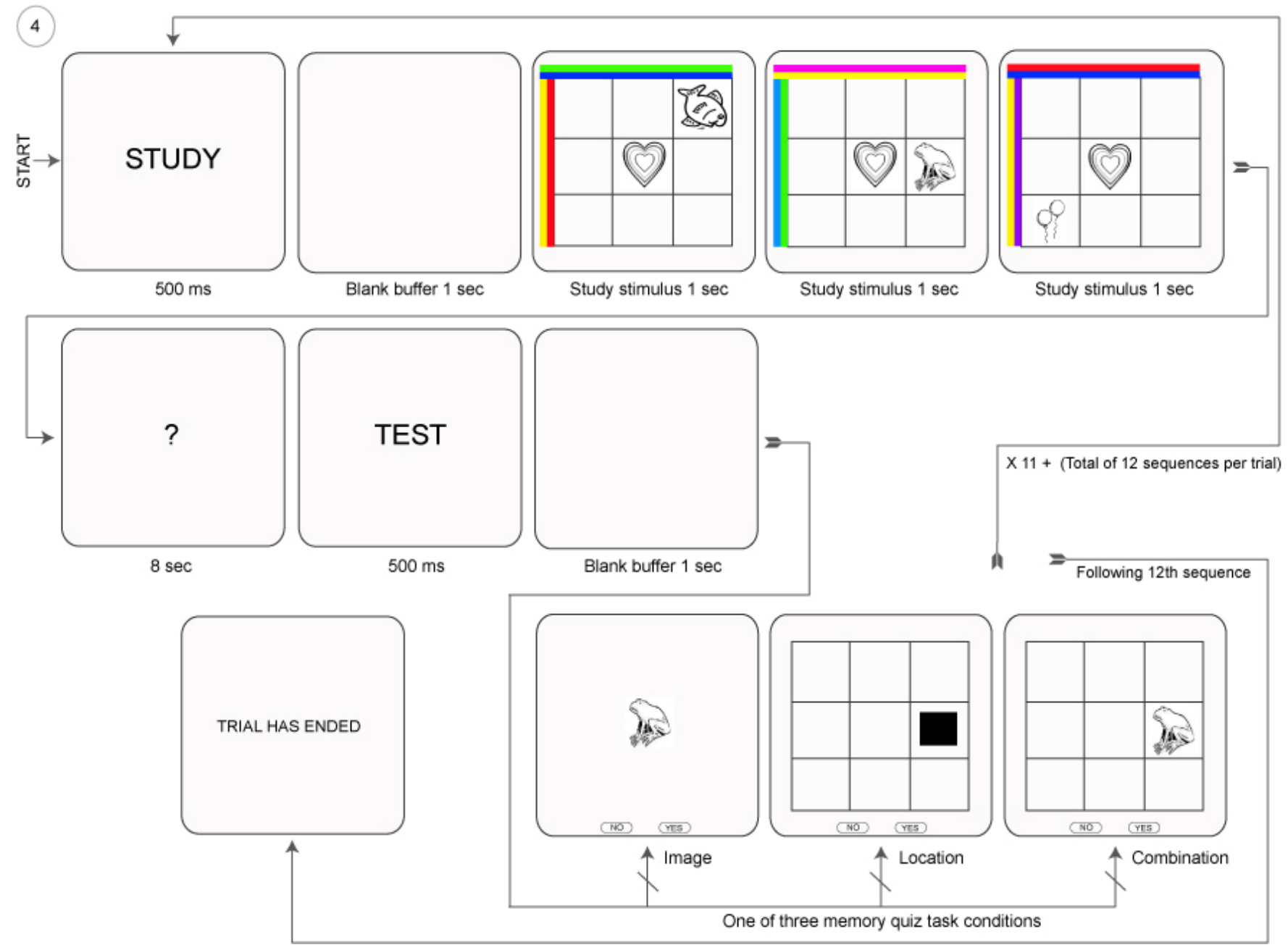

Fig. 26: Stimulus condition four (Color bars, animation). Note: Animated non-target image in center block does not change during study stimulus presentations. Note: Color bars do randomly change during study stimulus presentations. 


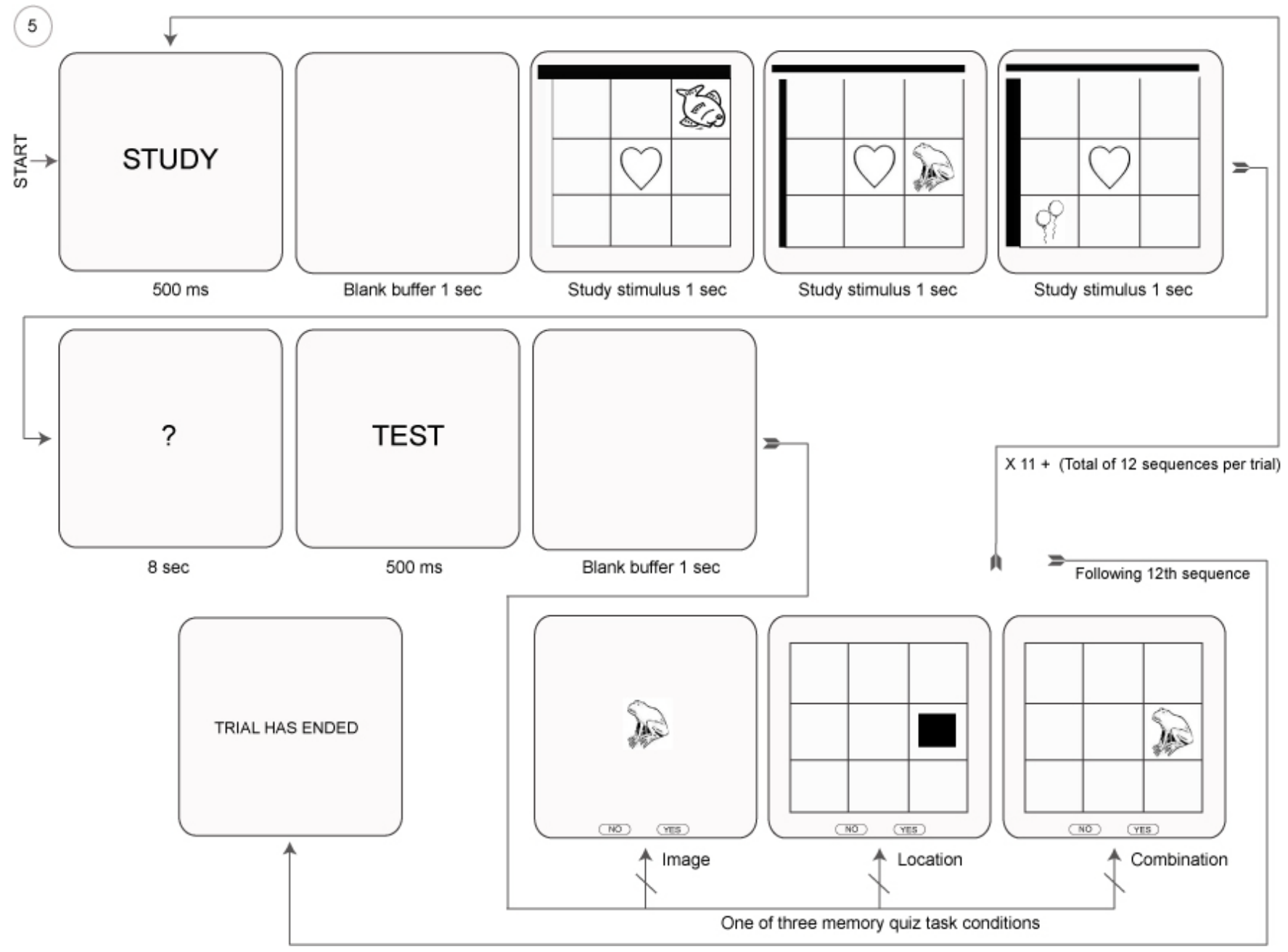

Fig. 27: Stimulus condition five (Black and white bars, no animation). Note: Static non-target image in center block does not change during study stimulus presentations. Note: Black and white bars do randomly change during study stimulus presentations. 


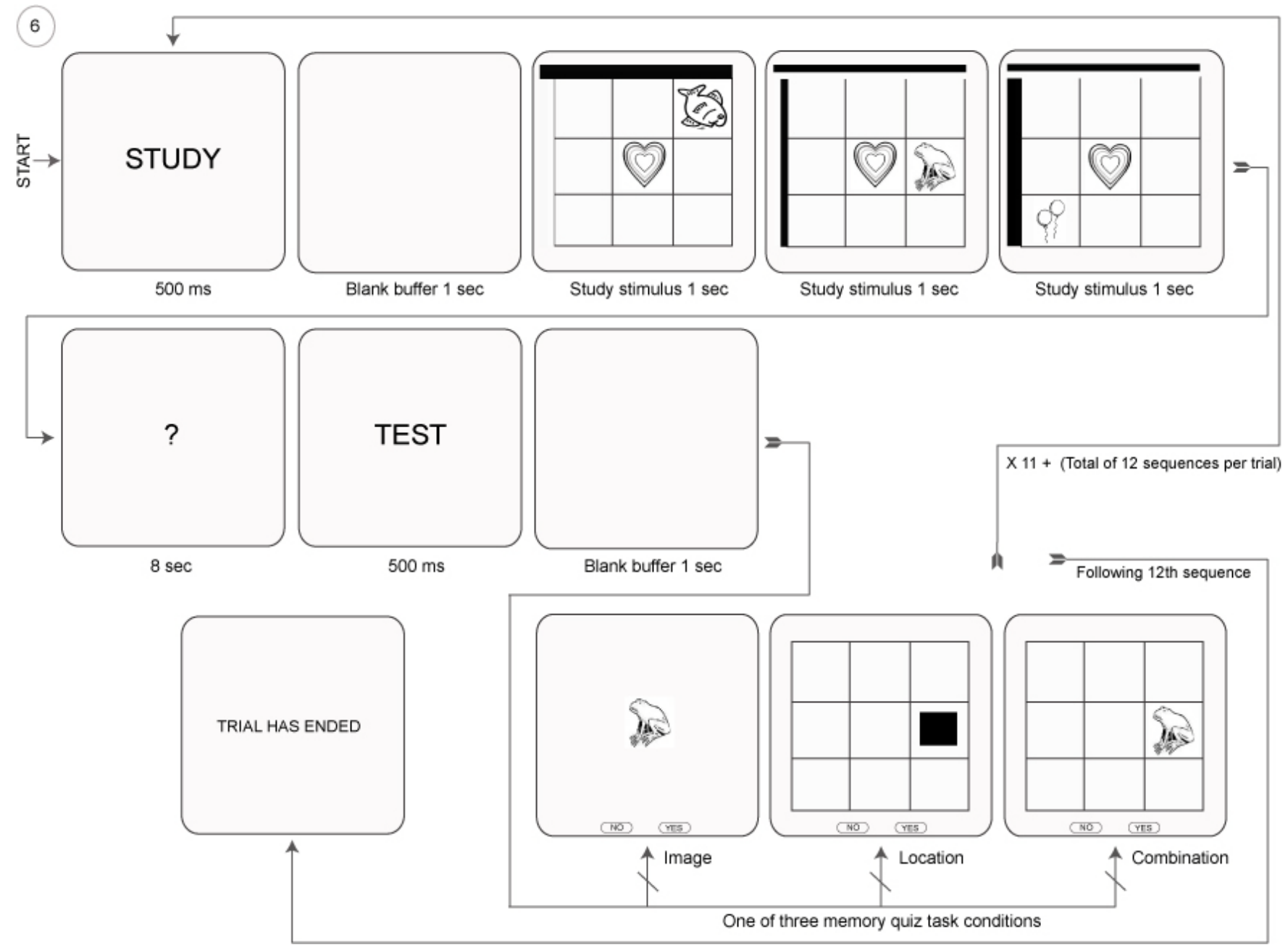

Fig. 28: Stimulus condition six (Black and white bars, animation). Note: Animated non-target image in center block does not change during study stimulus presentations. Note: Black and white bars do randomly change during study stimulus presentations. 


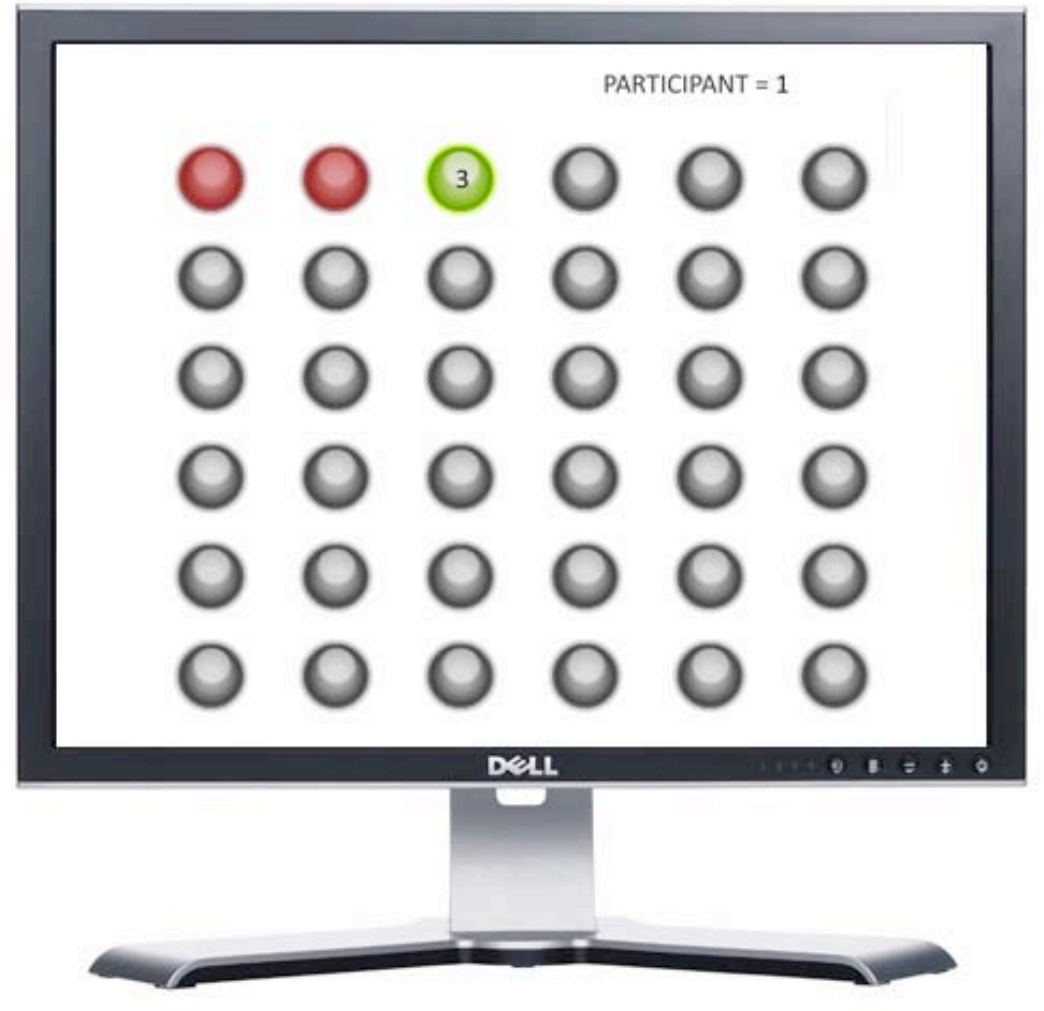

Fig. 29: Participant main user interface. Note: Two red buttons are completed trials. Note: Green number 3 button is enabled and ready to launch trial sequence number three. Note: All other grey buttons are disabled. 


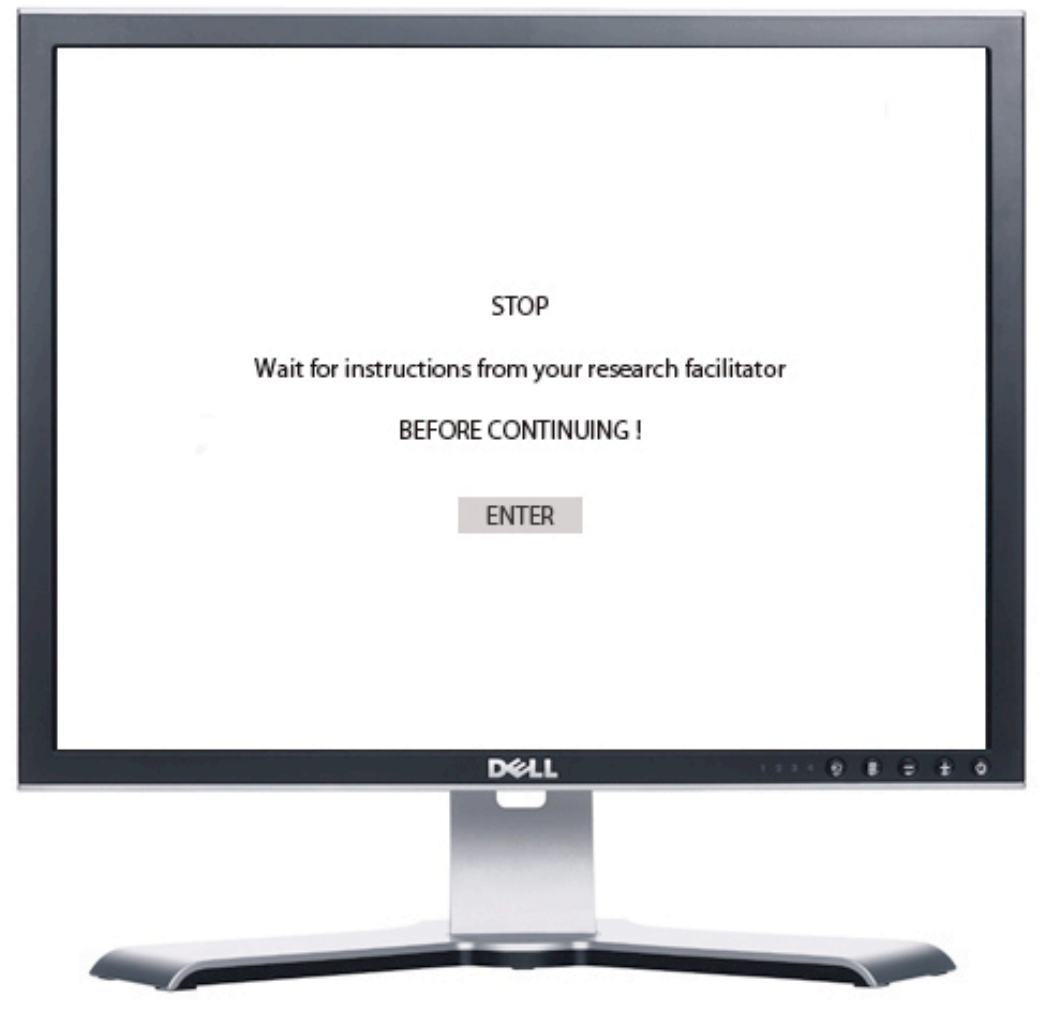

Fig. 30: Participant main user interface trial gateway page one. Note: Message. 


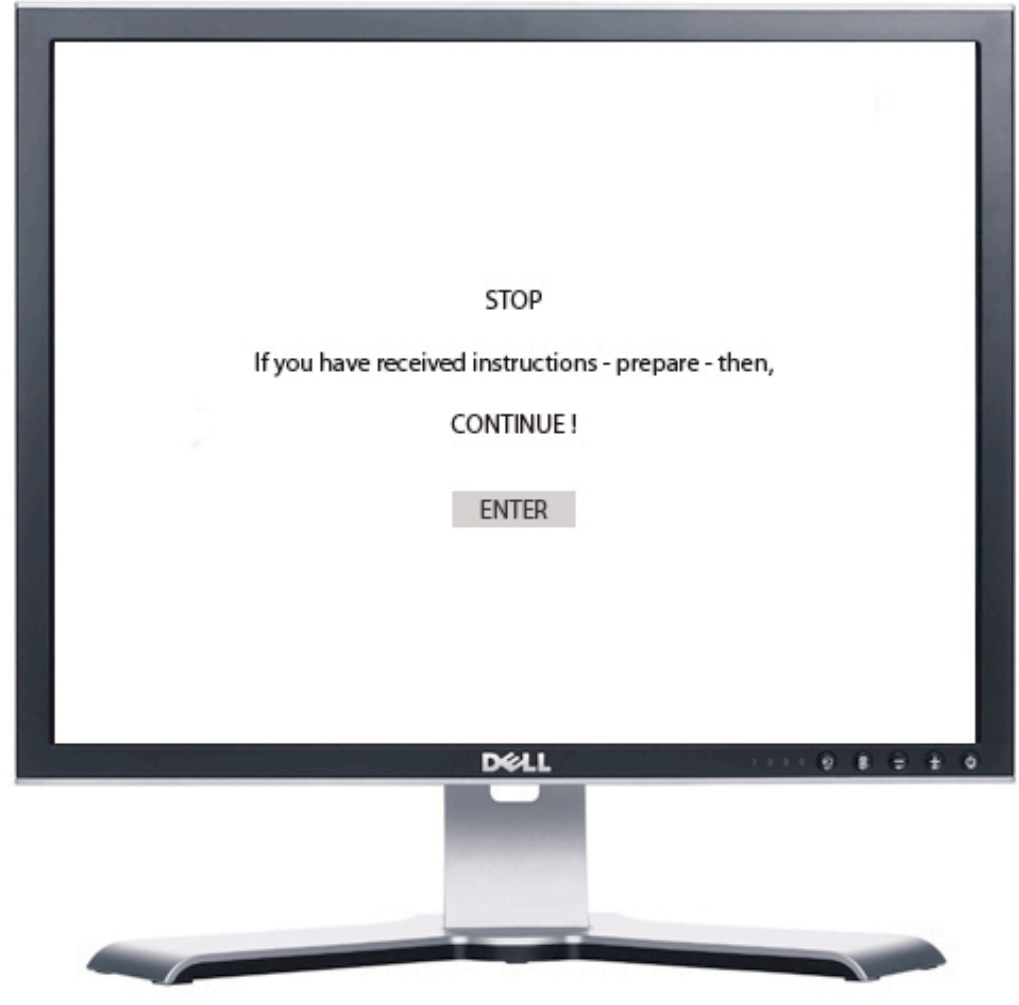

Fig. 31: Participant main user interface trial gateway page two. Note: Message. 


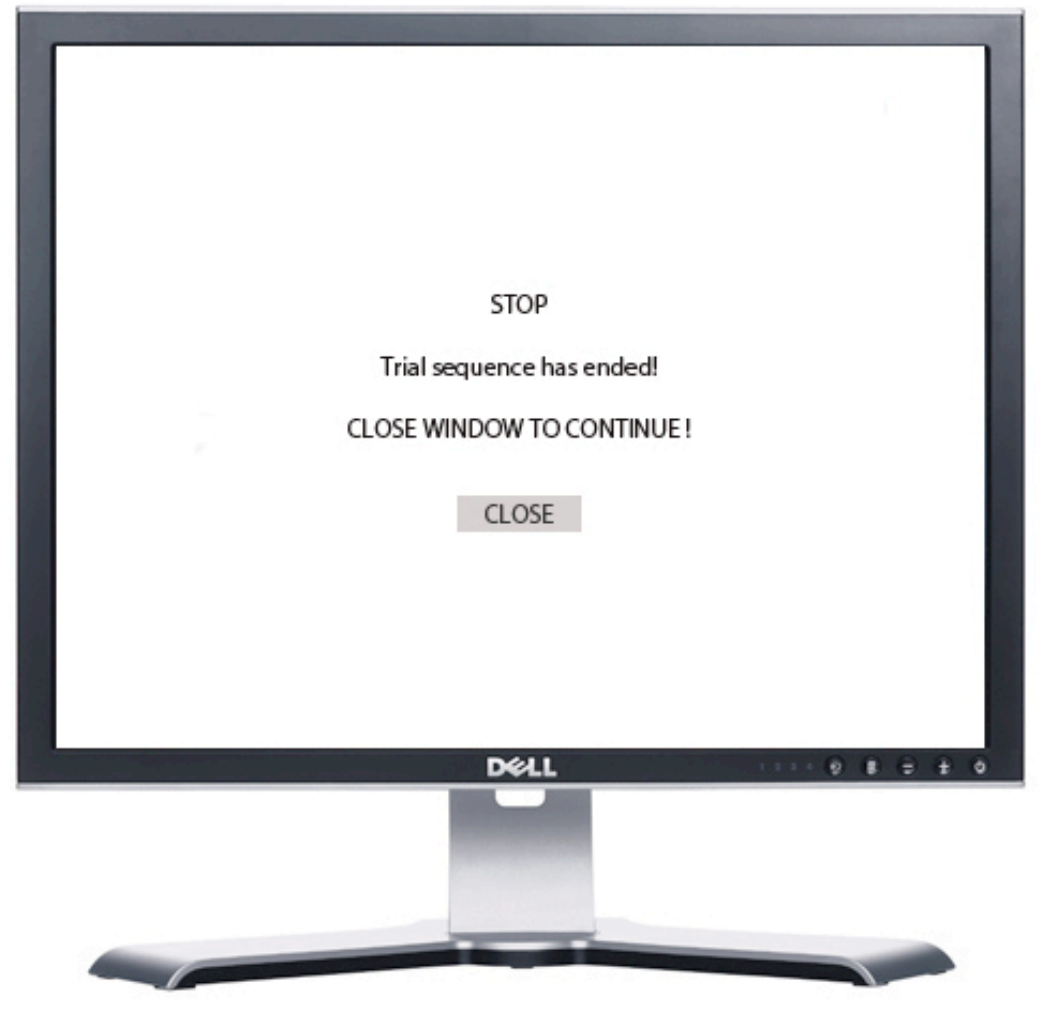

Fig. 32: Participant main user interface, trial sequence has ended information. Note: Message. 


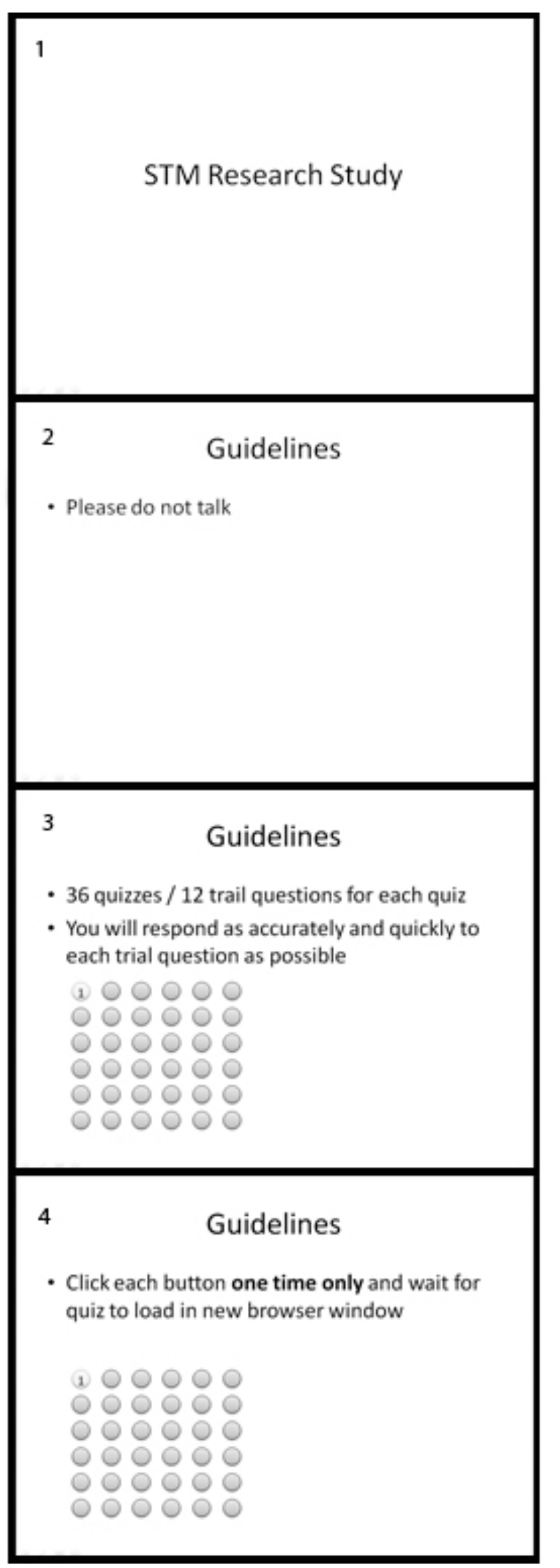

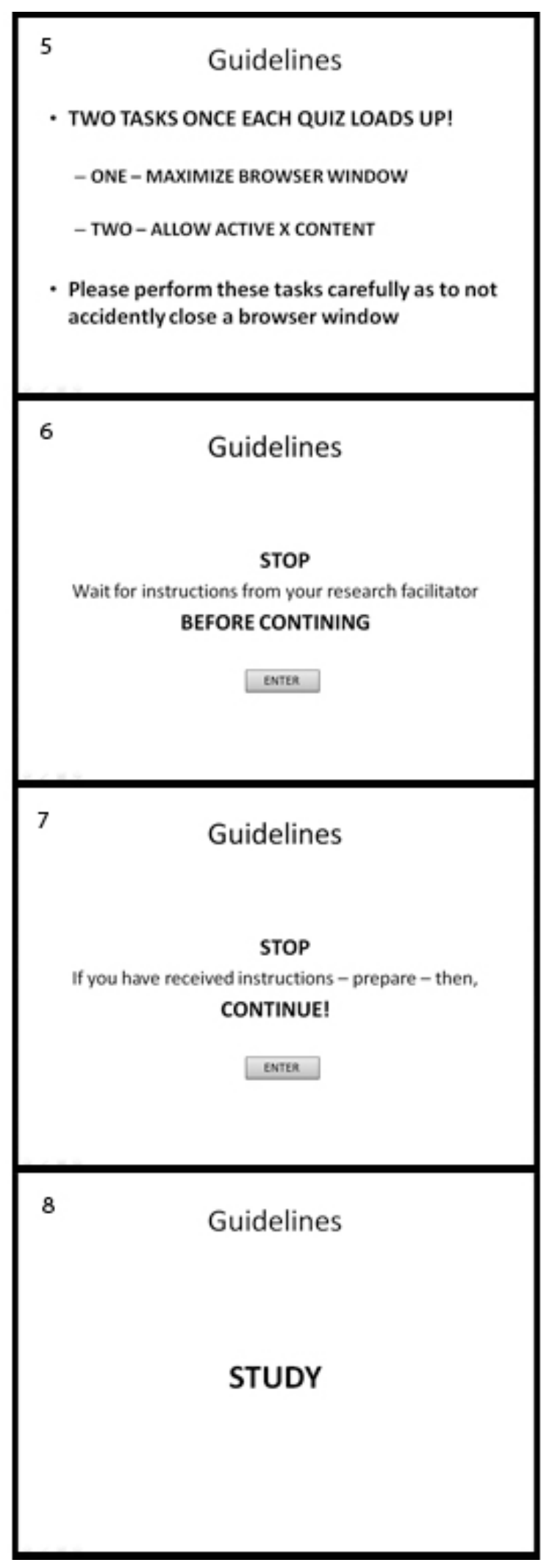

Fig. 34: Materials used in participant training. 

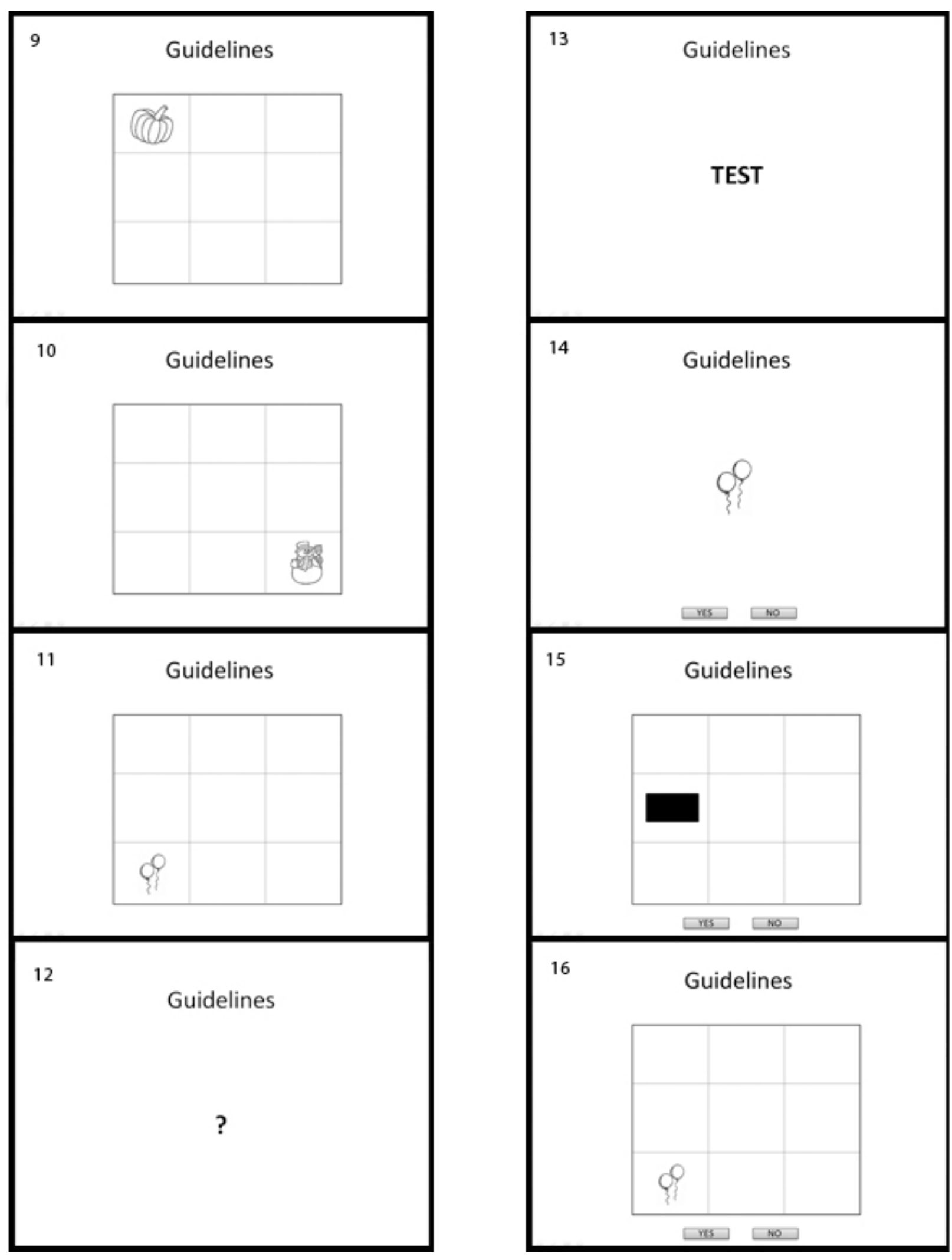

Fig. 35: Materials used in participant training. 


\section{APPENDIX II}

\begin{tabular}{|c|c|c|c|c|}
\hline \multirow{2}{*}{ STM } & & & \multicolumn{2}{|c|}{$95 \%$ Confidence Interval } \\
\cline { 4 - 5 } & Mean & Std. Error & Lower Bound & Upper Bound \\
\hline 1 & .942 & .009 & .923 & .961 \\
2 & .973 & .006 & .961 & .985 \\
3 & .924 & .015 & .893 & .956 \\
\hline
\end{tabular}

Fig. 34 estimated means: STM conditions - Estimated marginal means of scores. Note: Image $=.942 \%$, location $=.973 \%$, and combination $=.924 \%$.

\section{Estimates}

\begin{tabular}{|l|r|r|r|r|}
\hline \multirow{2}{*}{ color } & \multirow{2}{*}{ Color conditions estimated means } \\
\hline & Mean & Std. Error & Lower Bound & Upper Bound \\
\cline { 3 - 5 } 1 & .953 & .010 & .931 & .975 \\
2 & .958 & .007 & .943 & .972 \\
3 & .929 & .011 & .904 & .953 \\
\hline
\end{tabular}

Fig. 35: Color conditions - Estimated marginal means of scores. Note: Black and white $=.953 \%$, color bars $=.958 \%$, and black and white bars $=.929 \%$. 
Estimates

STM conditions*animation conditions estimated means

\begin{tabular}{|ll|r|r|r|r|}
\hline & \multirow{2}{*}{$\begin{array}{l}\text { animati } \\
\text { STM }\end{array}$} & & & \multicolumn{2}{|c|}{$95 \%$ Confidence Interval } \\
\cline { 5 - 6 } & on & Mean & Std. Error & Lower Bound & Upper Bound \\
\hline 1 & 1 & .938 & .009 & .918 & .958 \\
& 2 & .945 & .013 & .917 & .974 \\
\hline 2 & 1 & .978 & .006 & .966 & .990 \\
& 2 & .968 & .008 & .951 & .985 \\
\hline 3 & 1 & .941 & .015 & .909 & .973 \\
& 2 & .907 & .016 & .874 & .941 \\
\hline
\end{tabular}

Fig. 36: STM conditions*animation conditions - Estimated marginal means of scores. Note: Image*no animation $=.938 \%$, location*no animation $=.978 \%$, combination $*$ no animation $=.941 \%$, and image*animation $=.945 \%$, location*animation $=.968 \%$, combination*animation $=.907 \%$. 
Table 5: Tests of Within-Subjects Effects ANOVA - Accuracy of Scores

Tests of Within-Subjects Effects ANOVA - Accuracy of Responses

\begin{tabular}{|c|c|c|c|c|c|c|}
\hline Source & & $\begin{array}{c}\text { Type III Sum of } \\
\text { Squares }\end{array}$ & df & Mean Square & $\mathrm{F}$ & Sig. \\
\hline STM & Sphericity Assumed & .102 & 2 & .051 & 10.627 & .000 \\
\hline Error(STM) & Sphericity Assumed & .125 & 26 & .005 & & \\
\hline color & Sphericity Assumed & .040 & 2 & .020 & 6.883 & .004 \\
\hline Error(color) & Sphericity Assumed & .075 & 26 & .003 & & \\
\hline animation & Sphericity Assumed & .009 & 1 & .009 & 3.867 & .071 \\
\hline Error(animation) & Sphericity Assumed & .032 & 13 & .002 & & \\
\hline STM * color & Sphericity Assumed & .009 & 4 & .002 & 1.427 & .238 \\
\hline Error(STM*color) & Sphericity Assumed & .083 & 52 & .002 & & \\
\hline STM * animation & Sphericity Assumed & .018 & 2 & .009 & 3.616 & .041 \\
\hline Error(STM*animation) & Sphericity Assumed & .063 & 26 & .002 & & \\
\hline color * animation & Sphericity Assumed & .017 & 2 & .008 & 2.708 & .085 \\
\hline Error(color*animation) & Sphericity Assumed & .081 & 26 & .003 & & \\
\hline STM * color * animation & Sphericity Assumed & .012 & 4 & .003 & 1.053 & .389 \\
\hline Error(STM*color*animation) & Sphericity Assumed & .142 & 52 & .003 & & \\
\hline
\end{tabular}

a. Computed using alpha $=.05$ 
Table 6: Tests of Within-Subjects Effects ANOVA - Latency of Responses

Tests of Within-Subjects Effects ANOVA - Latency of Responses

\begin{tabular}{|c|c|c|c|c|c|c|}
\hline Source & & $\begin{array}{l}\text { Type III Sum of } \\
\text { Squares }\end{array}$ & $\mathrm{df}$ & Mean Square & $\mathrm{F}$ & Sig. \\
\hline STM & Sphericity Assumed & 5.353 & 2 & 2.677 & 1.227 & .310 \\
\hline Error(STM) & Sphericity Assumed & 56.727 & 26 & 2.182 & & \\
\hline color & Sphericity Assumed & 3.346 & 2 & 1.673 & 1.226 & .310 \\
\hline Error(color) & Sphericity Assumed & 35.483 & 26 & 1.365 & & \\
\hline animation & Sphericity Assumed & .052 & 1 & .052 & .034 & .857 \\
\hline Error(animation) & Sphericity Assumed & 19.957 & 13 & 1.535 & & \\
\hline STM * color & Sphericity Assumed & 7.745 & 4 & 1.936 & 1.381 & .253 \\
\hline Error(STM*color) & Sphericity Assumed & 72.924 & 52 & 1.402 & & \\
\hline STM * animation & Sphericity Assumed & 4.126 & 2 & 2.063 & 1.542 & .233 \\
\hline Error(STM*animation) & Sphericity Assumed & 34.785 & 26 & 1.338 & & \\
\hline color * animation & Sphericity Assumed & 7.555 & 2 & 3.777 & 2.544 & .098 \\
\hline Error(color*animation) & Sphericity Assumed & 38.611 & 26 & 1.485 & & \\
\hline STM * color * animation & Sphericity Assumed & 8.098 & 4 & 2.025 & 1.348 & .265 \\
\hline Error(STM*color*animation) & Sphericity Assumed & & 52 & 1.502 & & \\
\hline
\end{tabular}

a. Computed using alpha $=.05$

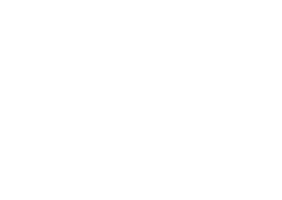

